Esteganografia em vídeos comprimidos MPEG-4

Diego Fiori de Carvalho 


\title{
Esteganografia em vídeos comprimidos MPEG-4
}

\author{
Diego Fiori de Carvalho
}

Orientador: Prof. Dr. Rudinei Goularte

Dissertação apresentada ao Instituto de Ciências Matemáticas e de Computação - ICMC/USP, como parte dos requisitos para obtenção do título de Mestre em Ciências de Computação e Matemática Computacional.

USP - São Carlos

Outubro/2008 
Dedico este trabalho a minha família e a minha namorada Natália, pelo amor incondicional. Dedico ao meu tio Cláudio Sérgio da Rós de Carvalho (In Memorian).

'A alegria está na luta, na tentativa, no sofrimento envolvido e não na vitória propriamente dita.' ( Mahatma Gandhi) 


\section{Agradecimentos}

Agradeço a Deus pela força e inspiração nas atividades deste presente trabalho.

Agradeço a FAPESP por financiar este trabalho, ao ICMC-USP (funcionários e professores) pelo suporte e profissionalismo sempre presente.

Agradeço aos professores do grupo Intermidia, principalmente ao meu orientador $\mathrm{Ru}$ dinei Goularte, pelos inúmeros conselhos, pela amizade e suporte técnico prestado no decorrer desses anos. Agradeço a Rafael Chies por sua destreza e capacidade técnica no auxílio do desenvolvimento do MESE. Agradeço a profa. Luciana Martimiano pelo suporte prestado e conselhos no desenvolvimento da aplicação para integridade de vídeos. Agradeço a Renan Prates Lopes de Campos e Mateus Godoi Milanez pelo auxílio no desenvolvimento da SecBox.

Agradeço aos colegas de laboratório: André Freire, Davi, Manzato, Rigolin, Sadao, Júlio Estrella nos momentos de trabalho e descontração. Agradeço a paciência de meus amigos, principalmente Rafael Vidal Aroca, Cristiano (Ceará), José Fernando de Lima, José Camacho Guerreiro e Renato Bulcão nos momentos que me ouviram falar sobre o tema esteganografia!

Agradeço aos organizadores de eventos por escolherem cidades tão bonitas para os congressos! Adorei visitar Poços de Caldas, Rio de Janeiro, Gramado e Lisboa.

Bom agradeço as pessoas que me deram sugestões, dicas e as que me questionaram de forma construtiva e destrutiva em congressos, seminários, palestras que proferi.. Aprendi muito com elas...

Marco, Rita, Dã, Vera, Darcy, Osvaldo, Egma e Wilmera obrigado pela força e apoio nessa vida.

Ná, mais uma etapa da vida vencida, obrigado por me fazer feliz e me dar colo em todos os momentos que precisei!!! Te amo!! 
Abstract $\quad x$

1 Introdução 1

2 Esteganografia 4

2.1 Considerações Iniciais . . . . . . . . . . . . . . . . . . . . . . 4

2.2 Esteganografia - Visão Geral . . . . . . . . . . . . . . . . . . . . 4

2.3 Terminologia para Esteganografia . . . . . . . . . . . . . . 5

2.4 Esteganálise . . . . . . . . . . . . . . . . . . . . . . . . 7

2.5 Modelo Geral para Esteganografia em Vídeos . . . . . . . . . . . . . . . 7

2.6 Considerações Finais . . . . . . . . . . . . . . . . . . . . . . 8

3 Compressão MPEG de Vídeos Digitais 9

3.1 Considerações Iniciais . . . . . . . . . . . . . . . . . . . . . . . . . . . . . . 9

3.2 Compressão MPEG . . . . . . . . . . . . . . . . . . . . . . . . . . 10

3.2 .1 Compressão Espacial . . . . . . . . . . . . . . . . . . . . 10

3.2.2 Compressão Temporal . . . . . . . . . . . . . . . . . . . . . . . . . . . . . . . . . . . .

3.2.2.1 Tipos de Quadros . . . . . . . . . . . . . . . . 12

3.2.2.2 Compensação de Movimento . . . . . . . . . . . . . . 13

3.3 O padrão MPEG-4 . . . . . . . . . . . . . . . . . . . . . . . . . 14

3.3.1 Estrutura da Cena MPEG-4 e Multiplexação de Objetos . . . . . . 15

3.3 .2 MPEG-J . . . . . . . . . . . . . . . . . . 16

3.4 Projeto GPAC . . . . . . . . . . . . . . . . . . . 17

3.4 .1 MP4Box ............................ 17

3.4.2 Player OSMO - Projeto GPAC . . . . . . . . . . . . . . 18

3.5 Considerações Finais . . . . . . . . . . . . . . . . . . . . 18

4 Revisão Sistemática da Literatura $\quad 20$

4.1 Considerações Iniciais . . . . . . . . . . . . . . . . . . . . . . . . 20

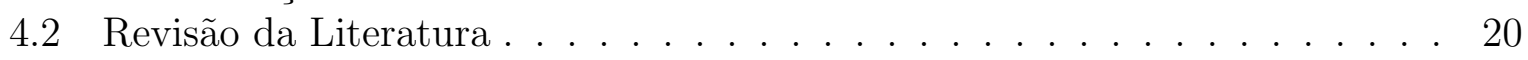

4.2.1 Protocolo de Revisão . . . . . . . . . . . . . . . . . . . . . . . . 22 
4.2 .2 Condução da Revisão . . . . . . . . . . . . . . . . . . . . . . . . 22

4.2.3 Resultados da Revisão Sistemática . . . . . . . . . . . . . . . 23

4.3 Classificação para Técnicas de Esteganografia em Vídeos . . . . . . . . . . 23

4.3.1 Abordagens para Esteganografia em Vídeos . . . . . . . . . . . . 23

4.3.2 Análise das Técnicas de Esteganografia . . . . . . . . . . . . . . . . 26

4.4 Considerações Finais . . . . . . . . . . . . . . . . . . . . . . . 29

5 Técnica MP4Stego 30

5.1 Considerações Iniciais . . . . . . . . . . . . . . . . . . . . . . . . . . . . . . . . . . . . . . . . . .

5.2 MP4Stego . . . . . . . . . . . . . . . . . . . . . . 31

5.2 .1 MPEGLet . . . . . . . . . . . . . . . . . . 32

5.2.2 MESE: MPEGLet Elementary Stream Encoder . . . . . . . . . . . 33

5.2.3 Processo de Esteganografia . . . . . . . . . . . . . . . 33

5.3 Modelo MP4Stego para Esteganografia em Vídeos . . . . . . . . . . . . . . 35

5.4 Considerações Finais . . . . . . . . . . . . . . . . . . . . . . 37

6 Aplicações da Técnica MP4Stego 38

6.1 Considerações Iniciais . . . . . . . . . . . . . . . . . . . . . . . . . . . . . . 38

6.2 Escrita Secreta . . . . . . . . . . . . . . . . . . . . 40

6.2.1 Descrição da Aplicação . . . . . . . . . . . . . . . . . . . . . . . . . . . . . 40

6.2.2 Amostras para os Testes . . . . . . . . . . . . . . . . . 41

6.2.3 Testes e Análises . . . . . . . . . . . . . . . . . . . . . . . 43

6.3 Integridade Digital de Vídeos . . . . . . . . . . . . . . . . . 46

6.3.1 Metodologia de Segurança . . . . . . . . . . . . . . . . . 47

6.3.2 Modelo da Técnica . . . . . . . . . . . . . . . . . . . . . . . . . . . . . . . . . . . . . 49

6.3 .3 Descrição da Aplicação . . . . . . . . . . . . . . . . . . . . . . . . . . . . . . . 49

6.3 .4 Testes e Análise . . . . . . . . . . . . . . . . . . . . . 50

6.4 Considerações Finais . . . . . . . . . . . . . . . . . . . . 52

7 Conclusões e Trabalhos Futuros $\quad 54$

7.1 Considerações Iniciais . . . . . . . . . . . . . . . . . . . . . . 54

7.2 Contribuições . . . . . . . . . . . . . . . . . . . . 55

7.3 Limitações . . . . . . . . . . . . . . . . . . . . . . . . . . . . . . . . . . . . . . . . . . . . . . . .

7.4 Trabalhos Futuros . . . . . . . . . . . . . . . . . 56

7.5 Produção Científica . . . . . . . . . . . . . . . . 56

$\begin{array}{ll}\text { Referências } & 61\end{array}$

$\begin{array}{ll}\text { Apêndice A } & 63\end{array}$

$\begin{array}{ll}\text { Glossário } & 66\end{array}$ 


\section{Lista de Figuras}

2.1 Esteganografia Digital com inserção de conteúdo oculto [Zhao, 1998]. . . . 6

3.1 Processo típico de compressão de dados do padrão MPEG. . . . . . . . . . . 10

3.2 Codificação (encoding) e reconstrução de bitstream MPEG [Ebrahimi, 2002]. 11

3.3 Tipos de Quadros. . . . . . . . . . . . . . . . . . . 12

3.4 Estimativa de Movimento. . . . . . . . . . . . . . . . . . 13

3.5 Multiplexação de objetos. [Goularte, 2003]. . . . . . . . . . . . . . 16

4.1 Processo de revisão sistemática, adaptado de [Barbara, 2004] . . . . . . . . 21

4.2 Gráfico da distribuição das técnicas. . . . . . . . . . . . . . . . . . 23

4.3 Localização das abordagens para esteganografia em vídeos comprimidos no processo de compressão MPEG. . . . . . . . . . . . . . . . . . 25

5.1 Esquema geral da arquitetura MP4Stego. . . . . . . . . . . . . . . 31

5.2 Processo de esteganografia de vídeos MPEG-4 usando a técica MP4Stego. . 34

5.3 Processo de esteganografia reversa em vídeos MPEG-4 usando a técnica MP4Stego. . . . . . . . . . . . . . . . . . 35

5.4 Screenshot da MP4Stego aplicada para o player OSMO estendido. . . . . . 36

6.1 Modelo de Esteganografia em Vídeos. . . . . . . . . . . . . . . . . . . 39

6.2 Escrita Secreta em Vídeos MPEG-4. . . . . . . . . . . . . . . . . . . . 41

6.3 Screenshot da Aplicação para Escrita Secreta em Vídeos MPEG-4. . . . . . 42

6.4 Gráfico das amostras após teste. . . . . . . . . . . . . . . . 45

6.5 Processo de integridade digital utilizando esteganografia e criptografia. . . 48

6.6 Processo de Segurança da aplicação para Integridade de Vídeos. . . . . . . 50

6.7 Screenshot da Aplicação para Integridade em Vídeos MPEG-4. . . . . . . . 51

6.8 Adaptação do ataque MITM aplicado na verificação de integridade em vídeos. 52 


\section{Lista de Tabelas}

4.1 Técnicas de Esteganografia para Vídeos Comprimidos . . . . . . . . . . . . 27

4.2 Análise das técnicas de Esteganografia para Vídeos. . . . . . . . . . . . 28

6.1 Tabela contendo os dados obtidos dos testes, A: Amostra, TA: Tamanho total da amostra (KB), EN: Elemento N, M: Média (KB), DP: Desvio Padrão. 44

6.2 Resultado dos testes da aplicação. TA: Tamanho total da amostra (Kb), TVF: Tamanho do Vídeo Final (Kb), VS: Video Stream (Kb). . . . . . . 45

7.1 Técnicas de Esteganografia para Vídeos. . . . . . . . . . . . . . 55 


\title{
Lista de Siglas
}

\author{
BIFS - Binary Format For Scenes \\ CPU - Central Processing Unit \\ DV - Digital Video \\ DCT - Discrete Cossin Transform \\ FTP - File Transfer Protocol \\ GOV - Group of VOPS \\ GPL - General Public License \\ HDTV - High Definition Television \\ HTML - HyperText Markup Language \\ HTTP - Hypertext Transfer Protocol \\ ICMC - Instituto de Ciências Matemáticas e de Computação \\ IDCT - Inverse Discrete Cossin Transform \\ IEC - International Eletrotechnical Comission \\ JMF - Java Media Framework \\ JVM - Java Virtual Machine \\ IP - Internet Protocol \\ ISDN - Integrated Services Digital Network \\ ITU - International Telecommunication Union \\ ISO - International Standard Organization \\ MPEG - Moving Picture Experts Group \\ PDA - Personal Digital Assistant \\ TCP - Transmission Control Protocol \\ UDP - User Datagram Protocol \\ URL - Uniform Resource Locator \\ USP - Universidade de São Paulo \\ VLC - Variable Length Coding \\ VOP - Video Object Plane \\ XML - Extensible Markup Language
}


A esteganografia em vídeos digitais possibilita o ocultamento de um grande volume de informações quando comparada a técnicas em imagens. Contudo, esta tarefa não é trivial quando aplicada a vídeos comprimidos, pois a inserção de informações ocultas pode adicionar ruído dificultando a perfeita recuperação das mesmas durante a decodificação. Este trabalho apresenta uma técnica para esteganografia em vídeos comprimidos, denominada MP4Stego, a qual explora estruturas e tecnologias do padrão de vídeo MPEG-4 de modo a proceder recuperação de informações sem perda e apresentar maior capacidade de inserção de dados ocultos. Entre os benefícios da técnica estão: A capacidade de ocultamento de grande volume de dados; a capacidade de reprodução do vídeo contendo dados ocultos em players não especializados (ajudando a dar a ilusão de que se trata de um vídeo comum), sua imunidade, até o momento, a técnicas de esteganálise. 


\section{Abstract}

Dgital video steganography makes possible to hide higher volumes of information than the broadly used image steganography techniques. However, apply steganography to compressed digital videos is not a trivial task because the information hiding process may add noise to the original data. In this way, during the video decoding, the recovered hidden information is not an exact copy of the original data. This work presents a new steganographic technique, called MP4Stego, which explores new video structures of the MPEG-4 standard in order to recover hidden data without loss and in order to provide higher capacity of hidden data insertion. Some benefits of the MP4Stego technique are: to hide high volumes of data; to playback steganographyed videos by the means of non specialized players (this helps users to think that it is a regular video); so far, it's immunity to stegoanalysis techniques.

Keywords: Steganography, MPEG-4, Video Codification, MPEG-J, MPEGLets. 


\section{Capítulo \\ 1 \\ Introdução}

A esteganografia é um método antigo, utilizado para inserção de informações ocultas em meios não convencionais de modo que tais informações passem despercebidas para terceiros. Diversos foram os episódios históricos em que pessoas realizaram tentativas bem sucedidas de ocultar informações em outros meios. Entre elas podemos citar que na Grécia antiga, um dos meios de comunicação era a utilização de textos escritos em tábuas de madeira revestidas de cera. Demeratus, um grego, necessitava avisar a cidade-estado de Esparta sobre as intenções de uma intervenção hostil de Xerxes (rei da Pérsia). Então ele removeu toda a cera do pedaço de tábua e escreveu a mensagem na própria madeira revestindo a tábua com cera novamente. Desse modo, o objeto contendo a mensagem foi repassado para os militares gregos, que por sua vez retiraram a cera do pedaço de madeira, podendo ler a mensagem [Singh, 2001].

$\mathrm{Na}$ era da informação a esteganografia evoluiu para o meio digital. Assim diversas modos de introdução de dados sigilosos em mídias digitais foram criados, utilizando mídias como imagens, áudio e vídeo, tanto academicamente quanto comercialmente. Atualmente a esteganografia digital tem sido bastante explorada em imagens, utilizando as estruturas de compressão sem perda. Como exemplo de trabalhos que exploram esteganografia digital em imagens pode-se citar o projeto Camaleão [Rocha A., 2004] e JPEG-JSTEG [Chang C. L., 2000].

Várias técnicas utilizadas em imagens podem ser diretamente aplicadas a vídeos, como é o caso das técnicas empregadas em marcas d'água (watermarking) [Lu, 2003] [Lou, 2002], muito utilizadas por emissoras de TV para inserir seus logo-tipos durante as transmissões. Tais técnicas geram ruído e a informação decodificada não é uma cópia exata da informação original. Em domínios de aplicação como o das marcas d'água esse fato não é um problema.

Diferentemente do domínio de marcas d'água, no domínio de escrita secreta pretende-se trocar informações textuais de modo sigiloso na íntegra, assim faz-se necessário que a informação recuperada seja uma cópia exata da original. As vantagens da utilização de esteganografia em mídias do tipo vídeo em relação a imagens são: Possibilidade de inserção 
de dados em maior quantidade e maior dificuldade em encontrar o conteúdo secreto (Qual o quadro do vídeo que contém informações secretas?).

A dificuldade na introdução de informações em vídeos comprimidos relaciona-se com a perda de dados provenientes da passagem dos mesmos por estruturas de compressão temporal e compressão com perda, como a compensação de movimento e a quantização [Petitcolas, 1996]. Assim, aplicações como integridade digital, que necessitam garantir que nenhum bit do conteúdo seja alterado, são sensíveis à compressão com perda.

Os trabalhos encontrados na literatura sobre o tema exploram, basicamente, os padrões MPEG-1 e MPEG-2 [ISO, 2000]. Tais trabalhos possuem como características peculiares a inserção de baixo volume de dados ocultos e elevada complexidade para inserção dos mesmos [Zhao, 1998], [Yin, 2006], [Wolf, 1998], [Dugelay, 2003], [Girod, 1998]. Assim existe uma lacuna na literatura no que se refere a uma técnica com alta capacidade de inserção de dados ocultos em vídeos digitais comprimidos.

O surgimento do padrão MPEG-4 [Chiariglione, 2002] trouxe nova luz ao problema, uma vez que apresenta novos elementos que potencialmente podem ser utilizados para ocultar um maior volume de informações e de modo menos complexo. Entre as novidades especificadas pelo padrão estão a codificação da cena por meio de objetos e a possibilidade de codificação de programas Java como objetos de vídeo.

Assim, o propósito deste trabalho é a criação de uma técnica de esteganografia em vídeos comprimidos. A técnica desenvolvida introduz informações ocultas no interior de vídeos no padrão MPEG-4 explorando recursos únicos desse padrão em relação aos demais. Como características adicionais da técnica, diferentemente dos trabalhos relacionados: o vídeo esteganografado pode ser exibido em qualquer player-padrão MPEG-4, a informação oculta é recuperada na íntegra (sem perdas), o método é mais simples que os demais e possui potencial para ocultar uma maior quantidade de informações.

Para validação da técnica MP4Stego desenvolvou-se duas aplicações. A primeira refere-se na criação de uma aplicação de escrita secreta na qual se insere grande quantidade de texto no interior do vídeo e se utiliza um canal de comunicação para envio do mesmo pela Internet para o/os destino(s).

A segunda aplicação está relacionada com segurança digital, mais especificamente com integridade de vídeos digitais. Essa aplicação alia esteganografia e criptografia aumentando o nível de sigilo da informação ocultada para garantia de integridade. Assim, demonstra-se que a técnica é genérica o suficiente para ser aplicada a diferentes domínios.

Esta dissertação está organizada da seguinte maneira: no Capítulo 2 são apresentadas algumas das principais definições e detalhes a respeito de técnicas de esteganografia, a terminologia da área, as técnicas de esteganálise e realiza-se um detalhamento de um modelo matemático genérico para este tipo de técnica.

No Capítulo 3, são apresentados em detalhes os tipos de compressão em vídeos digitais MPEG 1,2 e 4. Também são apresentados detalhes de projetos e ferramentas pertinentes para o presente trabalho.

O Capítulo 4, detalha-se o processo de revisão sistemática da literatura para busca de técnicas de esteganografia em vídeos digitais. Como resultado dessa revisão sistemática foi obtida uma classificação de técnicas de esteganografia em vídeos comprimidos agrupadas por abordagens.

Já no Capítulo 5, é apresentada a técnica para esteganografia em vídeos MPEG-4 desenvolvida neste projeto, denominada MP4Stego. Na apresentação da técnica descreve-se 
seus requisitos, sua arquitetura, detalhes de funcionamento e ferramentas de apoio desenvolvidas.

O Capítulo 6, detalha as aplicações desenvolvidas para validação da técnica MP4Stego. A aplicação de escrita secreta e a aplicação para integridade de vídeos.

Finalmente, o Capítulo 7, apresenta as conclusões, discutindo, inicialmente, as contribuições alcançadas, em seguida, identificando as limitações do presente trabalho. Por fim, menciona-se possíveis trabalhos futuros a serem considerados. 


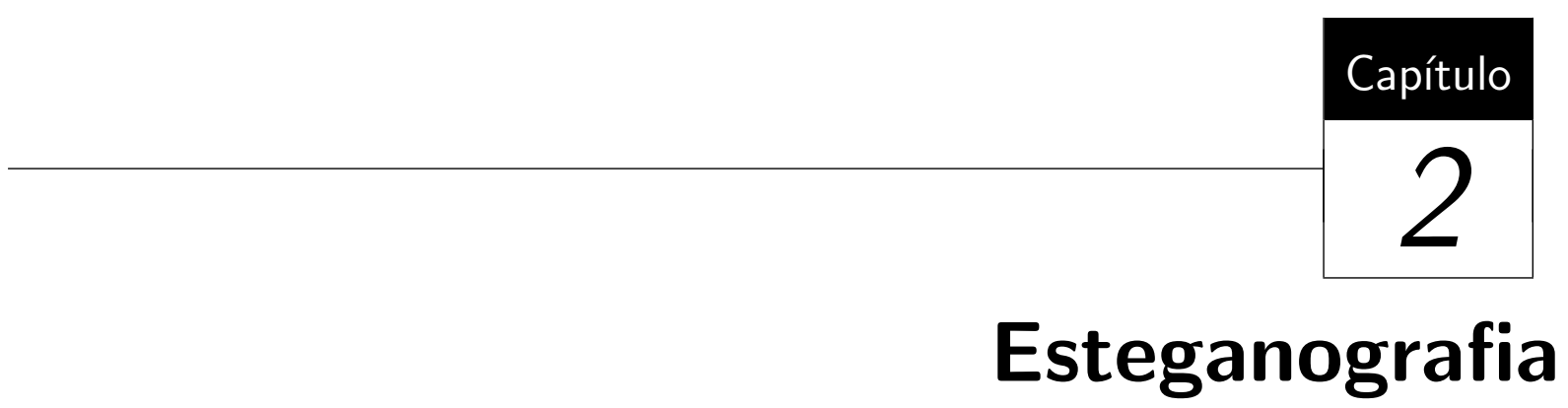

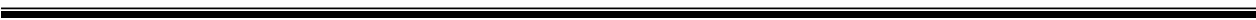

\subsection{Considerações Iniciais}

A crescente preocupação com privacidade dos dados trafegados pela Internet tem levado à pesquisas que visam manter o sigilo dos mesmos. Para este fim, tradicionalmente, tem-se utilizado técnicas de criptografia. A diferença principal entre criptografia e esteganografia, é o fato de que na primeira percebe-se a presença de uma mensagem na forma codificada, enquanto que na esteganografia esta informação não é visível. Uma mensagem criptografada permite ser detectada e até mesmo inutilizada caso seja interceptada. Com apenas a utilização da criptografia, a informação cifrada pode ser ilegível, mas este fato remete a existência de um segredo naquela cifra. Assim, a utilização de esteganografia em conjunto com a criptografia aumenta o nível de sigilo da cifra.

A introdução de informações ocultas em vídeos apresenta como vantagens a maior capacidade de dados ocultos e maior dificuldade na obtenção das informações de interesse por pessoas não autorizadas. No entanto, alguns tipos de vídeo não permitem grande inserção de dados devido as suas características de compressão que prejudicam aplicações de Escrita Secreta (veja capítulo 4).

O objetivo deste capítulo é apresentar definições e formalismos técnicos referentes a esteganografia. A seção 2.2, apresenta as definições e motivações acerca do tema esteganografia. A seção 2.3 descreve a terminologia básica nas classificação de técnicas de esteganografia. A seção 2.4 explica a esteganálise. A seção 2.5 descreve a formulação matemática de uma técnica genérica para esteganografia em vídeos. A seção 2.6, relata as considerações finais do capítulo.

\subsection{Esteganografia - Visão Geral}

A esteganografia foi um método muito utilizado nas Guerras mundiais, particularmente na comunicação, espiões alemães na Primeira Grande Guerra colocavam pequenos pontos 
de tinta invisível sobre letras de revistas e jornais de grande circulação [Singh, 2001]. As folhas de revistas pontuadas, quando aquecidas, revelavam a seqüência das letras [Wayner, 2002]. Já na Segunda Grande Guerra, outro método que começou a ser utilizado em esteganografia foram os micropontos, devido ao aumento da qualidade das câmeras, lentes e filmes. Por meio desse método uma mensagem secreta poderia ser fotografada e reduzida ao tamanho de um ponto (.), e podendo este ser um ponto final de sentença ou o ponto de uma letra $(i)$ de uma outra mensagem qualquer [Tomás, 2004].

Assim como na criptografia temos a criptoanálise, que corresponde a um conjunto de técnicas capazes de descobrir mensagens embutidas em uma cifra, do mesmo modo para a esteganografia, temos a esteganálise que corresponde ao conjunto de técnicas capazes de descobrir se existe alguma mensagem oculta em dada mídia de entrada. Foi com a utilização de esteganálise que foi possível descobrir inúmeros ataques e comunicações de escrita secreta pelos órgãos de investigação internacionais como FBI e Interpol.

Recentemente, a esteganografia foi utilizada por terroristas do grupo Al Kaeda para transmissão de mensagens pela Internet, segundo o jornal Estado de São Paulo. Segundo o jornal [Estadao, 2001], Khaled Al-Fawaz, aliado de Bin Laden, e acusado de comando dos ataques às embaixadas norteamericanas no Quênia e Tanzânia, em 1998, é doutor em Engenharia Elétrica e Computação e tem a atribuição das investidas de Bin Laden na Internet, onde, por meio da esteganografia, estaria transmitindo recados a seus comparsas.

A literatura reporta trabalhos que abordam a utilização de esteganografia em imagens, como por exemplo, o projeto Camaleão [Rocha A., 2004] e a técnica pioneira JPEG-JSTEG [Chang C. L., 2000] que exploram a inserção de informações nos bits menos significativos dos arquivos das imagens. Contudo a generalização dessas técnicas para uso em vídeos digitais comprimidos não tem sido explorada (veja capítulo 4).

\subsection{Terminologia para Esteganografia}

As técnicas de esteganografia podem ser classificadas quanto ao seu tipo e quanto à necessidade de permanência da marca ${ }^{1}$ [Albuquerque, 2007]:

- Robustos: são aqueles em que mesmo após a tentativa da remoção a marca permanece intacta.

- Frágeis: são os sistemas em que qualquer tentativa de modificação na mídia acarreta a perda da marcação.

Aplicações que necessitam da permanência da marca para fins de verificação de autenticidade, tais como, watermarks e fingerprints são consideradas robustas. Como exemplo de técnicas frágeis podemos citar a verificação de cópias ilegais, em que se um usuário editar o conteúdo original que contém a marca a mesma se perde.

Já quanto à percepção da marca, as técnicas de esteganografia podem ser classificados como [Albuquerque, 2007]:

- Marcação Imperceptível: são os sistemas onde a marca encontra-se no objeto ou material, porém não é visível.

\footnotetext{
${ }^{1}$ Nesta dissertação 'marca' também será definida como 'mensagem' $(M)$.
} 
- Marcação Visível: nesse sistema a marca do autor deve ficar visível para comprovar a autoria visualmente.

Como exemplo de técnica que utiliza marcação imperceptível pode-se citar a escrita secreta (Information Hiding), e como exemplo de marcação visível podemos citar marcas d'águas (watermarks) presentes em cédulas de dinheiro e em sêlos [Albuquerque, 2007].

A esteganografia provê meios de inserir informações ocultas no interior de mídias, sejam elas discretas ou contínuas. Essa inserção de informações ocultas está tipicamente relacionada ao conceito de chaves que visam dificultar a obtenção de seu conteúdo por pessoas não autorizadas. Segundo Petitcolas [Petitcolas, 1996], durante o Primeiro Workshop Internacional de Escrita Secreta (First International Workshop on Information Hiding), definiu-se uma terminologia para representação de esteganografia em mídias digitais, descritas a seguir.

O objeto de mídia utilizado para inserção de material oculto recebe a nomenclatura de Objeto de Cobertura. Já o objeto contendo a mensagem oculta recebe o nome de Estego Objeto (stego object). Por exemplo se for inserida uma mensagem texto (ASCII) em um documento texto, este receberá o nome de Estego Texto (Stegotext). Se for inserido um texto no interior de uma imagem esta receberá o nome de Estego Imagem (StegoImage). Uma ilustração de uma Estego Imagem pode ser visualizado na Figura 2.1.

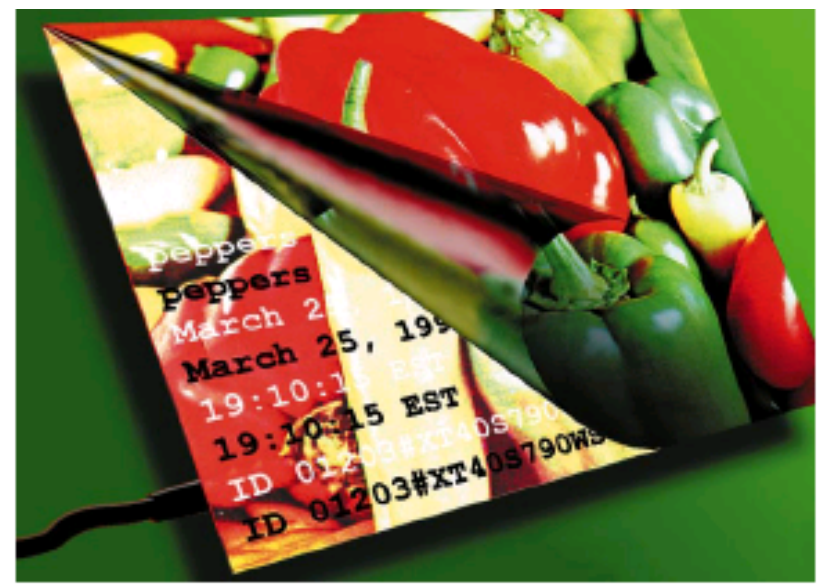

Figura 2.1: Esteganografia Digital com inserção de conteúdo oculto [Zhao, 1998].

Na Figura 2.1, pode-se verificar que existem informações embutidas na imagem, porém, essas informações não são visíveis para os usuários, ou seja o tipo de marcação é imperceptível.

Os termos destacados por Petitcolas [Petitcolas, 1996] são:

- Dado ou Objeto embutida(o) (Embedded Data): são os dados que serão enviados de maneira secreta. Os dados podem ser embutidos em forma de mensagem (strings) ou até mesmo a inserção de um arquivo binário, como também uma figura ou vídeo.

- Objeto de cobertura (Cover Object): É o objeto que servirá de base para mascaramento do dado ou objeto embutido. Esse objeto de cobertura pode ser texto, imagem, áudio, vídeo, entre outro.

- Estego-Objeto (Stego-Object): Após a inserção dos dados ou objetos embutidos no objeto de cobertura obtém-se o estego-objeto. 


\subsection{Esteganálise}

A esteganálise é arte de detectar mensagens ocultadas via esteganografia, pode ser comparada a criptanálise da criptografia. O objetivo da criptanálise é decifrar mensagens a partir de cifras e chaves utilizadas no processo de criptografia. Já a esteganálise atua de duas formas, a primeira tem como objetivo identificar a presença de mensagens ocultas na mídia e a segunda tem o objetivo de extrair da mídia a mensagem esteganografada.

Segundo Albuquerque et. al [Albuquerque, 2007], atualmente, as pesquisas em esteganálise estão mais concentradas em simplesmente identificar a presença de mensagens escondidas ao invés de extraí-las. Recuperar os dados escondidos, no momento, está além da capacidade da maioria das técnicas de esteganálise encontradas na literatura.

Os tipos de técnicas de esteganálise conhecidos são [Albuquerque, 2007]:

- Ataques Aurais: Retiram as partes significativas do objeto de cobertura como um meio de facilitar a busca por ruídos adicionados via esteganografia.

- Ataques Estruturais: Visam procurar alterações no padrão de arquivo do objeto de cobertura.

- Ataques Estatísticos: Procuram encontrar padrões de comportamento do conteúdo do arquivo.

Os ataques estatísticos são os mais encontrados na literatura, dentre técnicas conhecidas podemos citar: Chi-quadrado [Provos, 2001] e Análise RS [Fridrich, 2002] as quais são aplicadas na busca por inter-relações entre os componentes, principalmente de imagens (pixels).

Dentre todos esses fatores também vale ressaltar que na literatura dificilmente são encontradas aplicações e técnicas de ataques de esteganálise para mídias contínuas, tais como áudio e vídeo. O foco principal das pesquisas refere-se a esteganálise de imagens.

\subsection{Modelo Geral para Esteganografia em Vídeos}

A importância de um modelo geral para esteganografia em vídeos refere-se a formalização teórica de técnicas de esteganografia com o objetivo de determinar duas funções principais: codificação (função de ida) e decodificação (função de volta) do Estego Vídeo.

O funcionamento geral dessas técnicas descrito por meio de um modelo, recebe o nome, neste trabalho, de VideoStego.

VideoStego: Seja a quíntupla $\varphi=<C, S, M, D, E>$, onde $C$ representa o objeto de cobertura, $S$ o objeto contendo o conteúdo esteganografado, $M$ a mensagem a ser embutida do tipo texto, imagem, binário, entre outros, $E$ a função de codificação e $D$ a função de decodificação.

Na função de ida $(E)$ corresponde a: $E: C \star M \rightarrow S$

$E(C, M)=S$

A mensagem, na função de ida $(E)$, pode ser separada em partes sendo que:

$M=\left\{m_{\gamma}, m_{\gamma+1}, \ldots, m_{\gamma+n}\right\}$ para todo $\gamma \in A, A=\{1,2, \ldots, n\}$ e $m_{\gamma} \neq m_{\gamma+1}$

Caso a técnica utilize os fluxos de áudio ou vídeo para inserir o valor de $\mathrm{M}$, pode-se utilizar uma separação do objeto de cobertura $\mathrm{C}$ em partes menores, como por exemplo em alguns quadros específicos do fluxo de vídeo. Assim sendo: 
$C=\left\{c_{\gamma}, c_{\gamma+1}, \ldots, c_{\gamma+n}\right\}$ para todo $\gamma \in A, A=\{1,2, \ldots, n\}$ e $c_{\gamma} \neq c_{\gamma+1}$

Desse modo a função de Ida $(E)$ corresponde a:

$S=E\left(c_{1}, m_{1}\right)+E\left(c_{2}, m_{2}\right)+\ldots+E\left(c_{n}, m_{n}\right)=s_{1}+s_{2}+\ldots+s_{n}$

$D$ corresponde a uma função para decodificação (função de volta), tem-se:

$D: S \rightarrow M$

$D(E(C, M))=M$

De acordo com a função de volta (D), para recuperar a mensagem $(\mathrm{M})$ :

$M=D\left(E\left(c_{1}, m_{1}\right)+E\left(c_{2}, m_{2}\right)+\ldots+E\left(c_{n}, m_{n}\right)\right)=D\left(s_{1}+s_{2}+\ldots+s_{n}\right)$

A VideoStego deve respeitar as seguintes propriedades:

$|C| \geq|M|$

$|S| \geq|M|$

$E\left(c_{\gamma}, m_{\gamma}\right) \cap E\left(c_{\gamma+1}, m_{\gamma+1}\right)=\emptyset$ para todo $\gamma \in A$

Dessa maneira o tamanho do objeto de cobertura $(C)$ deve ser maior ou igual ao tamanho da mensagem $(M)$, o objeto esteganografado $(S)$ deve ser maior ou igual ao tamanho da mensagem $(M)$ e qualquer combinação de elementos na função de entrada $(E)$ entre $c_{\gamma+n}$ e $m_{\gamma+n}$ deve resultar em vazia uma vez que não existem quaisquer valores iguais para essas variáveis.

\subsection{Considerações Finais}

Basicamente o que deseja-se é a criação de um sistema de esteganografia de marcação imperceptível criando assim um Estego Vídeo contendo uma mensagem oculta em seu interior. Essa mensagem oculta deve poder ser integralmente (sem perdas) retirada desse objeto de cobertura do tipo vídeo sem adição de ruído na reprodução do vídeo. O próximo capítulo apresenta um estudo sobre os tipos de compressão MPEG para explorar possibilidades visando o desenvolvimento de uma técnica de esteganografia em vídeos digitais comprimidos.

No contexto deste projeto, o interesse é inserir texto no interior de vídeos comprimidos criando assim uma marcação imperceptível no Estego Vídeo (Stego Video). Esse Estego Vídeo será do tipo de marcas frágeis pois edições no tipo de mídia vídeo determinam a perda da mensagem esteganografada. 


\section{Capítulo

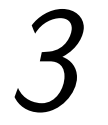 \\ Compressão MPEG de Vídeos Digitais}

\subsection{Considerações Iniciais}

As técnicas de esteganografia digitais, muito difundida em imagens, exploram estruturas da compressão espacial para inserir dados ocultos. Para criação de uma técnica de esteganografia em vídeos digitais comprimidos é importante ressaltar que além da presença de compressão espacial temos a presença de compressão temporal em muitos padrões. A compressão temporal tem o papel de analisar quadros parecidos do vídeo, realizar relacionamentos entre quadros e codificar apenas partes necessárias dos quadros. Ou seja, é um sistema de compressão com perdas e os dados descomprimidos não são idênticos aos dados originais. Quanto maior compressão se quer atingir, maior é a perda de qualidade visual, degradando assim conseqüentemente as informações ocultas que estavam armazenadas no interior de alguns quadros do vídeo.

A família MPEG de padrões abertos é hoje em dia uma das mais importantes e utilizadas para codificação de vídeos digitais. Tal família utiliza tanto compressão espacial quanto compressão temporal, o que pode dificultar sua utilização para fins de esteganografia. Contudo, o padrão MPEG-4, além das estruturas de compressão, contém novas estruturas para interação, e organização de dados que podem ser exploradas para o desenvolvimento de uma técnica de esteganografia. Assim, o objetivo deste capítulo é apresentar um estudo do padrão de compressão genérico da família MPEG, bem como das novas estruturas presentes no padrão MPEG-4.

A seção 3.2 apresenta os princípios básicos da família de padrões MPEG para realizar remoção de redundâncias espaciais e temporais durante a compressão de vídeos; a seção 3.3 detalha como o padrão MPEG-4 utiliza o conceito de objetos audiovisuais, uma das novidades introduzidas por esse padrão refere-se na capacidade de inserção de programas Java denominados MPEGLets. A seção 3.4 tem o papel de explicar as ferramentas do projeto GPAC (framework MPEG-4 utilizado neste projeto). E finalmente a seção 3.5 apresenta as considerações finais deste capítulo. 


\subsection{Compressão MPEG}

Algoritmos do padrão MPEG utilizam uma combinação de técnicas de compressão com perda aliadas a compressão sem perda no processo de codificação de vídeo. Um típico processo de codificação de vídeo MPEG pode ser verificado na Figura 3.1.

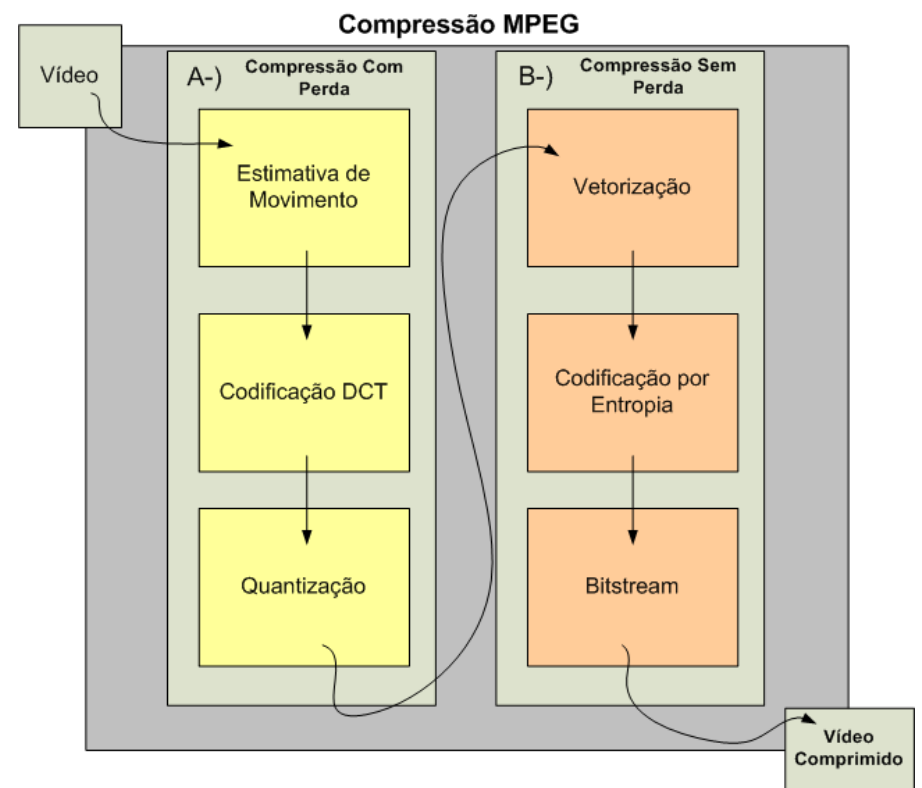

Figura 3.1: Processo típico de compressão de dados do padrão MPEG.

A compressão com perda pode ser dividida em três estágios (Bloco A da Figura 3.1): Estimativa de Movimento, Codificação por DCT e Quantização. A Estimativa de Movimento é responsável por reduzir as redundâncias temporais dos quadros do vídeo. Já a Codificação por DCT e Quantização são responsáveis por eliminar as redundâncias espaciais.

Em todos esses estágios algoritmos de compressão trazem como vantagem a obtenção de um arquivo comprimido de menor dimensão, mantendo, no entanto, uma qualidade mínima em relação ao original, conforme o objetivo que se pretende. Algoritmos de esteganografia que trabalham na compressão com perda não podem ser utilizados quando pretende-se obter uma técnica que mantenha as informações ocultas de forma íntegra no interior do vídeo.

As próximas seções tem o objetivo de explicar as etapas específicas que ocorrem perda proveniente da compressão realizada.

\subsubsection{Compressão Espacial}

Utiliza-se diferentes formas de compressão dos dados para possibilitar a geração do fluxo elementar do vídeo. A codificação do fluxo de dados pode ocorrer de duas maneiras: codificação (encoding) e reconstrução (reconstrution) [ISO, 2000]. Na Figura 3.2, pode-se verificar o processo de codificação e reconstrução do bitstream MPEG a partir de cada frame. 


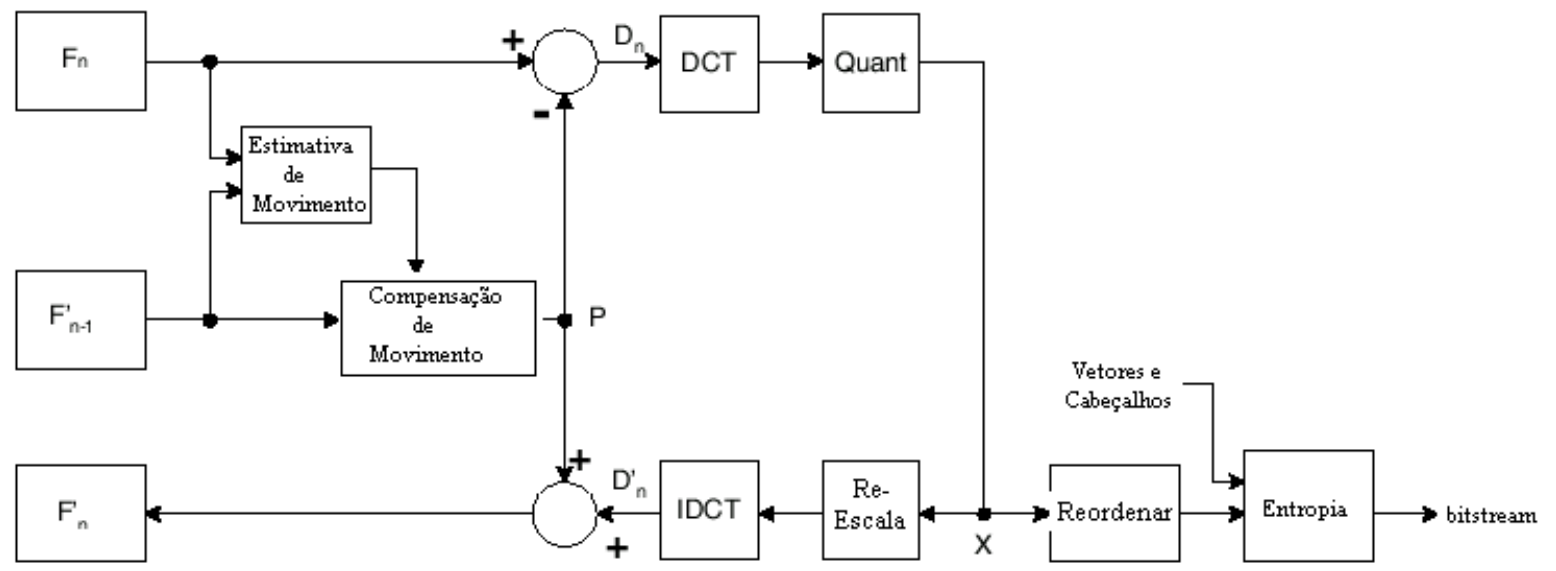

Figura 3.2: Codificação (encoding) e reconstrução de bitstream MPEG [Ebrahimi, 2002].

O processo de codificação (encoding) de um típico frame MPEG segue os seguintes passos [Richardson, 2003] conforme mostrado na Figura 3.2:

1. Cada macrobloco dos quadros de entrada do vídeo é processado.

2. O quadro de entrada é comparado com o quadro de referência para realização da compressão temporal.

3. Após gerado o vetor de movimento cria-se uma matriz de compensação P.

4. P é subtraído do macrobloco corrente e cria-se uma matriz de erros.

5. Cada macrobloco passa pelo processo de compressão espacial. Tipicamente dividi-se os macroblocos em sub-blocos de 8 × 8 e 4 x 4 que passam pela transformada discreta dos cossenos (DCT) separadamente.

6. Cada sub-bloco é quantizado (X). Ou seja, porções do sub-bloco com valores abaixo de um certo limite são eliminados.

7. Os coeficientes da DCT de cada sub-bloco são reordenados utilizando codificação sem perda lossless no domínio VLC ${ }^{1}$.

8. Finalmente, os coeficientes, vetores de movimento e cabeçalhos de informação de cada macrobloco sofrem codificação por entropia e é produzido o bitstream comprimido.

O processo de reconstrução ocorre após realização dos seguintes passos [Richardson, 2003]:

1. Cada macrobloco X (3.2) quantizado é redimensionado e aplicado a transformada dos cossenos inversa produzindo uma matriz de decodificação residual D'. Importante notar que D é diferente de D', pois esse processo gera distorção (ruído) no interior da figura.

\footnotetext{
${ }^{1}$ Variable Length Coding: Tipo de codificação de seqüências de bits tais como Run length, Huffman, LZW.
} 
2. O vetor de movimento P é adicionado ao D' para reconstrução do macrobloco e assim esse processo é realizado para cada macrobloco visando a reconstrução do frame do vídeo.

Importante salientar que na reconstrução dos macroblocos existe um processo de perda de dados, uma vez que muitos arrendondamentos em operações de pontos flutuantes são realizadas na decoficação de D assim como na decodificação da matriz residual D'. Desse modo, não podemos afirmar que o macrobloco X' (recuperado após o processo de compressão) refere-se ao mesmo conteúdo de X (macrobloco de entrada).

\subsubsection{Compressão Temporal}

Na codificação de diversas imagens de um vídeo percebe-se um alto nível de informação visual redundante entre quadros consecutivos de uma cena. Os modelos de redundância temporal exploram as similaridades entre os quadros vizinhos, sejam eles anteriores ou posteriores, visando a eliminação destas informações redundantes. Basicamente procura-se as informações repetidas presentes em quadros próximos para codificar apenas um desses quadros e eliminar a codificação da informação nos demais diminuindo a quantidade de informação a ser codificada no bitstream final [Richardson, 2003].

\subsubsection{Tipos de Quadros}

Para efeito de redução de informação temporal os formatos de vídeos atuais utilizam um mecanismo de diferenciação na codificação de seus quadros visando uma maior compressão. Os tipos de quadros típicos dos padrões MPEG são: Quadro I (Intra coded picture), Quadro P (Predictive coded picture) e Quadro B (Bidirectionally predictive coded picture) [Ebrahimi, 2002].

A Figura 3.3 ilustra a disposição dos tipos de quadros em um vídeo típico MPEG. Pode-se verificar a seqüência de treze quadros, sendo nove quadros do tipo B $(2,3,4,6,7$, $8,10,11,12)$, dois quadros do tipo $\mathrm{P}$ (5 e 9) e dois quadros do tipo I (1 e 1). Os quadros $\mathrm{B}$ e $\mathrm{P}$ fazem referência a quadros do tipo I ou $\mathrm{P}$ anteriores e referência a quadros do tipo I ou $\mathrm{P}$ posteriores. Assim entre dois quadros I temos uma seqüência de dois quadros $\mathrm{P}$ contendo três quadros B entre quadros do tipo I ou P.

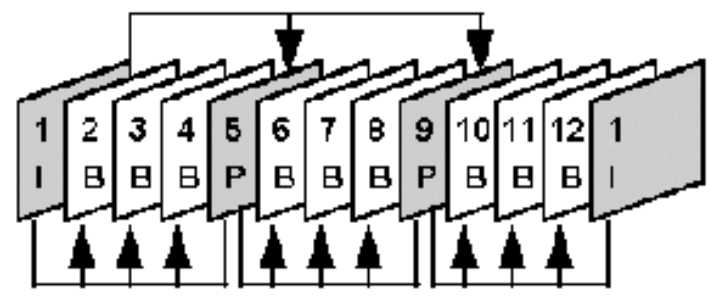

Figura 3.3: Tipos de Quadros.

O quadro I é codificado independentemente dos demais segundo o algoritmo JPEG [Pennebaker B. W., 1993], é dito ser um quadro completo pois não utiliza partes do conteúdo de nenhum outro quadro durante a codificação podendo ser considerado com uma 
imagem JPEG propriamente dita (possui apenas compressão espacial). Esse tipo de quadro alcança taxas de compressão na ordem de 10:1 a 20:1. Já os quadros P e B estão relacionados ao processo de compensação de movimento explicados em detalhes na seção 3.2.2.2.

\subsubsection{Compensação de Movimento}

Predição por compensação de movimento é uma poderosa ferramenta para reduzir redundâncias temporais entre quadros e é usado extensivamente nos padrões MPEG. Desde que a maioria dos quadros de uma seqüência de imagens são muito similares, exceto por deslocamentos devido a movimentos como os da lente de uma câmera através de um cenário, é possível codificar um quadro por meio do cálculo do vetor de movimento em relação a imagem anterior. No caso do MPEG as imagens são separadas em macroblocos de 16x16 pixels e apenas um vetor de movimento é estimado, codificado para cada um desses blocos. O erro de estimativa, ou seja, a diferença entre um quadro e sua estimativa também é codificado [Richardson, 2002]. A codificação de quadros P de cada macrobloco alvo é comparado pixel a pixel com o macrobloco correspondente no quadro de referência. Quando a busca encontra macroblocos iguais dois parâmetros são codificados:

- Vetor de movimento: indica o offset (deslocamento) do macrobloco.

- Erro de estimativa: 3 matrizes, uma para cada componente Y,Cb,Cr contendo diferenças de valores dos pixels do macrobloco e retornados após a busca.

A Figura 3.4 ilustra o processo de estimativa de movimento. Basicamente

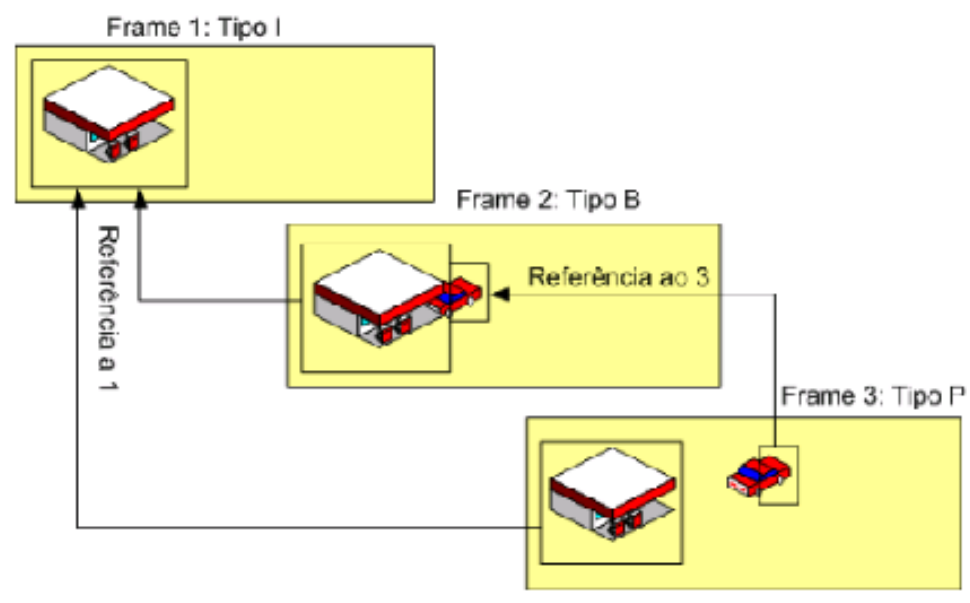

Figura 3.4: Estimativa de Movimento.

No caso do quadro P, elimina-se a redundância espacial e temporal a partir de quadros passados, conforme visto na Figura 3.4. Já nos quadros B, estima-se primeiro o vetor de movimento e as matrizes de diferenças usando-se o quadro P ou I anterior. Depois estima-se os mesmos parâmetros usando-se o macrobloco alvo e a média dos valores previstos nos dois passos anteriores. O conjunto com os menores valores é escolhido para ser codificado. Nesse tipo de quadro elimina-se a redundância espacial e temporal a partir de quadros passados e futuros conforme visto na Figura 3.4 Na codificação dos quadros 
P e B são gerados vetores de movimento e aplicado técnicas de codificação por diferenças e Huffman. Também são geradas matrizes de diferenças que sofrerão compressão DCT, quantização e codificação por entropia.

A precisão da predição depende do quão boa é a estimativa de movimento de um quadro para outro. Esta operação é conhecida como Estimativa de Movimento. Como a estimativa de movimento não é precisa, também precisam ser enviados valores de diferença entre a posição estimada e a posição real dos elementos. Tal operação é conhecida como compensação do movimento [Richardson, 2002].

Importante salientar que o processo de compensação de movimentos, por utilizar referência a quadros passados e futuros, não viabiliza a recuperação na íntegra das informações - a informação recuperada possui erro.

\subsection{O padrão MPEG-4}

O padrão MPEG-4, desenvolvido pela ISO/IEC ${ }^{2}$ em 1998, possui uma enorme lista de funcionalidades que foram criadas após o MPEG-2, visando beneficiar tanto usuários finais quanto criadores de vídeo.

Novas tecnologias e técnicas foram agregadas ao padrão possibilitando que o conteúdo seja reutilizável e flexível com foco na convergência entre HDTV (TV digital), WWW ( Web) e animações, permitindo altos níveis de interação do usuário final com o conteúdo.

MPEG-4 está dividido em dez partes, algumas sendo padrões internacionais e outras sendo relatórios técnicos [Ebrahimi, 2002]. As partes desse padrão são:

- Parte 1 (ISO/IEC 14496-1)- Sistemas: Especifica descrição de cenas, multiplexação, sincronização, gerenciamento de armazenamento local temporário (buffer) e gerenciamento e proteção de propriedade intelectual.

- Parte 2 (ISO/IEC 14496-2)- Visual: Especifica a representação codificada de objetos visuais naturais e sintéticos.

- Parte 3 (ISO/IEC 14496-3)- Áudio: Especifica a representação codificada de objetos de áudio naturais e sintéticos.

- Parte 4 (ISO/IEC 14496-4)- Teste de Compatibilidade: Define condições, no que diz respeito a bitstreams e a dispositivos, para testar implementações de ferramentas MPEG-4.

- Parte 5 (ISO/IEC 14496-5)- Software de Referência: Corresponde à implementação da maioria das partes do padrão MPEG-4. Tem valor apenas informativo e visa auxiliar o desenvolvimento de ferramentas reais compatíveis com o padrão.

- Parte 6 (ISO/IEC 14496-6)- Arcabouço para Integração de Distribuição Multimídia (Delivery Multimedia Integration Framework - DTMF). Define um protocolo de sessão para gerenciamento de fluxo multimídia sobre tecnologias de distribuição genéricas.

\footnotetext{
${ }^{2}$ ISO acrônimo de International Organization for Standardization (Organização Internacional de Padronização) e IEC acrônimo de International Engeneering Consortium (Consórcio Internacional de Engenharia)
} 
- Parte 7 (ISO/IEC 14496-7)- Software de Referência Visual Otimizado. Inclui software otimizado para ferramentas visuais como estimativa de movimento. Essa parte é um relatório técnico e não uma especificação padronizada.

- Parte 8 (ISO/IEC 14496-8)- Transporte de Conteúdo MPEG-4 sobre Redes IP. Especifica o mapeamento de conteúdo MPEG-4 para vários protocolos baseados em IP.

- Parte 9 (ISO/IEC 14496-9)- Descrição de Hardware de Referência. Incluirá descrições de ferramentas MPEG-4 em linguagem de hardware VHDL.

- Parte 10 (ISO/IEC 14496-10) - Codificação de Vídeo Avançada: Especifica a sintaxe de vídeo e ferramentas de cofificação baseadas na especificação H.264 da ITU-T.

Apesar da maioria das partes serem padrões internacionais apenas as partes 1,2,3,6,8 e 10 compõem o núcleo tecnológico do MPEG-4. Este projeto de mestrado especificamente utiliza a parte 10 do padrão.

O padrão MPEG-4, apresenta codificação linear de áudio e vídeo diferente em relação ao MPEG-1/2. A codificação MPEG-4 é baseada em objetos, isto é, as cenas áudio-visuais são codificadas em termos de objetos. Um objeto pode ser uma imagem ou um vídeo: um carro em movimento, uma fotografia. Também pode ser um objeto de áudio: um instrumento de uma orquestra, o som de um carro. A associação de áudio e vídeo é chamado de objeto áudio-visual [Koenen, 2002].

\subsubsection{Estrutura da Cena MPEG-4 e Multiplexação de Objetos}

A parte Sistemas do padrão MPEG-4 especifica a descrição de cenas audiovisuais. Uma típica cena MPEG-4 contém um número de objetos com diferentes formas para serem combinados antes da apresentação ao usuário [Ebrahimi, 2002].

Uma importante tarefa na estruturação de uma apresentação MPEG-4 é a descrição de todos os fluxos contidos nesta, incluindo informações como decodificadores a serem utilizados e taxa de transferência.

Para a composição de uma cena através dos objetos audiovisuais necessita-se saber dados relativos a sua posição, translações, rotações e interações com demais objetos. Assim, a descrição da cena serve para relatar a composição espacial e temporal da cena.

O modelo adotado pelo padrão MPEG-4 para descrever a composição de cenas multimídia complexas é baseado na VRML Virtual Reality Modeling. Mais especificamente, utiliza-se uma extensão da linguagem VRML para descrever cenas. Após a descrição da cena realiza-se a codificação em uma representação binária. O formato binário para essa descrição é o BIFS (binary format for scenes) [Richardson, 2003], e ele define como os objetos são combinados para formar a apresentação.

Para facilitar a produção de conteúdos, a parte Sistemas do padrão define o Formato Textual MPEG-4 Extensível (Extensible Multimedia Integration Language - XMT) [Ebrahimi, 2002]. A cena é construída por meio da descrição dos objetos em grafos, basicamente tem-se uma estrutura de árvore contendo nós que representam os objetos audiovisuais formando uma estrutura hierárquica [Ebrahimi, 2002]. 
Para que uma cena possa ser apresentada no terminal do receptor, a estrutura da cena deve estar disponível antes dos objetos. Assim as informações de composição são disponibilizadas separadamente em um fluxo elementar [Ebrahimi, 2002].

O vídeo MPEG-4 é formado pela multiplexação de todos os fluxos elementares dos objetos audiovisuais pertencentes à cena, formando assim um único fluxo MPEG-4. Essa etapa de multiplexação pode visualizada na Figura 3.5.

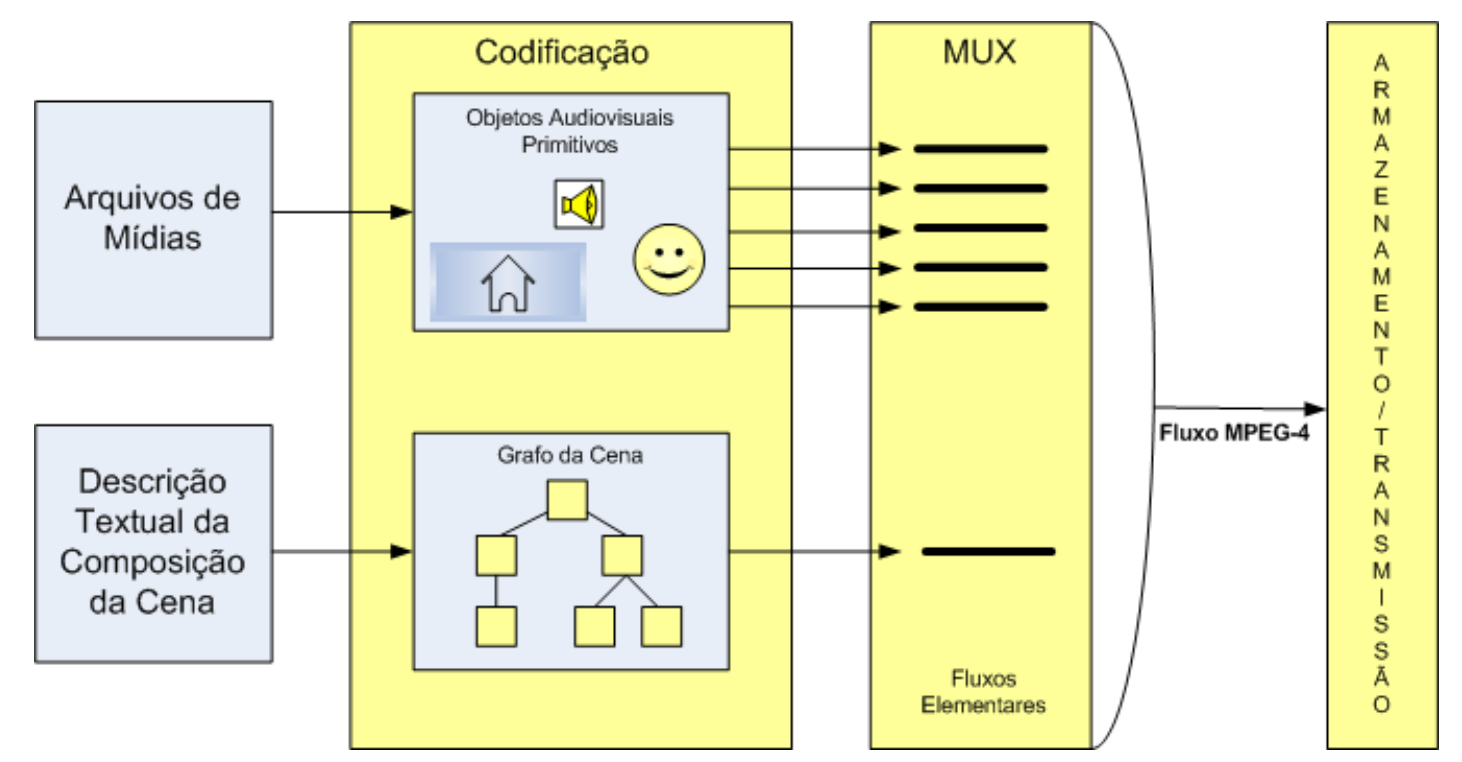

Figura 3.5: Multiplexação de objetos. [Goularte, 2003].

Um típico codificador MPEG-4 gera como saída objetos audiovisuais primitivos na forma de fluxos elementares MPEG-4 comprimidos. Tais fluxos elementares podem ser armazenados ou enviados ao multiplexador que gera como saída um único fluxo de MPEG-4, o qual pode também ser armazenado e/ou transmitido em rede.

\subsubsection{MPEG-J}

MPEG-J [Ebrahimi, 2002] foi introduzido na versão 2 do padrão MPEG-4 e consiste de um conjunto de APIs que possibilitam que aplicações Java possam acessar e manipular interativamente o conteúdo MPEG-4. MPEG-J suporta a manipulação da cena, permitindo respostas apropriadas para os eventos da rede, do servidor ou das entradas do usuário.

Como já mencionado, um arquivo MPEG-4 pode conter diversos tipos de objetos audiovisuais. Um desses objetos, pode ser um programa Java, em especial MPEGLets. O termo MPEGLet é uma alusão aos applets Java. É um programa Java desenvolvido por meio da API MPEG-J, a qual permite a um terminal MPEG-4 acessar e modificar o grafo da cena. MPEGlets são transmitidos em um fluxo elementar MPEG-4 para serem executados em um terminal no cliente.

Por trás disso, busca-se a interatividade do usuário com uma cena de vídeo já que MPEG-J tem a capacidade de controlar a apresentação produzida no terminal do cliente, podendo dessa maneira criar interações com a cena reproduzida no terminal alterando seu roteiro original [Ebrahimi, 2002]. 
A parte Systems do padrão MPEG-4, especifica como os objetos audiovisuais são posicionados e sincronizados com outros objetos. MPEG-J define um conjunto de APIs que possibilitam às aplicações interagirem com o terminal. [Ebrahimi, 2002]

Os pacotes que compõem as APIs do MPEG-J são:

- org.iso.mpeg.mpegj.scene: Acesso à cena permitindo a criação e modificação dos nós da cena declarados no grafo de cena;

- org.iso.mpeg.mpegj.resourceManager: Gerenciamento dos recursos do sistema, acesso as características dinâmicas do player;

- org.iso.mpeg.mpegj.network: Acesso e controle dos decodificadores usados;

- org.iso.mpeg.mpegj.decoder: Acesso e controle dos componentes de rede de um player MPEG-4.

Uma aplicação MPEG-J apresenta três camadas: Presentation Engine, Execution Engine e Application Engine. O BIFS da cena é interpretado pela Presentation Engine. A camada Execution Engine realiza a decompressão dos fluxos referente aos objetos audiovisuais. MPEG-J define a Application Engine oferece o acesso e controle para modificações da cena MPEG-4. A API MPEG-J junto com a JVM formam a Application Engine. Desse modo, o player decodifica o fluxo elementar referente a MPEGLet e repassa a execução dos .class para JVM.

\subsection{Projeto GPAC}

GPAC (GPAC Project on Advanced Content) [GPAC, 2002] é um framework multimídia baseado no padrão MPEG-4, desenvolvido em linguagem de programação ANSI $\mathrm{C} / \mathrm{C}++$, compilado em ambiente Windows ou Linux. O objetivo do projeto é fornecer uma alternativa as ferramentas comerciais MPEG-4, na modalidade de código livre [GPAC, 2002].

Os codificadores são responsáveis por gerar os fluxos elementares MPEG-4 a partir de mídias de entrada, como por exemplo áudio e vídeo. Em particular existe um codificador de grafos de cena MPEG-4. O grafo de cena MPEG-4 descreve a organização dos elementos audivisuais, relacionamentos e interações da cena MPEG-4. Essa descrição é criada por meio da linguagem XMT [Ebrahimi, 2002] e é codificada também como um fluxo elementar.

Todos os fluxos elementares são multiplexados em um único arquivo MPEG-4 por meio da ferramenta MP4Box. Este arquivo gerado pode ser reproduzido pelo player do projeto chamado Osmo.

\subsubsection{MP4Box}

A MP4Box é uma ferramenta do projeto GPAC utilizada para diversas etapas da concepção de um vídeo no formato .mp4. Suas duas funcionalidades básicas são: a multiplexação dos diversos fluxos elementares e a geração do arquivo binário em formato MPEG-4 (.mp4). 
Inicialmente é realizado um parsing no arquivo XMT, preenchendo assim os valores das estruturas que guardam informações sobre os objetos e fluxos. O modo de escrita no arquivo final é o mesmo estipulado no formato padrão do arquivo .mp4, ou seja, primeiro todo o cabeçalho do vídeo e de cada fluxo, e depois os próprios arquivos de mídia.

Basicamente a MP4Box, trata fluxos elementares como mídias que precisam ser importadas para depois serem inseridas, com seus respectivos cabeçalhos, em arquivos .mp4. Na implementação nativa da MP4Box não está desenvolvido o parser para fluxos elementares de MPEGLets.

\subsubsection{Player OSMO - Projeto GPAC}

O player Osmo 4 é o software de reprodução de conteúdo audiovisual MPEG-4 do framework do GPAC. Foi desenvolvido em $\mathrm{C}++$ e utiliza extensivamente MFC (Microsoft Foundation Classes) para lidar com chamadas ao sistema e gerenciar a interface.

Conforme já mencionado, a MP4Box multiplexa todos os fluxos elementares em único arquivo .mp4. O Osmo possui decodificadores para extração desses fluxos elementares presentes no arquivo .mp4. O Osmo possui decodificadores para Vídeo, Áudio, Grafo de cena XMT, entre outros.

Originalmente o player Osmo não tem a capacidade para decodificação de MPEGLets e conseqüentemente possibilitar a entrega de arquivos .class para a máquina virtual Java (JVM) e cliente.

\subsection{Considerações Finais}

Os sistemas de compressão de vídeo com perdas estão baseados no princípio de remoção de redundância subjetiva, elementos da imagem ou da seqüência de vídeo que podem ser removidos sem afetar significativamente a percepção do expectador quanto à qualidade visual. Os métodos de codificação de vídeos MPEG exploram redundância temporal e espacial para alcançar compressão. No domínio temporal, há normalmente uma alta correlação (semelhança) entre quadros de vídeo que foram capturados em instantes próximos de tempo.Normalmente, quadros adjacentes têm uma semelhança (correlação), especialmente se a taxa de transmissão de quadros é alta. No domínio de espaço, há normalmente uma correlação alta entre os pixels (amostras) que estão perto um ao outro, isto é, os valores vizinhos de amostras são freqüentemente bem parecidos.

Para desenvolvimento de uma técnica de esteganografia para vídeos digitais comprimidos da família MPEG, necessita-se explorar formas de inserção de dados que não sofram interferência das estruturas de compressão com perda. Conforme visto na seção 3.2.1, a compressão espacial possibilita a inserção de dados em quadros do vídeo funcionando do mesmo modo como imagens. Porém, a exploração de técnicas desse tipo em vídeos não permite a inserção de dados em volume expressivo em seu interior, uma vez que em sua maioria trabalham com pequenas porções dos macroblocos que não sofrem alteração durante a quantização. Maiores detalhes a respeito dessa afirmativa serão apresentados no capítulo 4.

Já em relação a compressão temporal não é possível recuperar dados na íntegra na exploração dos algoritmos de predição e compensação de movimento. Somente seria possível a inserção de dados em quadros I, uma vez que os mesmos apenas possuem compressão 


\section{CAPÍTULO 3. COMPRESSÃO MPEG DE VÍDEOS DIGITAIS}

espacial. Os quadros P e B possuem referências a outros quadros em cascata impossibilitando o agrupamento das informações inseridas na codificação.

Uma nova possibilidade refere-se ao uso do padrão MPEG-4, o qual apresenta novas estruturas que podem ser exploradas para esteganografia, embora o projeto de referência de código livre GPAC [GPAC, 2002] não apresente suporte a todas essas estruturas, necessitando ser estendido para tal finalidade.

O próximo capítulo apresenta um estudo bibliográfico de técnicas de esteganografia em vídeos comprimidos e técnicas em estruturas de compressão que podem ser adaptadas para construção de uma nova técnica de esteganografia em vídeos comprimidos da família MPEG. 


\section{Revisão Sistemática da Literatura}

\subsection{Considerações Iniciais}

Como já mencionado, existe uma dificuldade na aplicação de esteganografia em vídeos comprimidos pois os mesmos apresentam compressão espacial e temporal nos seus quadros, diferentemente das imagens que utilizam apenas compressão espacial.

Neste capítulo, é apresentado um levantamento bibliográfico a fim de verificar o estado da arte em técnicas de esteganografia. Esse levantamento bibliográfico foi realizado por meio de uma revisão sistemática da literatura.

Como conseqüência dessa revisão da literatura, estabeleceu-se uma classificação de técnicas de esteganografia em vídeos digitais comprimidos. Vale ressaltar que essa classificação de técnicas é inédita e caracteriza-se como contribuição deste trabalho.

A seção 4.2, tem o papel de apresentar os estudos na literatura para levantamento do estado da arte na área. A seção 4.3, descreve uma classificação criada para as diversas técnicas de esteganografia em vídeos e finalmente a seção 4.4 apresenta as considerações finais deste capítulo.

\subsection{Revisão da Literatura}

Realizou-se uma revisão sistemática sobre o tema de esteganografia em vídeos ${ }^{1} \mathrm{com}$ o objetivo de verificar o estado da arte. Segundo Conte et al. [Horta, 2005] as revisões sistemáticas são baseadas em uma estratégia de pesquisa bem definida, que visa detectar o máximo possível de material bibliográfico relevante.

O principal objetivo de uma revisão sistemática é produzir uma síntese completa de trabalhos publicados sobre uma questão de pesquisa específica [Barbara, 2004], utili-

\footnotetext{
${ }^{1}$ Esta revisão sistemática encontra-se publicada como relatório técnico do ICMC de número 292 [Carvalho, 2007].
} 
zando um processo robusto e bem definido para guiar o procedimento de busca e análise de trabalhos [Mafra S., 2005]. Em revisões não sistemáticas, mesmo quando são conduzidas de acordo com regras de boas práticas, a revisão não é dotada de rigor científico. O desenvolvimento de uma revisão sistemática para a pesquisa bibliográfica tem como objetivo estabelecer um processo mais formal e controlado para condução desse tipo de investigação [Mafra S., 2005].

De acordo com Kitchenham [Barbara, 2004], os principais motivos que podem levar um pesquisador a optar por conduzir uma revisão sistemática são:

- Sumarizar a existência de evidências referentes a um tratamento ou tecnologia.

- Identificar lacunas no estado da arte em uma área de pesquisa para sugerir novas áreas de investigação.

- Prover conhecimento para direcionar atividades de pesquisa.

Dentre as principais vantagens de se utilizar uma revisão sistemática ao invés de uma revisão informal pode-se citar:

- Busca abrangente e exaustiva.

- Critérios de qualificação claros e passíveis de reprodução.

- Avaliação crítica de acordo com método explícito e pré-determinado.

A metodologia de revisão sistemática tem sido amplamente utilizada em pesquisa de medicina há bastante tempo, desde o início do século XX. De uma forma geral, o processo de revisão sistemática pode ser analisado como um processo de três etapas, partindo dos conceitos, passando por estudos encontrados na literatura, pela análise dos resultados dos estudos e, finalmente, pela conclusão, como ilustrado na Figura 4.1.

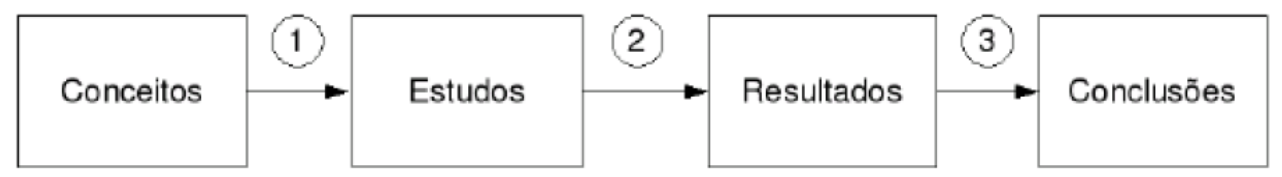

Figura 4.1: Processo de revisão sistemática, adaptado de [Barbara, 2004].

A revisão sistemática geralmente envolve as seguintes atividades:

- 1. Planejamento da revisão

Identificação da necessidade de uma revisão

Desenvolvimento de um protocolo de revisão

- 2. Condução da Revisão

Identificação das fontes de busca relevantes

Seleção de estudos primários

Avaliação da qualidade dos estudos

Extração dos dados

Síntese dos dados 
- 3. Documentação da revisão

Para esta dissertação descreve-se apenas as partes principais da revisão: Protocolo de Revisão (seção 4.2.1), a Condução da Revisão (seção 4.2.2) e os Resultados da Revisão Sistemática (seção 4.2.3) ${ }^{2}$.

\subsubsection{Protocolo de Revisão}

Um protocolo de revisão define o método que deve ser utilizado para realizar uma revisão sistemática. Um protocolo pré-definido é necessário para reduzir possíveis vieses de pesquisa [Barbara, 2004].

O protocolo de revisão descrito a seguir foi baseado nas diretrizes indicadas por Kitchenham [Barbara, 2004] e foi utilizado para guiar todo o processo de levantamento. Informações mais detalhadas sobre o protocolo e materiais utilizados estão documentadas em relatório técnico [Carvalho, 2007].

- Objetivo: o principal objetivo desta revisão foi o de identificar trabalhos de pesquisa relacionados a técnicas de esteganografia em imagens, áudio e vídeos sem perda de informações. A motivação para esta pesquisa é indicar um panorama do estado da arte em técnicas de esteganografia.

- Questão de pesquisa: Quais técnicas de esteganografia das que estão disponíveis podem ser adaptadas para utilização em vídeos comprimidos MPEG-4?

- Método para busca de fontes: as fontes de pesquisa devem ser recuperadas por Web. A busca manual não foi considerada nesta pesquisa.

- Palavras-chave: Steganography, Video.

- Lista de fontes: artigos e anais de eventos disponíveis em bibliotecas digitais e indexados pela IEEE Xplore ${ }^{3}$, ACM Digital Library ${ }^{4}$, Springerlink ${ }^{5}$, Science Direct $(\text { Elsevier })^{6}$.

\subsubsection{Condução da Revisão}

Durante a extração dos dados alguns refinamentos foram necessários para excluir artigos fora do escopo da pesquisa. Realizada esta etapa, a pesquisa resultou em 62 artigos da Elsevier, 27 artigos da ACM, 16 artigos da IEEE e 4 artigos da Springer, totalizando 109 artigos encontrados e pertinentes para a pesquisa.

Esses artigos foram divididos em categorias, entre elas: Técnicas (Imagens, Áudio, Vídeo), Overview descrevendo possibilidades de pesquisas e Surveys, Ataques (Esteganálise) e Aplicações.

\footnotetext{
${ }^{2}$ Maiores detalhes da revisão sistemática podem se encontrados no relatório técnico [Carvalho, 2007], disponível em: http://www.icmc.usp.br/ biblio/BIBLIOTECA/rel_tec/RT_292.pdf

${ }^{3}$ http://ieeexplore.ieee.org

${ }^{4}$ http://portal.acm.org

${ }^{5}$ http://www.springerlink.com

${ }^{6}$ http://www.sciencedirect.com
} 


\subsubsection{Resultados da Revisão Sistemática}

Foi possível obter um gráfico de posicionamento da pesquisa em relação aos trabalhos que mais têm sido publicados na área. Na Figura 4.2 pode-se observar um gráfico sobre a proporção de trabalhos publicados nas sub-classificações de técnicas.

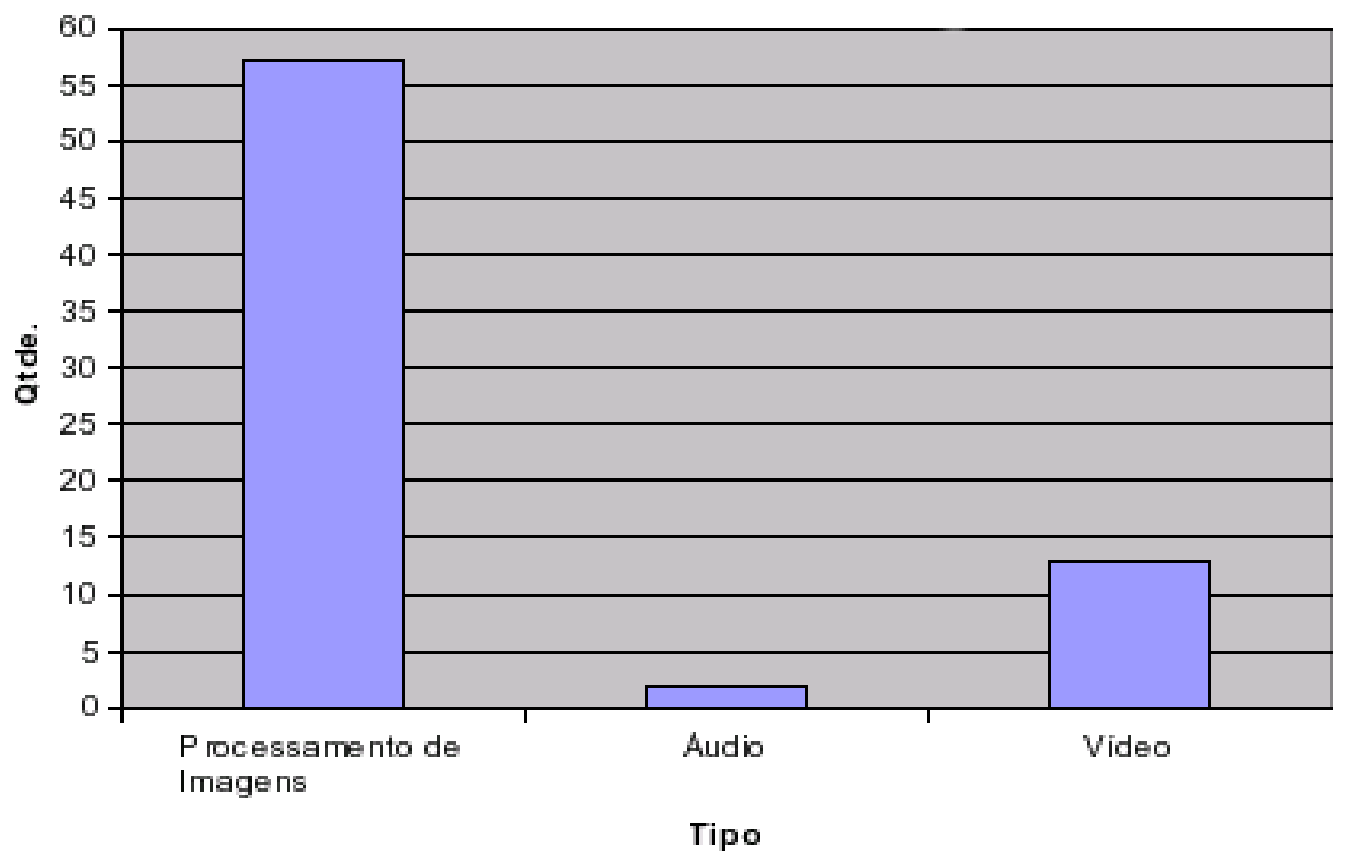

Figura 4.2: Gráfico da distribuição das técnicas.

Ficou evidente que a maioria dos trabalhos em esteganografia estão presentes na área de processamento de imagens, mais especificamente 57 trabalhos enquanto que apenas 13 trabalhos de técnicas de esteganografia em vídeos foram publicados nos últimos 10 anos. Este fato remete a característica incipiente de pesquisa na área de esteganografia em vídeos motivando dessa maneira a busca por técnicas deste gênero. Outro resultado importante advindo dessa revisão foi o suporte científico para podermos criar uma classificação para técnicas de esteganografia em vídeos digitais.

\subsection{Classificação para Técnicas de Esteganografia em Ví- deos}

Com a realização da revisão na literatura foi possível criar uma classificação das técnicas de esteganografia para vídeos. Dessa maneira agrupou-se os artigos de acordo com a atuação de cada técnica desenvolvida nas diversas etapas de codificação dos formatos de vídeos.

\subsubsection{Abordagens para Esteganografia em Vídeos}

Diversas classificações são propostas no campo da esteganografia digital. Uma classificação muito adotada na literatura é a de Petitcolas [Petitcolas, 1996], que descreve 
métodos em esteganografia separando-os em 3 casos. No primeiro caso, Sistemas Simples (Simple Systems), estão presentes técnicas de inserção de texto cifrados ou não no interior de imagens por meio de técnicas de BMS (Bit Menos Significativo, ou Least Significant Bit) criando Estego Imagens e técnicas de alterações de amostras de áudio para criação de Estego Áudio. No segundo caso, em Operações no Domínio Espacial (Operating in a Transform Space), são apresentadas algumas técnicas que aproveitam a operação de compressão de dados para inserção de informações ou ruído, por meio de redundância, em arquivos como aúdio (MPEG audio layer e MP3), imagens JPEG e vídeos MPEG. Finalmente, no terceiro caso, em Um Modelo Geral (A General Model), descreve meios mais robustos de esteganografia aliando novas técnicas dos dois casos anteriorermente descritos.

No caso Sistemas Simples de Petitcolas, leva-se em consideração apenas técnicas com baixa capacidade de inserção de dados. Já o caso Operações em Domínio Espacial classifica técnicas que não permitem a perfeita recuperação de informações esteganografadas por utilizarem estruturas com compressão com perda. Assim, para um refinamento, visando criar uma nova classificação de técnicas de esteganografia em vídeos comprimidos necessitamos separá-las por etapas de compressão.

As abordagens presentes em nossa classificação são:

- Abordagem $A$ : Fase de Compensação de movimento e predição de erros

A1: Técnicas são aplicadas às Matrizes de erro.

A2: Técnicas são aplicadas diretamente nos objetos visuais (I-VOP's, P-VOP's).

- Abordagem B: Codificação Sem Perda (Lossless)

B1: Técnicas são aplicadas diretamente nos vetores e cabeçalhos oriundos da reorganização dos coeficientes DCT.

B2: Técnicas são aplicadas na codificação por entropia e no bitstream final.

- Abordagem $C$ : Adição de funcionalidade

$C 1$ : Criar estrutura de dados à parte na codificação do bitstream final.

$C 2$ : Explorar novas estruturas descritas no padrão de vídeo para inserir dados ocultos.

A Figura 4.3 ilustra as diversas abordagens ao longo do processo de codificação de vídeos MPEG. Independentemente da abordagem escolhida, considera-se requisitos para o vídeo final:

- Deve poder ser reproduzido em player comum sem alteração visual perceptível ao usuário, garantindo o sigilo da técnica.

- Deve ser passível de recuperação de informações inseridas quando utilizado um player específico, ou seja, deve haver uma aplicação cliente capaz de retirar as informações inseridas via esteganografia do interior do Estego Vídeo.

A Figura 4.3 representa as etapas de compressão do padrão MPEG, separadas em blocos. Basicamente os quadros (frames) tanto correntes quanto de referência passam por uma estimativa de movimento e posteriormente para a compensação de movimento. 


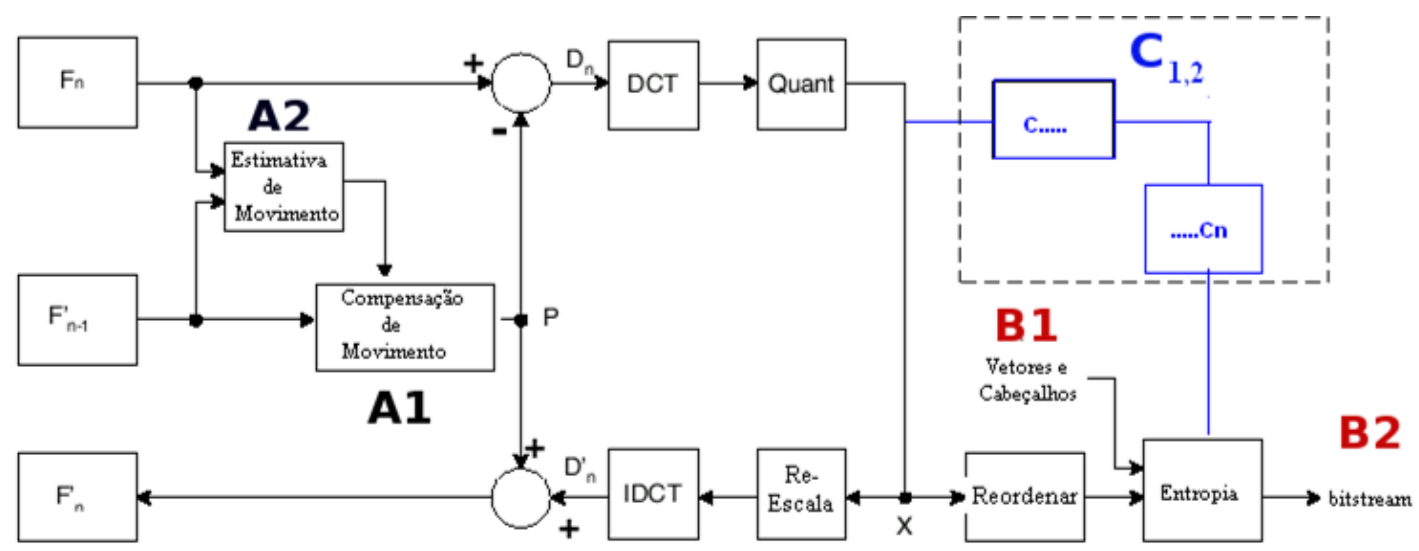

Figura 4.3: Localização das abordagens para esteganografia em vídeos comprimidos no processo de compressão MPEG.

A abordagem $A 1$ está presente na etapa de compensação de movimento, mais especificamente no momento que o algoritmo MPEG cria as matrizes de erros associadas a etapa de estimativa de movimento. Já a abordagem $A 2$ está presente na etapa de estimativa de movimento no momento que são tratados os objetos visuais I-VOP's e P-VOP's. As técnicas da abordagem $A$ estão presentes anteriormente a etapa de compressão com perda do padrão MPEG. Após a etapa de compressão temporal segue a fase de compressão com perda em que realiza-se a aplicação das transformadas no nível de freqüência (DCT). Após a DCT é realizada a quantização e conseqüentemente realiza-se a reordenação e aplica-se algoritmos de entropia capazes de comprimir os dados finais e posteriormente elaborar o bitstream final. A abordagem $B 1$ atua diretamente na reorganização dos dados, mais especificamente alterando vetores e cabeçalhos. Já a abordagem $B 2$, alteram os algoritmos de entropia para inserção de dados ocultos ou manipulam a confecção do bitstream final. As técnicas da abordagem $C$ estão representadas na Figura 4.3 por uma região hachurada. A abordagem $C 1$, cria uma estrutura de dados não pertecente originalmente ao padrão. Já a abordagem $C 2$ explora novas estruturas presentes no padrão MPEG para inserção de dados ocultos.

As abordagens $A$ e $B$ trazem como vantagem a realização de modificações em estruturas presentes ao padrão, podendo assim o vídeo ser reproduzido normalmente. Porém essas técnicas tem como pontos negativos a inserção de ruído nas imagens do vídeo podendo prejudicar a qualidade visual na reprodução do mesmo. Além disso, a abordagem A contém dificuldade intrínseca na recuperação precisa das informações inseridas pois encontra-se anterior a etapa de compressão por transformada (DCT).

Já a abordagem $C$ traz como vantagem a garantia da qualidade visual do vídeo pois não insere ruído em suas imagens, uma vez que utiliza estrutura de dados adicionais ao padrão MPEG ou a exploração de estruturas conhecidas do padrão que não são utilizadas nas etapas de compressão. A abordagem $C$ tem capacidade para introduzir maior quantidade de informação no interior de um vídeo em relação as demais técnicas. E apresenta como desvantagem a dificuldade para viabilização correta reprodução do vídeo em player comum, pois o mesmo não está preparado para interpretar a estrutura de dados adicional.

Idealmente a técnica a ser utilizada deve possibilitar que a qualidade visual do vídeo final seja igual ao vídeo original, deve garantir a reprodução do vídeo em um player qualquer e fundamentalmente deve ter a capacidade de recuperação de informações ocultas 
em player específico. Faz-se necessário verificar a viabilidade de tais técnicas para alcançar o melhor processo de inserção de dados no interior de um vídeo comprimido.

\subsubsection{Análise das Técnicas de Esteganografia}

A tabela 4.1 apresenta as técnicas obtidas na revisão sistemática que trabalham com inserção de esteganografia sem perda em vídeos, agrupadas por abordagens.

As técnicas da abordagem $A$ não foram adicionadas a tabela pois não garantem a correta recuperação das informações inseridas, pois atuam em etapa anterior a fase das transformadas do nível de freqüência e quantização, alterando os dados inseridos.

Os trabalhos inclusos na abordagem B1 ([Yin, 2006], [Wolf, 1998]) são variações da técnica de BMS (Bit Menos Significativo) comumente utilizada em imagens. Essas técnicas trazem como vantagem a rápida inserção de informações no reagrupamento dos coeficientes DCT (etapa de quantização), porém como desvantagem pode-se citar a fragilidade para descoberta da esteganografia (esteganálise) pelo fato da adição de ruído nos frames do vídeo e por tratar-se de técnicas amplamente conhecidas no domínio espacial. Já os demais trabalhos desta abordagem ([D. Robie, et. al. 2001], [Ning Wu, 2002], [D. Robie, 2001]) inserem informações nos coeficientes da DCT explorando as características dos GOPs (Group of pictures) do padrão MPEG-2 dificultando a descoberta da esteganografia. Testes experimentais da técnica de GOPs em MPEG-2 são apresentados em [Ning Wu, 2002] demonstrando que o impacto no aumento do tamanho do arquivo Stego Video é baixo.

Para a abordagem $B 2$, foram encontradas técnicas que podem ser divididas em duas subcategorias:

1. Algoritmos de Entropia: Variante LZW ([Lonardi, 2003]), Run Length adaptative ([Chang., 2004]), VLC modificado ([Lu, 2005]) e RVLC modificado ([Bijan G., 2005]).

2. Alteração de bitstream final MPEG-2: [Dugelay, 2003] e [Girod, 1998].

O trabalho de Lonardi [Lonardi, 2003], altera a estrutura do algoritmo LZW utilizado na compressão do tipo ZIP. Nesse artigo pode-se verificar que a capacidade de quantidade de informação codificada adicionalmente é pequena uma vez que a técnica depende de uma grande árvore de dados binários codificada para obter melhor desempenho. Em testes experimentais o autor adicionou 14,524 bytes de informação oculta modificando em 3 bytes o tamanho do arquivo original com compressão GZIP. Como vantagem essa técnica apresenta um bom desempenho computacional no momento de inserção de dados que é da ordem de $O(\log n)$.

Em seu trabalho, Wang [Chang., 2004] altera o funcionamento do algoritmo Run Length em imagens a partir de dois métodos: BRL (Introdução de informação oculta em bitmaps) e GRL (Introdução de informação genérica). O método BRL não é interessante para o escopo deste projeto pois trabalha no RLE de arquivos BMP. Já o método GRL é interessante para este projeto pois apresenta uma estrutura simples de codificação Run-Length codificando cada par de pixels em um número fixo $(n)$ de bits secretos, denotado por $S(n)$. Esse método apresenta bons resultados experimentais para valores de $S(n)$ iguais a 4 e 5 com baixa intensidade de ruído nas imagens. 
Tabela 4.1: Técnicas de Esteganografia para Vídeos Comprimidos .

\begin{tabular}{|c|l|l|}
\hline Abordagem & Técnicas & Artigos \\
\hline \hline B2 & LZ77 (Variante do LZW) & {$[$ Lonardi, 2003] } \\
\hline B2 & Run Length adaptative & [Chang., 2004] \\
\hline B1 & $\begin{array}{l}\text { ALV(Average Luminance Value) e } \\
\text { RS-Code }\end{array}$ & [Yin, 2006] \\
\hline B2 & VLC e RVLC modificado & {$[$ [ijan G., 2005] e [Lu, 2005] } \\
\hline B2 & MPEG2 Bitstream & {$[$ Dugelay, 2003], [Girod, 1998] } \\
\hline C1 & A/S Tree adaptative & [Fenlin Liu, 2006] \\
\hline C2 & XMT em MPEG-4 & [Ziad Sakr, 2007] \\
\hline B1 & Coeficientes DC & [Wolf, 1998] \\
\hline B1 & AC's em GOPS & {$[$ D. Robie, et. al. 2001], } \\
& & [Ning Wu, 2002], [D. Robie, 2001] \\
\hline
\end{tabular}

A técnica de VLC (Variable Length Coding) modificado [Lu, 2005], trabalha na inserção de informações adicionando bits de erros a partir da codificação pelo algoritmo de Huffman. É adicionada nessa abordagem uma codificação de vídeo em duas direções e é criado um decodificador especial para recuperação das informações em vídeos MPEG-2. Os resultados experimentais apresentados demonstram que adição de erro propagado (ruído) no decorrer da codificação do vídeo é menor que $1 \%$, porém o tamanho do stegovideo final cresce em média $27 \%$.

Já a técnica de dependência de frames no domínio VLC (VFDW) [Bijan G., 2005], aborda a estruturação da informação a ser inserida pela dependência dos frames escolhidos alterando a manipulação dos macroblocos e organizando estes dados na etapa de codificação por entropia gerando assim um Stego Bitstream. Esse algoritmo foi testado experimentalmente para um típico vídeo MPEG2 e também foram realizados testes de ataques de resistência a consistência do vídeo, resistência ao corrompimento de frames do tipo $I$ e resistência a colisão de pacotes apresentando resultados experimentais interessantes.

Em se tratando de algoritmos que alteram o bitstream final MPEG-2 o artigo de Dugelay et al. [Dugelay, 2003] apresenta várias abordagens para esteganografia em vídeos para diversas aplicações diferentes. A técnica de DEW (Differential Energy Watermarks) realiza inserção de informações nos macroblocos de frames I após a etapa de compressão por transformada do algoritmo MPEG. A energia dos blocos originais com o Stego Bloco são medidas para recuperação das informações ocultadas.

Ja a técnica apresentada em [Girod, 1998], realiza inserção de informações a partir do espalhamento de espectro em frames I de vídeos MPEG reorganizando os índices da transformada na etapa de entropia e verificando consistência de bitstream final do vídeo MPEG, para que a correta reprodutção do vídeo seja garantida.

Os algoritmos da subcategoria entropia realizam alterações apenas em estruturas de dados e algoritmos bem conhecidos do padrão MPEG. Isso traz como vantagem a facilidade de reprodução do vídeo em player comum. Já as técnicas da subcategoria de alterações no bitstream final do vídeo apresentam como vantagem a fácil codificação e decodificação da informação, uma vez que trabalha-se na porção final do vídeo sem preocupar-se com todas as estruturas e procedimentos complexos existentes em etapas anteriores. As duas 
técnicas da abordagem $A$ apresentam como desvantagem em comum a possibilidade de ocasionar problemas na reprodução do vídeo caso ocorra algum erro na composição do bitstream final do vídeo.

Tabela 4.2: Análise das técnicas de Esteganografia para Vídeos.

\begin{tabular}{|c||l|l|l|l|l|}
\hline Técnica & Abord. & Complex. & MPEG & Carga & $\begin{array}{l}\text { Player } \\
\text { Comum }\end{array}$ \\
\hline \hline ALV & B1 & quadrático & 1,2 & médio & sim \\
\hline AC's GOP's & B1 & linear & 2 & baixo & sim \\
\hline DC's & B1 & linear & 1,2 & médio & sim \\
\hline DEW & B2 & quadrático & 2 & médio & sim \\
\hline LZ77 & B2 & logarítmico & 1,2 & baixo & sim \\
\hline Run Length & B2 & logarítmico & 1,2 & baixo & sim \\
\hline VLC - VFDW & B2 & quadrático & 1,2 & baixo & sim \\
\hline RVLC & B2 & quadrático & 1,2 & baixo & sim \\
\hline Girod & B2 & quadrático & 2 & baixo & sim \\
\hline XMT & C2 & logarítmico & 4 & alto & sim \\
\hline A/S Tree & C1 & logarítmico & 1,2 & alto & não \\
\hline
\end{tabular}

Foi encontrado apenas um trabalho referente a abordagem $C 1$, que codifica uma estrutura de dados à parte para inserção de informações ocultas ([Fenlin Liu, 2006]). Segundo o autor, para viabilizar a reprodução de vídeos MPEG-2, foi necessário a implementação de um player específico. Essa técnica traz como vantagem a capacidade de inserção de grande volume de informações e como desvantagem a não capacidade de reprodução em player de vídeos comum. Já em relação a abordagem $C 2$ foi encontrado apenas um trabalho ${ }^{7}$, XMT MPEG-4 [Ziad Sakr, 2007] o qual explora a representação textual da estrutura de cena MPEG-4 (XMT do formato MPEG-4) para criar uma metodologia hierárquica para inserção de dados ocultos nos diversos nodos da cena.

Para nortear o desenvolvimento do presente trabalho uma análise detalhada foi realizada para verificar as vantagens e desvantagens das técnicas encontradas na revisão sistemática. Métricas foram analisadas nas diversas técnicas encontradas, observadas de acordo com o conteúdo disponibilizado nos artigos estudados. Desse modo, foram analisadas cinco métricas:

- Tipo de Abordagem de esteganografia $A, B(B 1, B 2)$ ou $C(C 1, C 2)$.

- Complexidade algorítmica na inserção de dados no interior do vídeo.

- Padrão de vídeo MPEG que pode ser aplicado diretamente.

- Capacidade de informações que pode ser inserida (Carga):

Alta: maior que $20 \%$ do tamanho do vídeo original.

\footnotetext{
${ }^{7}$ Esse artigo foi adicionado a pesquisa posteriormente a finalização da revisão sistemática visando a atualização das técnicas desenvolvidas desde a finalização do processo até a defesa desta dissertação
} 
Média: entre $10 \%$ e $20 \%$ do tamanho do vídeo original.

Baixa: menor que $10 \%$ do tamanho do vídeo original.

- Facilidade de reprodução em player comum.

Alguns trabalhos apresentaram detalhes a respeito de esteganálise e ruído adicionado à mídia, mas como não foram encontradas essas métricas para todas as técnicas nos artigos, não foram adicionadas nessa classificação.

A Tabela 4.2, apresenta algumas técnicas importantes para este trabalho encontradas na literatura e classifica as mesmas de acordo com as abordagens propostas analisando-as a partir das métricas citadas. A maioria das técnicas da abordagem $B 1$ apresentam em comum: complexidade quadrática ou linear na etapa de inserção de informações ocultas e reprodução em player comum. Já as técnicas da abordagem $B 2$ apresentam em comum: complexidade quadrática ou logarítmica na etapa de inserção de dados ocultos, baixa capacidade para inserção de informações e reprodução em player comum. E finalmente as técnicas da abordagem $C$ apresentam em comum grande capacidade de inserção de dados ocultos no vídeo.

\subsection{Considerações Finais}

Nenhum trabalho foi encontrado para alteração das estruturas na etapa de composição de movimento do padrão MPEG (Abordagem $A$ ). A dificuldade na aplicação da abordagem $A$ na esteganografia sem perda em vídeos relaciona-se ao fato da mesma funcionar antes do momento da utilização da operação de transformada (DCT) e quantização dificultando a correta recuperação de seus índices de predição de movimento na etapa de descompressão. Esse fato relaciona-se com características de erros adicionais presentes nos coeficientes de saída da transformada no nível da freqüência, os quais correspondem a valores aproximados devido a operações com pontos flutuantes. Como a aplicação pretendida exige a recuperação sem perda de informações, a abordagem $A$ tornou-se inviável para este projeto.

A maioria dos trabalhos buscam inserir informações na organização do bitstream final do vídeo (Abordagem $B$ ) e apenas dois trabalhos estão presentes na abordagem $C$, o primeiro cria uma estrutura de dados paralela, em forma de árvore binária para inserção de informações ocultas e o segundo explora as estruturas de cenas MPEG-4 para inserção de informações ocultas. Outras estruturas dos padrões de vídeos, principalmente MPEG-4, podem ser exploradas para inserção de dados ocultos, entre elas, podemos citar: MPEGLets, hierarquia de GOPs, VOPs, entre outros.

A combinação e/ou aprimoramento destas técnicas podem resultar em uma nova técnica que resolva problemas encontrados e aumente as características de vantagens para aprimoramento da mesma. Idealmente busca-se uma técnica que tenha rapidez no momento de inserção de informações ocultas, tenha complexidade baixa para inserção de dados, seja compatível com padrões de compressão MPEG, seja robusta para esteganálise, tenha adição de ruído baixa, alta capacidade de inserção de informações ocultas e permita reprodução do vídeo em player comum. O próximo capítulo descreve a técnica MP4Stego, desenvolvida para dar suporte a essas características. 


\subsection{Considerações Iniciais}

O objetivo deste capítulo é apresentar uma nova técnica para esteganografia em vídeos comprimidos, a MP4Stego. Diferente das abordagens atualmente encontradas na literatura, a MP4Stego possibilita a inserção de grande volume de dados ocultos e não adiciona ruído ao bitstream do vídeo. Para isso são utilizadas novas estrturas de vídeo especificadas pelo padrão MPEG-4 não presentes em padrões da vídeos anteriores. Em especial, utiliza-se MPEGLets para criar uma estrutura de dados para armazenar dados ocultos $($ Abordagem $C$ ). Como vantagens adicionais até o momento atual, não foi encontrada técnica de esteganálise capaz de identificar o conteúdo oculto no interior de um Estego Vídeo produzido pela MP4Stego.

Alguns requisitos buscados no desenvolvimento da técnica de esteganografia em vídeos MPEG-4 foram:

- Segurança: Capacidade de não levantar suspeita, enquanto tenta criar uma blindagem contra um algoritmo de esteganálise, o conteúdo escondido deve ser invisível tanto perceptivelmente quanto por meios estatísticos [Buccigrossi, 2000];

- Carga Útil: Capacidade de inserção de informações (mensagem) no objeto de cobertura, geralmente medida em KBytes;

- Fragilidade: Capacidade de perda das informações ocultadas quando o vídeo é editado, ou seja, qualquer tentativa de modificação na mídia (objeto de cobertura) acarreta perda da esteganografia.

Em relação ao requisito de segurança foi almejado o desenvolvimento de uma técnica que seja esteganograficamente segura [Duda R. O.; Hart, 2000], ou seja, não é possível descobrir a presença de estego-conteúdo usando qualquer método de esteganálise. Já em relação a carga útil, utilizamos a mídia do tipo vídeo como objeto de cobertura, a qual tem 
naturalmente mais capacidade para esteganografia quando comparada as demais mídias tanto contínuas como discretas.

Já o requisito de Fragilidade, possibilitará o desenvolvimento futuro de aplicações pertinentes na área de segurança digital, como por exemplo integridade digital.

As vantagens encontradas na MP4Stego em relação as demais técnicas são:

- É possível a reprodução do Estego Vídeo em qualquer player comum MPEG-4.

- A técnica não adiciona ruído no Estego Vídeo.

- Possui grande carga útil, uma vez que a quantidade de dados inseridos pode até mesmo ser maior que o próprio tamanho do vídeo.

- A MP4Stego não está suscetível a técnicas esteganálise conhecidas.

- Pode-se inserir informações de qualquer tipo no interior do vídeo.

A seção 5.2 apresenta o desenvolvimento da técnica MP4Stego, a seção 5.3 descreve um modelo formal para a técnica, e finalmente, na seção 5.4, são apresentadas as considerações finais deste capítulo.

\subsection{MP4Stego}

Para atender a todos esses requisitos foi criada uma arquitetura para MP4Stego contendo 4 entidades presentes em aplicações diferentes. A Figura 5.1, exibe essa arquitetura.

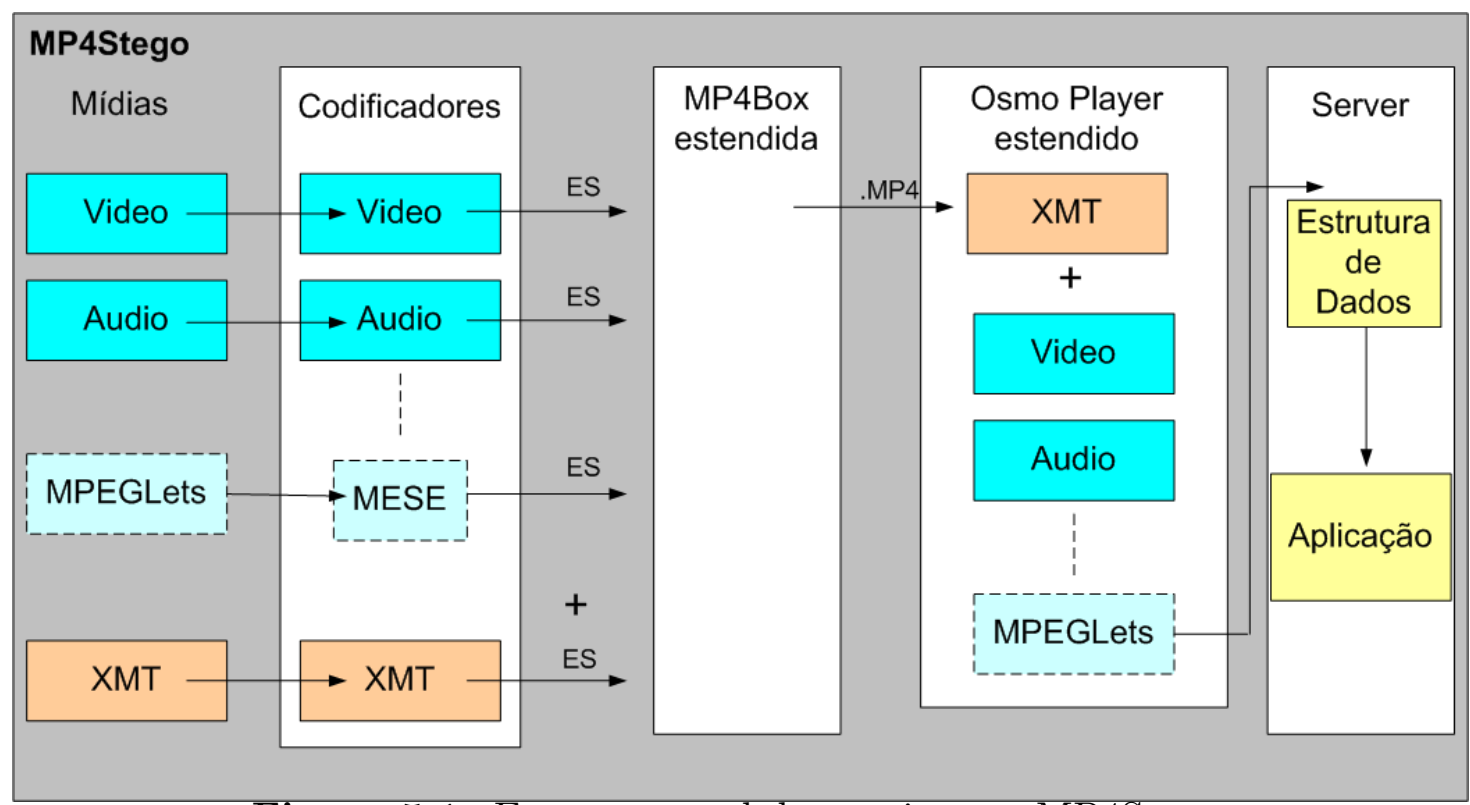

Figura 5.1: Esquema geral da arquitetura MP4Stego.

A primeira entidade corresponde ao conjunto de mídias a serem incluídas em um vídeo MPEG-4. A segunda entidade refere-se a um conjunto de fluxos de objetos necessários para criação de um vídeo no formato MPEG-4. A utilização de codificadores de vídeo, 
áudio e cena (XMT) estão atrelados ao projeto GPAC [GPAC, 2002]. Além desses, existe um fluxo correspondente a um programa Java denominado MPEGLet. Esse fluxo não é codificado originalmente pelo GPAC, assim sendo foi necessário adaptar um codificador para tal finalidade. O codificador JavaES (Java Elementary Stream) [ISO, 2001], foi adaptado para tal finalidade.

$\mathrm{Na}$ terceira entidade, os codificadores são responsáveis pela geração de fluxos elementares (Elementary Streams - ES) separadamente de cada tipo de fluxos de objetos MPEG-4. A partir dos fluxos elementares pode-se gerar um único fluxo elementar do tipo de arquivo .mp4. Esse processo corresponde na utilização de um multiplexador de fluxos elementares e codificador de vídeo MPEG-4 denominado MP4Box, também do projeto GPAC [GPAC, 2002]. Originalmente a MP4Box não tem o requisito de codificação de fluxos de MPEGLets, assim foi necessário modificá-la para tal finalidade.

A quarta entidade é responsável pela reprodução do vídeo MPEG-4. O player contêm decodificadores capazes de separar novamente os fluxos elementares das mídias MPEG-4 e sincronizá-las a partir da descrição de cena (XMT). O player utilizado foi o Osmo, do projeto GPAC [GPAC, 2002]. O Osmo foi estendido para possibilitar o entendimento de MPEGLets codificadas pelo MESE.

A quinta entidade corresponde a um servidor (Server) capaz de receber os dados da MPEGLet. A MPEGLet comunica-se com o Server repassando sua estrutura de dados, que contém as informações ocultas. Essas informações podem ser repassados para uma aplicação caso essa exista. O Server foi criado como um mecanismo para facilitar o uso da MP4Stego para diferentes aplicações. As aplicações serão melhores exploradas no capítulo 6.

O fluxo de MPEGLets, seu codificador MESE e seu decodificador presente no player Osmo estendido, estão representados por retângulos hachurados na Figura 5.1, por não estarem presentes no projeto GPAC.

\subsubsection{MPEGLet}

Uma MPEGLet pode ser definida como um fluxo elementar correspondente a uma aplicação Java presente em um arquivo MPEG-4. No desenvolvimento de MPEGLets faz-se necessário a utilização da API Java MPEG-J. A MPEG-J define um conjunto de aplicações para acessar diretivas de controle de um típico terminal MPEG-4 [Ebrahimi, 2002].

No desenvolvimento da MP4Stego, utiliza-se para inserção das informações ocultas, uma estrutura de dados não limitada, do tipo lista simplesmente encadeada, capaz de alocar variáveis do tipo byte. A utilização de variáveis do tipo byte, refere-se na capacidade de inserir qualquer seqüência de informações no interior da estrutura de dados, desse modo pode-se inserir mensagens ASCII e outros tipos de arquivos, tais como, imagens, binários, entre outros.

Para geração da MPEGLet, utiliza-se como entrada a estrutura de dados preenchida com os dados ocultados alocados em arquivo e as classes da aplicação Java correspondente a MPEGLet. Esses dados presentes em arquivos distintos são agrupados gerando assim uma MPEGLet serializada.

MPEGLet serializada presente na MP4Stego é capaz de comunicar-se com o servidor por meio de Sockets. Esse servidor (Server) pode tanto estar presente na máquina de 
origem (localhost) quanto em uma máquina distribuída na rede. Nessa comunicação existe uma troca de diretivas entre as entidades servidor e player para possibilitar a comunicação.

Uma vez estabelecida a comunicação, é possível iniciar a transmissão de dados. A MPEGLet decodifica sua estrutura de dados, contendo os dados esteganografados, e transforma-os em pacotes TCP para envio ao Server. O Server aguarda os dados enviados via rede em uma porta anteriormente definida.

O Server, tem o papel de definir o devido tratamento da informação recebida da MPEGLet de acordo com o tipo de aplicação em que a técnica MP4Stego é utilizada.

\subsubsection{MESE: MPEGLet Elementary Stream Encoder}

O MPEGLet serializado (descrito na seção 5.2.1) servirá de entrada para o MESE MPEGLet Elementary Stream Encoder. A partir do MPEGLet serializado o MESE é capaz de gerar um fluxo elementar de MPEGLets.

MESE foi baseado no software de referência ISO [ISO, 2001], sofrendo adaptações e otimizações para conceber um fluxo elementar de acordo com os padrões esperados pelos softwares do projeto GPAC. As ferramentas MP4Box e o player Osmo foram estendidos para realizar respectivamente, multiplexação e decodificação de fluxos elementares MPEG-J.

O processo de geração do fluxo consiste basicamente da geração de um arquivo (.mpj) contendo em seu início um header com diversas informações e uma área de payload contendo os bytes das classes da MPEGLet [Ebrahimi, 2002]. Na área de payload, se utiliza compressão do tipo LZW otimizando assim o tamanho do arquivo. Foi definida uma extensão para o arquivo do fluxo elementar MPEGLets, uma vez que o padrão MPEG-4 não estabelece extensão para esse fluxo. Foi adotada a extensão mpj, escolhida unicamente pela similaridade com a sigla que representa o fluxo MPEGLets (MPEG-J).

Dessa maneira, a saída gerada pelo MESE corresponde a um fluxo elementar MPEG-4, o qual será multiplexado conjuntamente com todos os demais fluxos elementares especificados para se produzir o vídeo MPEG-4 desejado.

\subsubsection{Processo de Esteganografia}

Para exemplificar o processo de esteganografia, tomemos como cenário um vídeo, como exibido na Figura 5.2. Essa cena MPEG-4 é formada pelos seguintes objetos: fundo do vídeo (1), imagem (2), objeto referente à uma pessoa (4) e por fim o áudio referente à voz da pessoa (5).

Adicionalmente a esses objetos são inclusos na cena: um objeto referente a descrição de cena (3) e um objeto do tipo MPEGLet (6). Tanto os objetos audiovisuais da cena quanto o objeto referente à composição da cena são codificados em fluxos elementares para posteriormente serem multiplexados e sincronizados com os demais fluxos de vídeo.

Cada objeto de cena é repassado para um codificador específico que gera um fluxo elementar correspondente ao tipo de objeto. Os codificadores presentes no projeto GPAC codificam os objetos de 1 a 5 da Figura 5.2. Para geração de um fluxo elementar do tipo MPEGLet (6 da Figura 5.2) utilizou-se o MESE. 


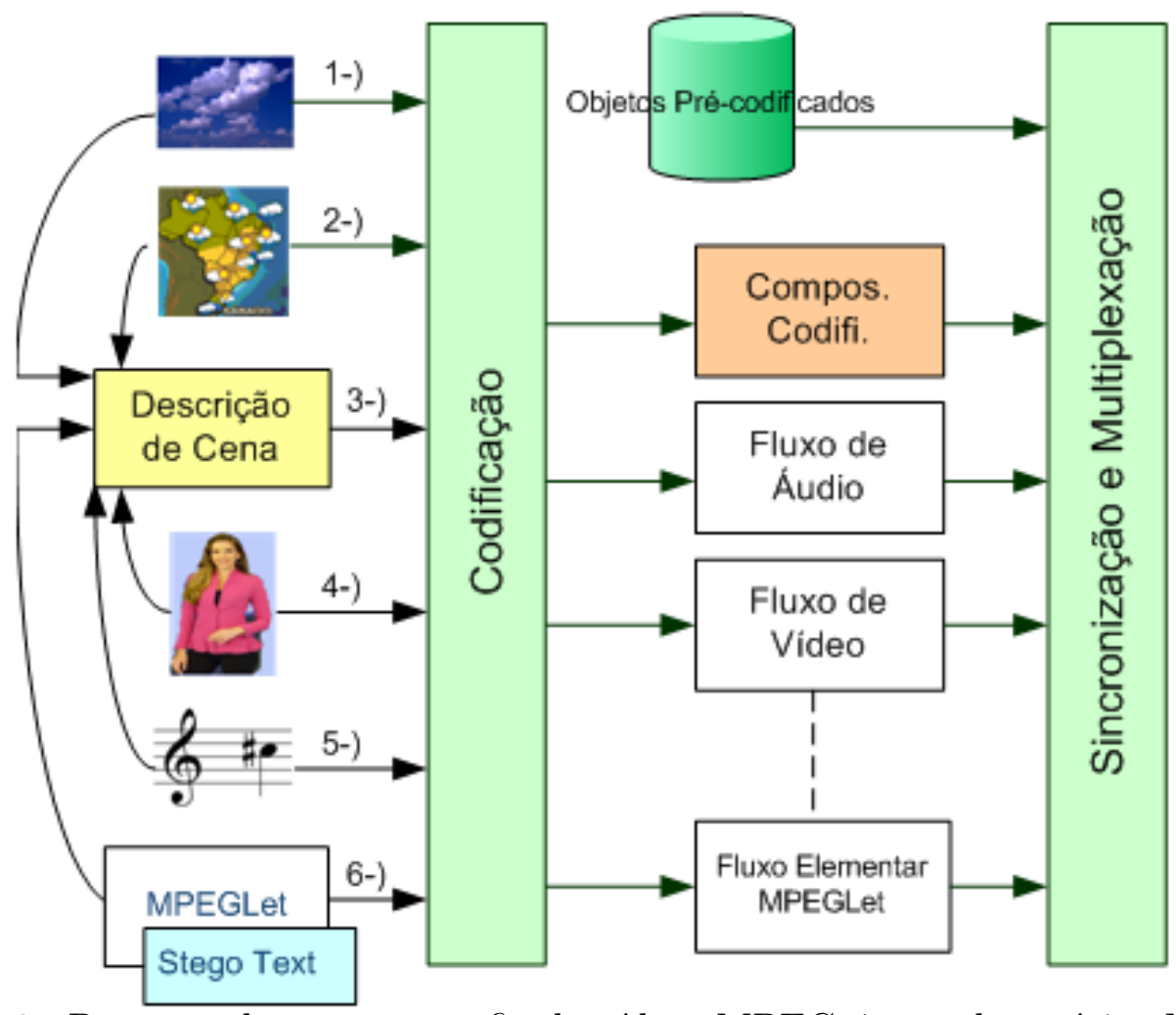

Figura 5.2: Processo de esteganografia de vídeos MPEG-4 usando a técica MP4Stego.

O objeto 6 corresponde a uma MPEGLet contendo uma aplicação capaz de decodificar o 'Stego Text'. Esse 'Stego Text' contém em seu interior as informações ocultadas. Essas informações ocultadas estão presentes em uma lista encadeada.

A construção do objeto MPEGLet respeita a seguinte ordem: 1- Inclusão de dados (Stego Text) na lista encadeada (um texto por exemplo); 2- Serialização da lista encadeada com a MPEGLet. Feito isso, o arquivo serializado é enviado para o codificador MESE (MESE integrado ao projeto GPAC), gerando assim um único fluxo elementar de MPEGLets.

Após a etapa de codificação os fluxos elementares são multiplexados conjuntamente com objetos pré-codificados de cenas anteriores gerando apenas um fluxo MPEG-4 final para fins de armazenamento ou transmissão em rede.

Todos os fluxos elementares são enviados para a ferramenta MP4Box estendida para multiplexação de um único fluxo MPEG-4 (Sincronização e Multiplexação na Figura 5.2) presente em um arquivo .mp4.

Já para a decodificação da cena, contendo o objeto esteganografado, realiza-se a demultiplexação dos objetos anteriormente codificados (Figura 5.3).

No player Osmo estendido, realiza-se a etapa de recuperação desses objetos audiovisuais da cena em conjunto com o objeto esteganografado, além do objeto de descrição de cenas. Esses objetos são somados aos objetos codificados anteriormente das outras cenas e aos objetos não codificados e assim gera-se a composição da cena para reprodução no player de vídeo MPEG-4.

Para a composição da cena, separa-se novamente os fluxos elementares do vídeo MPEG-4 e são executados de acordo com a programação inserida no objeto descritor 


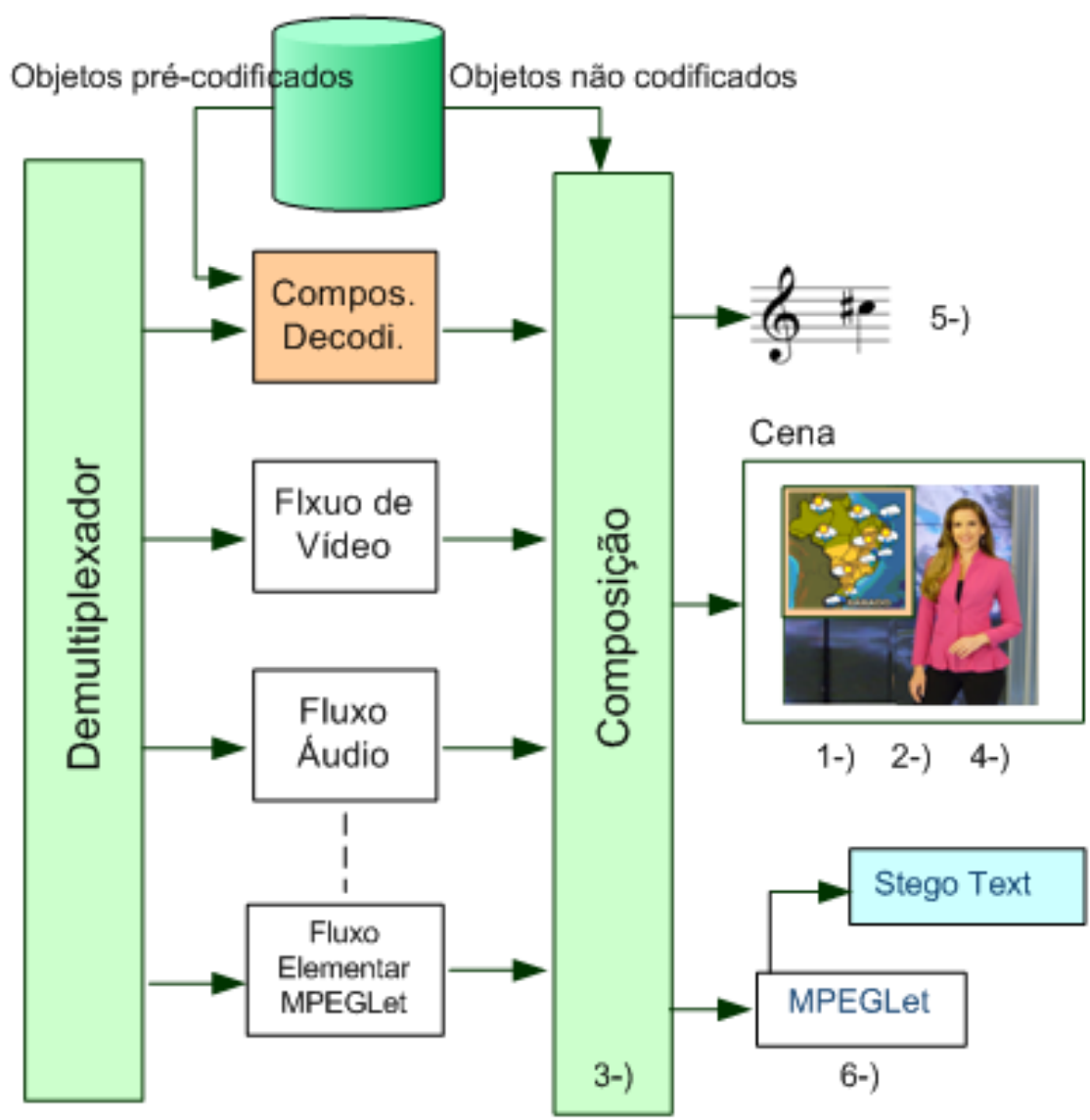

Figura 5.3: Processo de esteganografia reversa em vídeos MPEG-4 usando a técnica MP4Stego.

de cena. Assim os objetos 1,2 e 4, da Figura 5.3, serão compostos para reproduzir a cena, do mesmo modo como o objeto 5 é extraído do fluxo elementar de áudio.

A decodificação da MPEGLet consiste na recuperação do objeto esteganografado (Stego Text), o qual é chamado em um momento específico em relação ao tempo pelo descritor de cena (Objeto 3 da Figura 5.2). No exato momento específico, o player repassa a execução do fluxo de MPEGLets para a JVM Java Virtual Machine que decodifica a estrutura de dados (6) e executa uma aplicação com a finalidade de exibir o resultado referente ao texto ocultado no Stego Text. Na Figura 5.4, pode-se visualizar uma janela contendo a saída dos dados inseridos via esteganografia com classes da MPEGLet. O conteúdo adicionado das strings foram inseridos em 4 nós da lista encadeada resultando no texto "Diego Fiori de Carvalho".

\subsection{Modelo MP4Stego para Esteganografia em Vídeos}

A técnica MP4Stego pode ser convenientemente descrita por meio do seguinte modelo. MP4Stego: Seja a quíntupla $\varphi=<C, S, M, D, E>$, onde $C$ representa o objeto de cobertura referente ao fluxo MPEGlet, $S$ o objeto contendo a esteganografia, $M$ a mensagem a ser embutida, $E$ a função de esteganografia e $D$ a função de esteganografia 


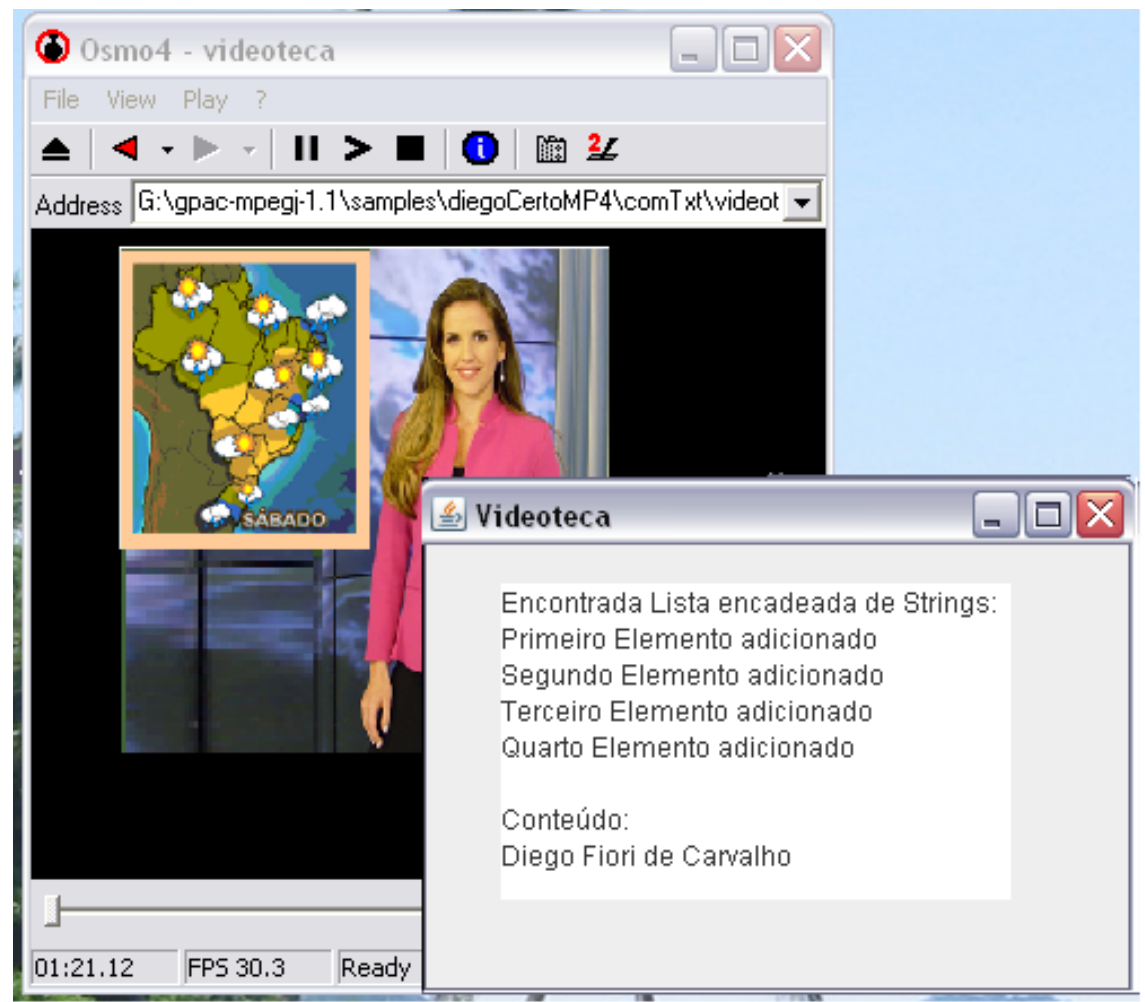

Figura 5.4: Screenshot da MP4Stego aplicada para o player OSMO estendido.

reversa. A função que descreve os componentes do objeto de cobertura pode ser descrita por:

$$
C=\left\{C_{v}, C_{a}, \ldots, C_{m}\right\}
$$

Cada um dos diversos fluxos elementares MPEG-4 estão presentes em $C$ : $C_{v}$ corresponde ao fluxo elementar de vídeo, $C_{a}$ corresponde ao fluxo elementar de áudio e $C_{m}$ ao fluxo elementar de MPEGLets. Os demais fluxos elementares presentes, no objeto cobertura, tais como fluxo de descrição de cena estão representados por reticêncicas (...).

A função de esteganografia, ou seja de ida $E$, corresponde a:

$$
\begin{aligned}
& E: C_{m} \star M \rightarrow S \\
& E\left(C_{m}, M\right)=S
\end{aligned}
$$

Já a função de volta (esteganografia reversa) $D$, corresponde a:

$D: S \rightarrow M$

$D\left(E\left(C_{m}, M\right)\right)=M$

Assim as seguintes propriedades são válidas:

$$
\left\{\begin{array}{l}
C|\forall| M \mid \\
|S| \geq|M|
\end{array}\right.
$$

Dessa maneira o tamanho do objeto de cobertura $C$ pode ser de qualquer tamanho em relação ao tamanho da mensagem $M$ uma vez que o objeto de cobertura alterado corresponde a $C_{m}$ sem qualquer alteração de $C_{v}$. Assim, pode-se inserir uma mensagem com tamanho superior ao tamanho do próprio objeto de cobertura. Outra propriedade válida corresponde ao objeto esteganografado $S$ deve ser maior ou igual ao tamanho da mensagem $M$.

Para cálculo do tamanho de arquivo do objeto esteganografado $S$ devemos proceder da seguinte maneira. 
$S \cong|C|+\frac{1}{3}|M|$

O tamanho de objeto esteganografado $S$ corresponde ao tamanho de $C$ somado a um terço do tamanho da mensagem original $M$.

\subsection{Considerações Finais}

Como resultados do desenvolvimento da MP4Stego foram produzidos: um codificador para MPEGLets (MESE), uma versão da MP4Box capaz de reconhecer fluxos elementares do tipo MPEGLet e uma versão do player Osmo capaz de decodificar MPEGLets. As ferramentas MP4Box e o player Osmo pertencem ao projeto livre GPAC [GPAC, 2002].

A maior contribuição da técnica MP4Stego refere-se na capacidade de introdução de uma mensagem $M$ maior que o tamanho do objeto de cobertura $C$, uma vez que todas as técnicas de esteganografia estudadas apresentam a relação de $|C| \geq|M|$. As técnicas de esteganografia encontradas na literatura buscam alterações em estruturas de compressão dos objetos de cobertura tais como: Imagens, Áudio e Vídeos. Desse modo não se alcança alto volume de inserção de dados, uma vez que ruído pode ser adicionado no objeto $S$. Porém para que uma técnica tenha maior capacidade de inserção de dados em vídeos no formato MPEG-4 foi necessário explorar as novas estruturas e formatos que o padrão especifica. A MP4Stego explora as MPEGLets para aumentar a capacidade de dados esteganografados em um vídeo MPEG-4, sem gerar ruído.

Uma desvantagem relaciona-se com a complexidade algorítmica linear $(O(n))$ para inserção de dados ocultos, uma vez que apenas temos a inserção em uma lista simplesmente encadeada de strings. Mais especificamente sua complexidade corresponde ao aumento gradativo das informações inseridas na lista encadeada a qual é linear para esse caso.

Os vídeos criados com a MP4Stego foram testados em outros players proprietários tais como Real Player e Quick Time (com o plug-in para vídeos MPEG-4 [Envivio, 2004]). Esses players não executaram a técnica MP4Stego na reprodução, porém não apresentaram ruído na execução do vídeo. Esse fato comprova a vantagem de somente o player modificado ter a capacidade de recuperação de dados da MPEGlet e players comuns poderem reproduzir o vídeo normalmente. Ficou comprovado que a técnica MP4Stego, não inviabiliza a correta reprodução do conteúdo presente no fluxo de vídeo em um player comum, quando comparada a técnica $A / S$ Tree Adaptative [Fenlin Liu, 2006], descrita na seção 5.2 .

Para provar a viabilidade da técnica, no capítulo 6 são apresentadas duas aplicações para a técnica MP4Stego. 


\section{Capítulo \\ 6 \\ Aplicações da Técnica MP4Stego}

\subsection{Considerações Iniciais}

Diversas aplicações podem ser implementadas a partir de uma técnica de esteganografia em vídeos. Segundo Zhao [Zhao, 1998], as aplicações de esteganografia podem ser classificadas de acordo com sua área de interesse. Os requisitos de Zhao [Zhao, 1998] para as técnicas necessitam de invisibilidade (capacidade de camuflagem da técnica), Robustez (capacidade de manter a esteganografia mesmo com edição do objeto de cobertura) e Quantidade de informação inserida.

As aplicações citadas por Zhao são:

- Segurança e Proteção de direitos autorais: Possuem como requisitos segurança, invisibilidade e robustez. Exemplos dessas aplicações são: marcas d'agua (watermark) e impressão digital (fingerprinting).

- Autenticação: Possui como requisitos segurança e invisibilidade. Exemplos dessas técnicas são marcas d'agua e assinaturas digitais esteganográficas.

- Comunicação Invisível: Possui como requisitos, segurança, invisibilidade e possibilidade de inserção de um grande volume de dados. Exemplos dessas técnicas são: LSB (bit menos significativo) e espalhamento de espectro em áudio.

- Escrita Secreta: Possui requisitos de robustez e grande volume de dados a serem inseridos. Exemplo dessa técnica corresponde a esteganografia em mídias.

Particularmente, em relação a garantia de integridade do material multimídia, as técnicas de marca d'água não possibilitam a recuperação, na íntegra, das informações ocultadas. Isto se deve a alterações destrutivas efetuadas em propriedades estruturais das imagens e vídeos. Por outro lado, a modalidade de Escrita Secreta apresenta técnicas que alteram propriedades estruturais de imagens e vídeos de forma não destrutiva. Desse modo, as 
informações ocultadas podem ser recuperadas integralmente, sem perdas. Este projeto utiliza uma técnica de Escrita Secreta em vídeos para garantir que não haja alteração das informações inseridas no vídeo.

Como meio de demonstrar a viabilidade da técnica MP4Stego foram escolhidos um ambiente com duas aplicações, a primeira é classificada na categoria de Escrita Secreta propriamente dita, a qual procura obter grande capacidade de inserção de dados ocultos em vídeos comprimidos. A segunda é classificada na categoria de Autenticação visa garantir a integridade de vídeos digitais. A escolha dessas aplicações foi inspirada em dois problemas clássicos do processo de comunicação de dados em que a esteganografia pode auxiliar a aumentar o nível da segurança. No caso da escrita secreta a esteganografia provê o aumento do nível de sigilo dos dados pois os mesmos são mascarados pelo objeto de cobertura ficando não visíveis a um intruso. Já na aplicação de integridade de vídeos busca-se a garantia de que não houve alterações no envio do vídeo entre a origem (provedor) e um destinatário (usuário final).

Previamente ao desenvolvimento das aplicações foi necessário definir um cenário de funcionamento para a metodologia de esteganografia em vídeos. Esse modelo respeita as terminologias de Petitcolas [Petitcolas, 1996] explorando a comunicação em rede e prevendo a garantia da correta reprodução do vídeo original no usuário destino. Basicamente a mensagem secreta é adicionada ao vídeo original pelo sistema de codificação para esteganografia gerando o Stego objeto. Esse Stego objeto é enviado por um canal de comunicação (rede de computadores) para o usuário final. O usuário final com posse do Stego objeto utiliza o sistema de decodificação para esteganografia para reproduzir o vídeo e recuperar a mensagem secreta. A Figura 6.1 ilustra esse modelo.

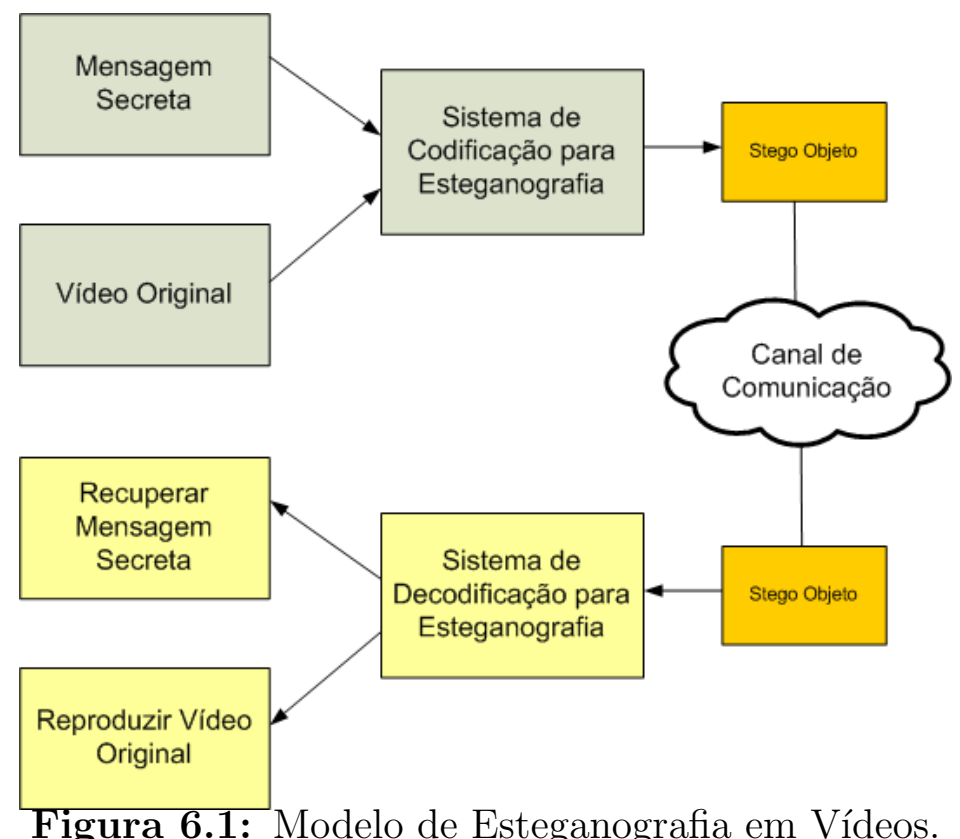

Esse sistema de decodificação para esteganografia é representado, em ambas as aplicações desenvolvidas, pelo player de vídeo especializado o qual apresenta a capacidade de recuperação da mensagem secreta. O fator diferencial entre as aplicações desenvolvidas corresponde no tratamento da mensagem secreta recuperada no player. A escrita secreta 
terá papel de visualização da mensagem para o usuário destino, enquanto que a aplicação de integridade de vídeos fará a verificação da segurança no envio do vídeo pela rede.

Este capítulo apresenta as duas aplicações desenvolvidas, na seção 6.2 é descrita a aplicação de escrita secreta e na seção 6.3 descreve-se aplicação de segurança para integridade de vídeos. Além das aplicações este capítulo também contém a seção 6.4 que apresenta as considerações finais.

\subsection{Escrita Secreta}

As aplicações de escrita secreta tem como objetivo a realização da transmissão oculta de mensagens de qualquer tamanho entre dois ou mais usuários. A esteganografia em vídeos favorece a utilização desse tipo de aplicação, uma vez que o objeto de cobertura do tipo vídeo permite uma quantidade de informação oculta maior que as demais mídias tais como áudio e imagens. Entretanto as técnicas encontradas na literatura, descritas no capítulo 4, para esteganografia em vídeos com finalidade de escrita secreta, não possuem capacidade para inserção de grande quantidade de dados, uma vez que exploram estruturas da compressão sem perda que são dependentes da quantidade de quadros do vídeo. Dessa maneira, o fator limitante da quantidade de informação a ser inserida no vídeo será a quantidade de quadros presente no vídeo, assim somente um vídeo de longa duração poderá receber MBytes de dados em seu interior.

A técnica MP4Stego, por trabalhar na criação de um fluxo adicional (Stream) do tipo MPEGLets, permite a inserção de grande volume de dadosem seu interior, inclusive maior que o próprio tamanho de arquivo do vídeo. Nas próximas subseções, será descrita em detalhes a aplicação de escrita secreta desenvolvida.

\subsubsection{Descrição da Aplicação}

A aplicação de Escrita Secreta consiste de 3 fases:

1. Ocultamento da mensagem em um vídeo;

2. Transmissão do vídeo esteganografado (Estego Vídeo);

3. Recuperação da mensagem oculta.

O ocultamento da mensagem no vídeo é realizado pela técnica MP4Stego e o envio do vídeo ocorre normalmente pelos protocolos já conhecidos e utilizados na web. Já a recuperação da mensagem oculta é realizado por duas aplicações, sendo essas o player especializado e o MP4Stego Server que recebe as informações enviadas pela aplicação MPEGLet iniciada pelo player.

O player especializado tem a capacidade de reproduzir naturalmente os vídeos normais ( sem esteganografia ) e os vídeos contendo informações ocultas. Para recuperação das informações ocultas no vídeo faz-se necessário a presença de uma MPEGLet em seu interior capacitada para tal tarefa. Quando presente a MPEGLet no vídeo, o player tem o papel de executar esse programa Java por meio da chamada a JVM (Java Virtual Machine). Essa MPEGLet irá repassar as informações ocultas para outra aplicação denominada MP4Stego Server. O MP4Stego Server com posse das informações irá apresentar ao 
usuário o conteúdo, inserido via esteganografia no vídeo, para que o mesmo possa ler a mensagem.

Para facilitar o entendimento da comunicação secreta a Figura 6.2 apresenta esse cenário em detalhes. O usuário 1 utiliza a técnica MP4Stego (MP4S) para ocultar uma determinada mensagem (M1) gerando MP4S(M1), a qual é enviada pela Internet para o usuário 2. Esse usuário, de posse do player especializado para esteganografia, reproduz o vídeo. No momento da reprodução do vídeo o player especializado envia M1 para o MP4Stego Server. Essa aplicação, presente na máquina do usuário 2, decodifica a mensagem escondida e a exibe para o usuário 2.

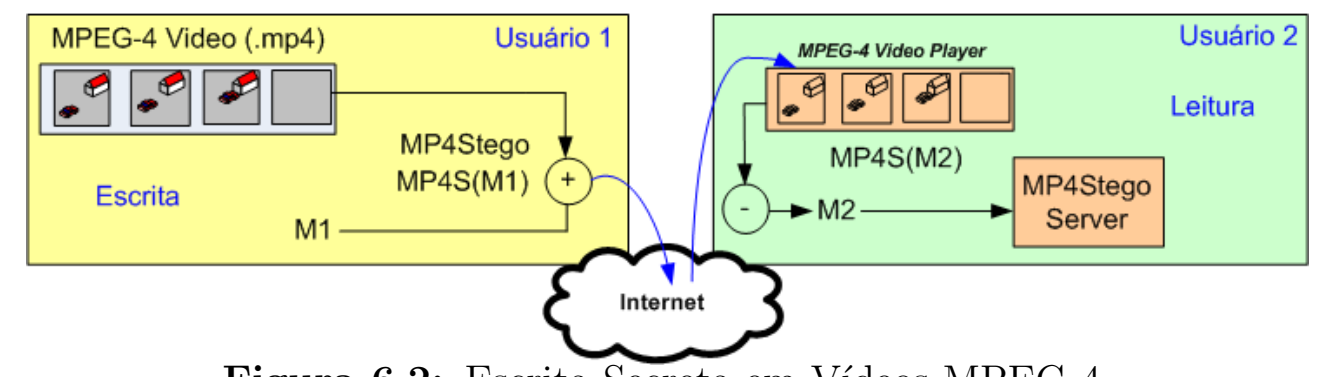

Figura 6.2: Escrita Secreta em Vídeos MPEG-4.

O MP4Stego Server foi desenvolvido com a capacidade de captar os dados decodificados de uma MPEGLet presente no vídeo a qual é executada pela JVM no player modificado. O MP4Stego Server utiliza um socket na porta 1568 para recebimento dos dados enviados pela MPEGLet. Estes dados recebidos são exibidos em uma caixa de texto para visualização da mensagem pelo usuário. O MP4Stego Server não necessariamente tem seu funcionamento atrelado a um sistema local (localhost), na verdade ele foi desenvolvido para ser utilizado em rede, ou seja, o usuário que reproduz o vídeo contendo a mensagem no player especializado pode enviar essa pela rede para o MP4Server presente em outro destino esperando a mensagem. Para essa aplicação de escrita secreta e particularmente para o cenário de testes criado foi utilizado o MP4Server no modo local (localhost).

A Figura 6.3, apresenta o screenshot da aplicação de escrita secreta exibindo o player modificado e o MP4Stego Server.

Na Figura 6.3, pode-se visualizar o player Osmo reproduzindo um vídeo MPEG-4 contendo um Electronic Program Guide (EPG). Esse vídeo MPEG-4 contém uma aplicação, implementada por meio de rotinas MPEG-J presente no fluxo MPEGLet, que tem a capacidade de criar um menu externo ao vídeo. Esse menu, contendo o label 'Escrita Secreta', pode também ser visualizado na Figura 6.3. Após verificar esse evento o usuário pode clicar no menu em 'Escrita Secreta' que a MPEGLet irá enviar as informações para o servidor MP4Server (caso o mesmo esteja no modo conectado) que recebe essas informações e apresenta as mesmas em uma caixa de texto. Os dados recebidos e o servidor MP4Server podem também ser vistos na parte inferior da Figura 6.3.

\subsubsection{Amostras para os Testes}

Para testes da técnica MP4Stego foram utilizados diversas amostras na aplicação de escrita secreta. Essas amostras referem-se a trechos de texto do tipo ASCII. Procurou-se criar amostras de tamanhos diferenciado para verificar a capacidade de inserção de infor- 


\section{CAPÍTULO 6. APLICAÇÕES DA TÉCNICA MP4STEGO}

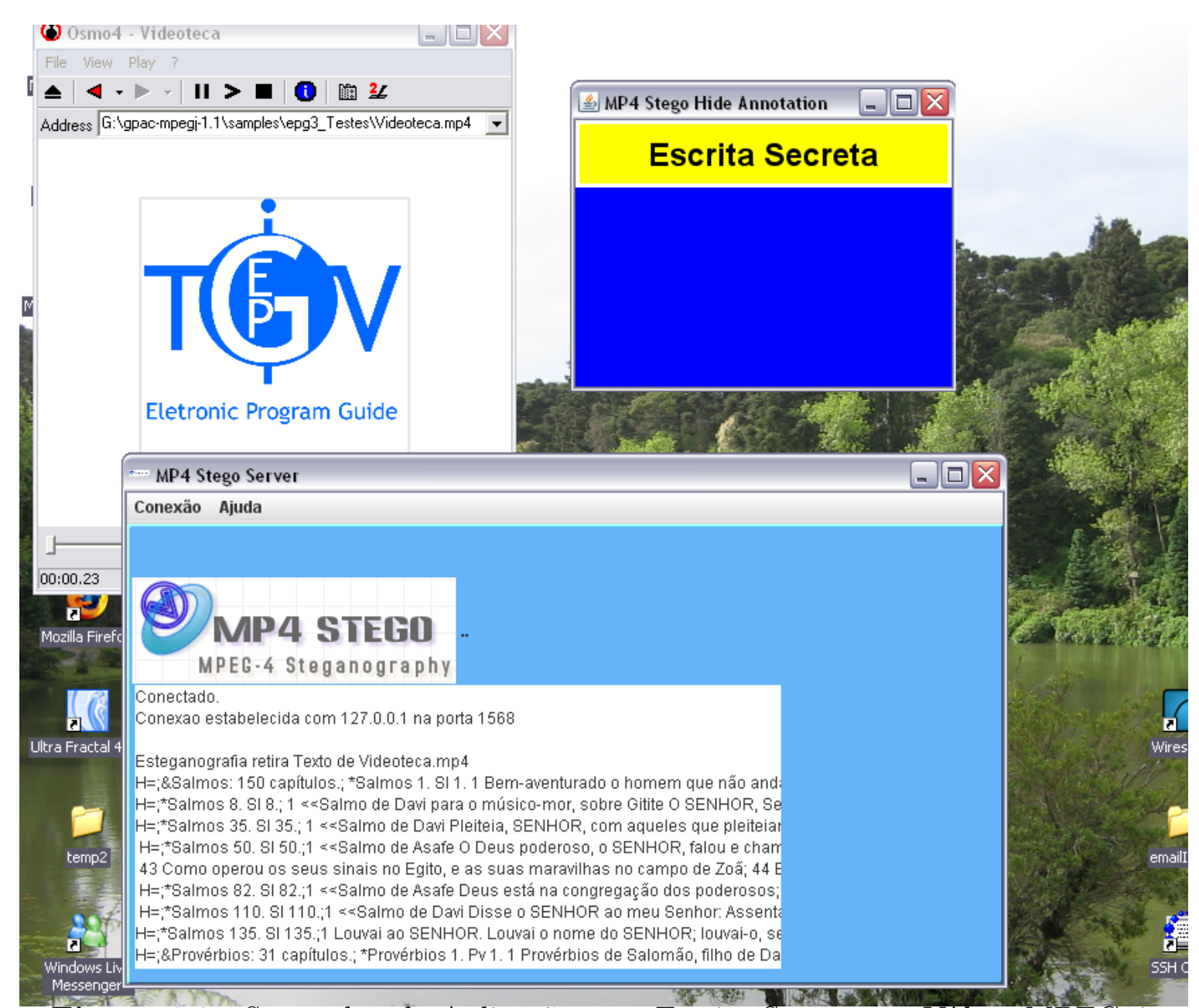

Figura 6.3: Screenshot da Aplicação para Escrita Secreta em Vídeos MPEG-4.

mações da técnica. Assim utilizou-se a escala exponencial de 2 a partir arquivos de $1 \mathrm{~Kb}$ 1 .

As amostras foram extraídas da Bíblia em português [Almeida, 2004], mais especificamente a trechos do antigo e novo testamento. A escolha desses textos devem-se a sua característica popular facilitando o processo de verificação intuitiva da quantidade de informação presente em cada amostra. A Bíblia no formato TXT corresponde ao montante de 3,79 Mb.

Todos os elementos foram agrupadas em 12 amostras $(1 \mathrm{~Kb}, \ldots, 2048 \mathrm{~Kb})$. As amostras contém 7 elementos diferentes, totalizando 84 elementos. Para confeccionar um elemento foi escolhido um trecho da bíblia contendo o tamanho correspondente a amostra. Após esta etapa utilizou-se uma rotina em linguagem $\mathrm{C}$ para misturar randomicamente seu contéudo gerando assim 7 elementos diferentes com o mesmo tamanho. A referência para o conteúdo de cada amostra pode ser visto no Apêndice A.

\footnotetext{
${ }^{1}$ Arquivos de $1 \mathrm{~Kb}, 2 \mathrm{~Kb}, 4 \mathrm{~Kb}, 8 \mathrm{~Kb}, \ldots, 2048 \mathrm{~Kb}$
} 


\subsubsection{Testes e Análises}

Partindo dos princípios dos domínios: Para o domínio de escrita secreta um ponto importante é a capacidade de inserção de dados ocultos oferecida pela técnica de esteganografia. Sendo assim realizaram-se testes para medir tal capacidade em relação à técnica proposta (MP4Stego). Para tanto, foram utilizadas as seguintes métricas:

- Diferença em Kb entre o vídeo esteganografado e o vídeo original: Métrica para verificar o tamanho do aumento do vídeo após a inserção das amostras pela MP4Stego.

- Valor do tamanho do stream de vídeo: Métrica para verificar se o stream de vídeo sofreu inserção de ruído após a execução da MP4Stego. Após a criação do vídeo esteganografado, chama-se a MP4Box para extrair o fluxo de vídeo do arquivo .mp4 verificando assim se o mesmo sofre algum tipo de alteração pela técnica MP4Stego. A realização desse processo visa verificar se a MP4Stego interfere na criação do stream final MPEG-4, mais especificamente se ela adiciona ruído no fluxo de vídeo.

- Relação entre a diferença em Kb e o tamanho da amostra: Métrica para verificar a taxa de compressão do texto inserido no vídeo pela MP4Stego.

O vídeo original utilizado nos testes corresponde a uma aplicação MPEGLet de um Electronic Program Guide (EPG). Esse vídeo foi utilizado pela MP4Stego para inserir as 12 amostras diferentes, contendo 7 elementos, de tamanho entre $1 \mathrm{~Kb}$ a $2048 \mathrm{~Kb}$. O vídeo do EPG contém uma MPEGLet que comunica-se com o MP4Stego Server para envio do texto esteganografado. O vídeo original sem conteúdo oculto possui o tamanho de 91,4 $\mathrm{Kb}$ (93.596 bytes).

O processo de realização dos testes ocorreu seguindo 4 etapas: preparação das amostras, esteganografia, coleta de dados e análise dos resultados.A etapa de preparação de amostras corresponde na utilização de uma aplicação para embaralhamento pseudorandômico do conteúdo de cada amostra. Já a etapa de esteganografia, utilizou a técnica MP4Stego para realização da inserção de dados no vídeo e o MP4Stego Server para leitura das mensagens, ambos em ambiente local.

As etapas executadas em cada teste são apresentadas a seguir:

1. Amostra: O elemento X, da amostra N (Z Kb) foi inserida no vídeo MPEG-4 utilizando a MP4Stego. Onde $\mathrm{X}$ é o número do elemento, $\mathrm{N}$ o número da amostra e $\mathrm{Z}$ o número de Kbytes da amostra.

2. Verificação Tamanho Estego Vídeo: Verifica-se o tamanho do vídeo final em Kbytes após a inserção da amostra em seu interior.

3. Verificação Cv (Cover Video): Extração do fluxo de vídeo para verificação de possível adição de ruído.

4. Reprodução no Player: Após a concepção do estego vídeo testa-se sua reprodução no player modificado Osmo.

5. Execução MPEGLet: Verifica-se se foi correta a execução da MPEGLet no envio de dados para o MP4Stego Server. 
6. Mensagem Recuperada: Com o conteúdo textual enviado ao MP4Server verifica-se se o mesmo corresponde ao conteúdo da Amostra inserida.

A primeira etapa, executada no teste foi a preparação das amostras, posteriormente as mesmas foram inseridas no vídeo MPEG-4 com auxílio da MP4Stego. A segunda etapa, consiste na verificação do tamanho dos estegos vídeos gerados. A tabela 6.1, apresenta os valores obtidos na etapa de 'Verificação Tamanho Estego Vídeo'. Com os dados sintetizados nessa tabela foi possível visualizar como resultado o valor de cada Estego Vídeo criado a partir dos elementos, também é exibido o valor médio em KBytes de cada amostra e o seu respectivo desvio padrão.

Tabela 6.1: Tabela contendo os dados obtidos dos testes, A: Amostra, TA: Tamanho total da amostra (KB), EN: Elemento N, M: Média (KB), DP: Desvio Padrão.

\begin{tabular}{|c|c|c|c|c|c|c|c|c|c|c|}
\hline A & TA & E1 & E2 & E3 & E4 & E5 & E6 & E7 & M & DP \\
\hline \hline $\mathbf{1}$ & 1 & 91.790 & 91.965 & 91.658 & 91.761 & 91.793 & 91.894 & 91.782 & 91.806 & 0.098 \\
\hline $\mathbf{2}$ & 2 & 92.050 & 92.108 & 92.098 & 92.056 & 92.203 & 92.226 & 92.030 & 92.110 & 0.076 \\
\hline $\mathbf{3}$ & 4 & 92.900 & 92.895 & 92.893 & 92.843 & 92.813 & 92.810 & 92.823 & 92.854 & 0.041 \\
\hline $\mathbf{4}$ & 8 & 93.901 & 93.943 & 93.921 & 93.899 & 93.881 & 93.832 & 93.884 & 93.894 & 0.035 \\
\hline $\mathbf{5}$ & 16 & 97.701 & 97.684 & 97.714 & 97.689 & 97.718 & 97.719 & 97.691 & 97.702 & 0.014 \\
\hline $\mathbf{6}$ & 32 & 103.008 & 102.912 & 103.100 & 102.945 & 102.914 & 102.942 & 103.100 & 102.988 & 0.082 \\
\hline $\mathbf{7}$ & 64 & 112.031 & 112.056 & 112.957 & 111.989 & 111.972 & 112.102 & 112.132 & 112.177 & 0.348 \\
\hline $\mathbf{8}$ & 128 & 139.010 & 138.982 & 138.941 & 139.108 & 139.056 & 140.045 & 138.910 & 139.150 & 0.400 \\
\hline $\mathbf{9}$ & 256 & 181.021 & 181.098 & 181.102 & 181.190 & 180.981 & 180.940 & 181.853 & 181.169 & 0.313 \\
\hline $\mathbf{1 0}$ & 512 & 242.098 & 241.861 & 241.752 & 242.065 & 242.185 & 243.198 & 232.222 & 242.197 & 0.473 \\
\hline $\mathbf{1 1}$ & 1024 & 424.019 & 425.100 & 424.971 & 424.401 & 424.951 & 423.855 & 423.555 & 424.407 & 0.615 \\
\hline $\mathbf{1 2}$ & 2048 & 783.113 & 783.209 & 784.091 & 784.084 & 782.092 & 785.100 & 783.200 & 783.555 & 0.960 \\
\hline
\end{tabular}

A etapa de 'Verificação Cv' foi realizada em cada amostra com auxílio da ferramenta MP4Box para extração do fluxo de vídeo. Essa etapa apresentou como resultado a não variação do fluxo de vídeo $C v$ em nenhum elemento.

Finalizada a verificação do tamanho do fluxo $C v$ realiza-se o teste de reprodução no player Osmo. Nessa etapa todos os vídeos foram reproduzidos corretamente no player Osmo estendido.

A etapa de 'Execução MPEGLet' é realizada com auxílio do MP4Stego Server o qual recebe os dados da MPEGLet. Com o conteúdo recuperado no MP4Stego Server pode-se analisar se o mesmo corresponde ao conteúdo inserido no momento da esteganografia. Todos os elementos foram recuperados na íntegra de forma correta pelo MP4 Server.

Um resumo de todas estas etapas pode ser visualizado em uma tabela. A tabela 6.2, apresenta os valores das diversas métricas utilizadas no teste sobre as 12 amostras.

Com os dados obtidos nas tabelas podemos gerar um gráfico com o comportamento da MP4Stego. Esse gráfico é exibido na Figrura 6.4.

O gráfico da Figura 6.4, apresenta no eixo X o tamanho do arquivo da amostra, e no eixo Y o tamanho do estego vídeo final, ambos em KBytes. Nesse gráfico foi possível 
Tabela 6.2: Resultado dos testes da aplicação. TA: Tamanho total da amostra (Kb), TVF: Tamanho do Vídeo Final (Kb), VS: Video Stream (Kb).

\begin{tabular}{|c|c|c|c|c|c|c|}
\hline Amostra & TA & TVF & VS & \% aumento & Diferença Kb & Dif Kb/Relação TA \\
\hline \hline 1 & 1 & 91,806 & 79,4 & 0,3440 & 0,4 & 0,40600 \\
\hline 2 & 2 & 92,110 & 79,4 & 0,6987 & 0,7 & 0,35500 \\
\hline 3 & 4 & 92,854 & 79,4 & 1,7009 & 1,5 & 0,36350 \\
\hline 4 & 8 & 93,894 & 79,4 & 2,8046 & 2,5 & 0,39388 \\
\hline 5 & 16 & 97,702 & 79,4 & 6,9950 & 6,3 & 0,39388 \\
\hline 6 & 32 & 102,989 & 79,4 & 12,7698 & 11,6 & 0,36216 \\
\hline 7 & 64 & 112,177 & 79,4 & 23,3375 & 20,8 & 0,32464 \\
\hline 8 & 128 & 139,150 & 79,4 & 52,0770 & 47,8 & 0,37305 \\
\hline 9 & 256 & 181,169 & 79,4 & 98,2863 & 89,8 & 0,35066 \\
\hline 10 & 512 & 242,197 & 79,4 & 164,8767 & 150,8 & 0,29453 \\
\hline 11 & 1024 & 424,407 & 79,4 & 364,0668 & 333,0 & 0,32520 \\
\hline 12 & 2048 & 783,556 & 79,4 & 757,2642 & 692,2 & 0,33797 \\
\hline
\end{tabular}

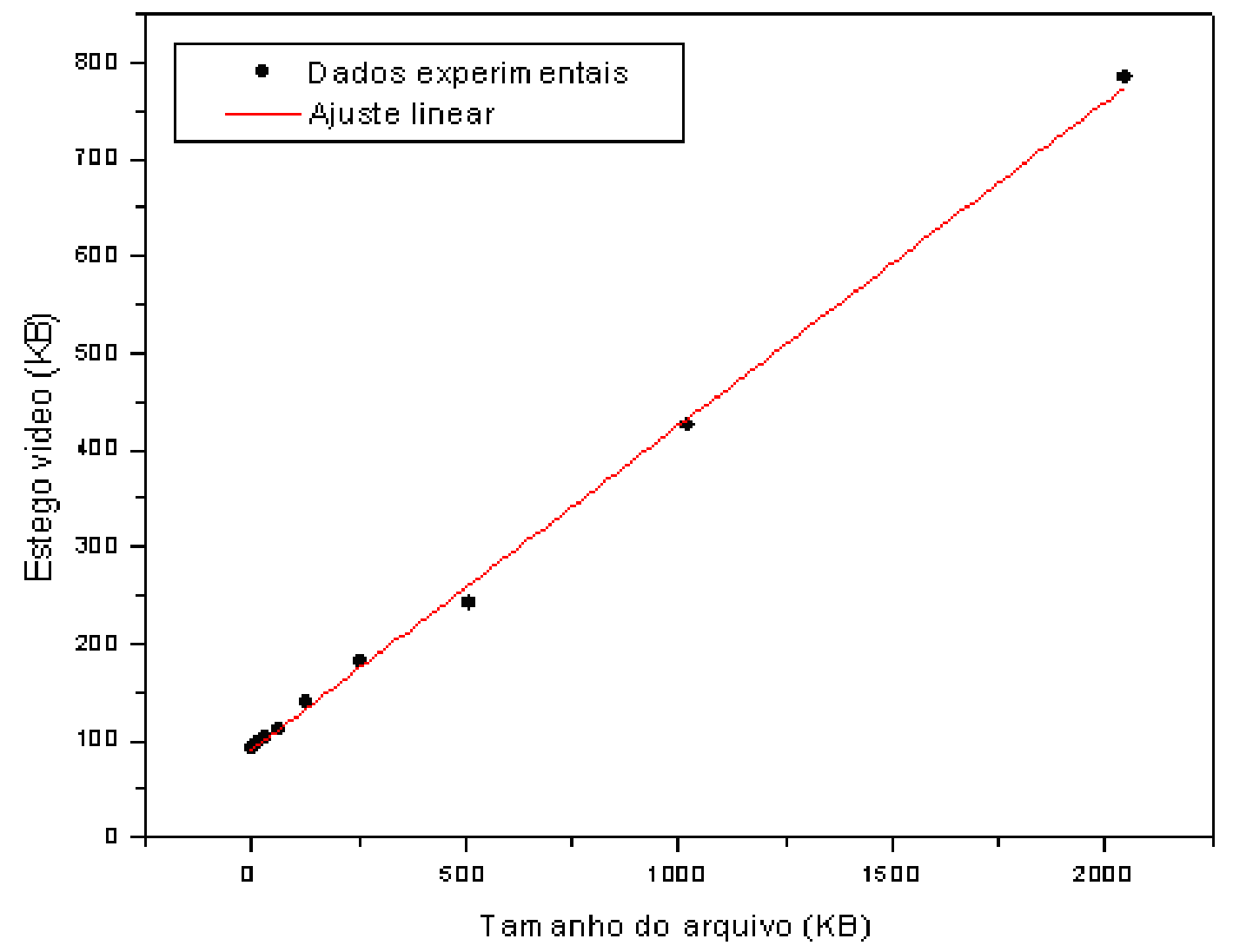

Figura 6.4: Gráfico das amostras após teste.

verificar o comportamento linear da MP4Stego que apresentou aumento relativo do vídeo (B) de 0,33457\% (com erro de 0.00375) comparado ao tamanho da amostra. 
Para exemplificar esse comportamento, tomemos como exemplo uma amostra de $1 \mathrm{~KB}$ de mensagem do tipo texto. Esse $1 \mathrm{~KB}$ será esteganografado em um vídeo de $100 \mathrm{~KB}$. Desse modo, com a compressão da mensagem no processo de esteganografia, resulta-se em 0,33 KB em média de adição ao tamanho do arquivo, resultando em um estego vídeo de 100,33 KB.

Além disso, foi calculado o índice de correlação linear para verificar se as amostras são suficientes para análise do comportamento da técnica. O índice de correlação linear tem a capacidade de verificar a relação entre duas variáveis e o erro residual no processo de amostragem [Motulsky, 2003]. A fórmula do índice de correlação linear corresponde a um modelo de regressão do seguinte tipo: $Y=A+B * X$.

Nesse cálculo, o valor de $R$ corresponde ao valor do índice de correlação linear, o valor de $N$ corresponde ao número de amostras utilizadas e finalmente $P$ corresponde ao erro residual. O valor de $R$ encontrado foi de 0,99862 , o valor de $N$ é igual a 84 e o valor do erro residual é igual a 0,00375. Cada ponto do gráfico refere-se a média dos elementos das amostras encontradas na tabela 6.1.

Esse cálculo do fator R, resultou em um valor de 0,99862 correspondendo a um excelente valor para o espaçamento do tamanho das amostras, uma vez que esse índice apresenta valor máximo igual a ' 1 '.

Como resultado dessa análise realizada foi possível chegar a seguinte conclusão:

- O tamanho do fluxo VS (VideoStream) em todos os testes com as amostras foi de 74,9 KB (76.787 bytes) comprovando que a técnica MP4Stego não altera dados dos demais fluxos do arquivo MPEG-4.

- O aumento do vídeo final, em relação ao tamanho da amostra, apresentou compressão em todos os casos na faixa de 0,33\%. Esse fato deve-se a compressão de dados realizada sobre o fluxo MPEG-J na ferramenta MESE. O MESE utiliza compressão de dados LZW. Assim dessa análise podemos obter a seguinte fórmula que resume o tamanho do estegovídeo final: (TVF: Tamanho do Vídeo Final, VS: Video Stream e TA: Tamanho da Amostra).

$$
T V F \cong|V S|+\frac{1}{3}|T A|
$$

\subsection{Integridade Digital de Vídeos}

Um problema clássico de segurança da informação relaciona-se com a integridade dos dados trafegados pelo canal de comunicação [Cintia Borges Margi, 2003]. A integridade consiste verificar se foram ou não realizadas alterações não autorizadas sobre os dados. No caso de vídeos digitais, como garantir que o vídeo que foi enviado pelo usuário origem é realmente o mesmo vídeo recebido pelo usuário destino? Mais especificamente, pretende-se garantir que o vídeo não foi alterado/editado durante seu envio pelo canal de comunicação.

Comumente técnicas de criptografia com assinaturas digitais são utilizadas para prover sigilo e integridade [Cintia Borges Margi, 2003]. O sigilo refere-se na capacidade de encontrar e compreender uma cifra, já a integridade é capaz de verificar a autenticidade daquela cifra. Porém, podemos criar uma abordagem alternativa utilizando a esteganografia em conjunto com técnicas de criptografia para aumentar o nível de sigilo da cifra que provê 
integridade ao material multimídia. Desse modo a esteganografia pode ser utilizada com a criptografia visando o ocultamento da cifra no interior de um vídeo.

Assim, esta seção apresenta a aplicação da técnica MP4Stego no domínio de integridade digital de vídeos, aliando esteganografia à criptografia comumente utilizada nesses ambientes. Como benefício da técnica podemos citar um aumento de segurança referente ao sigilo, uma vez que a utilização de esteganografia proteger a cifra.

Nas próximas subseções, são descritas a Metodologia de Segurança utilizada, a Descrição da Técnica, a Descrição da Aplicação e uma Análise dos testes da aplicação.

\subsubsection{Metodologia de Segurança}

Tradicionalmente sistemas de verificação de integridade de mídias são implementados com utilização somente de técnicas de criptografia. A utilização somente da criptografia possibilita a percepção da presença da mensagem na forma codificada. Uma mensagem criptografada pode ser detectada e dependendo do tipo de ataque até mesmo decifrada. Com apenas a utilização da criptografia, a informação cifrada pode ser ilegível, mas esse fato remete a existência de segredo naquela cifra. A esteganografia nessa aplicação tem o papel de aumentar o nível de segurança introduzindo sigilo à cifra criptográfica. Uma aplicação para integridade em vídeos tem o papel de validar se o conteúdo de arquivo do tipo vídeo enviado de um remetente para um destino por uma rede é íntegro. Mais especificamente, verifica-se se o arquivo não foi alterado durante a transmissão (podendo ser comparado a um checksum).

Para o correto funcionamento do sistema de integridade pode-se utilizar diversos algoritmos de criptografia de única via (hash), tais como o MD5 [Rivest, 1992], SHA [Burr, 2006] e Whirlpool [Rijmen, 2000]. Esses algoritmos geram uma mensagem de resumo referente ao parâmetro de entrada. Essa mensagem apresenta três propriedades importantes:

- Propriedade 1: Dado um hash, é computacionalmente improvável encontrar a mensagem original, com esforço matemático de $2^{n}$.

- Propriedade 2: Dado uma mensagem e o hash gerado por um algoritmo para essa mensagem, é computacionalmente improvável encontrar outra mensagem que, utilizando o mesmo algoritmo de hash, gere o mesmo resumo, com esforço matemático de $2^{n}$.

- Propriedade 3: É computacionalmente improvável encontrar duas mensagens distintas que, utilizando o mesmo algoritmo de hash gerem o mesmo resumo, com esforço matemático de $2^{\frac{n}{2}}$.

A escolha do algoritmo para geração de cifras hashs foi escolhido o SHA-256 [Burr, 2006] da National Security Agency, por não apresentar colisões até o presente momento e configurar-se como um avanço dos algoritmos da família MD (Message Digest MD4, MD5).

Assim, explorando essas propriedades das cifras do tipo hash aliadas a esteganografia, pode-se viabilizar a criação um sistema de integridade digital de vídeos MPEG-4. A Figura 6.5 , ilustra o processo de garantia de integridade digital em vídeos, o qual é dividido em três etapas. A primeira etapa corresponde na geração da cifra hash do objeto 1 (stream de 


\section{CAPÍTULO 6. APLICAÇÕES DA TÉCNICA MP4STEGO}

vídeo). Já a segunda etapa é reponsável por introduzir o hash gerado na primeira etapa no interior do vídeo. E por fim a terceira etapa tem a finalidade de verificar a integridade analisando a cifra hash extraída com a gerada na máquina local.
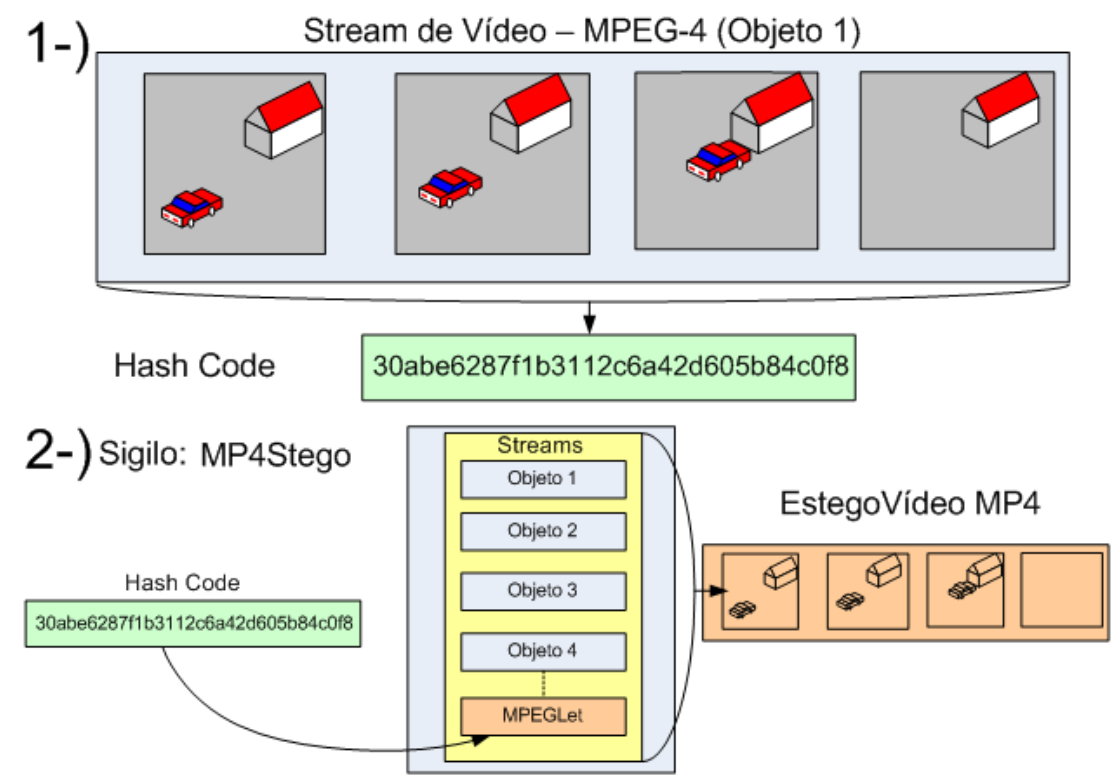

3-) Integridade:

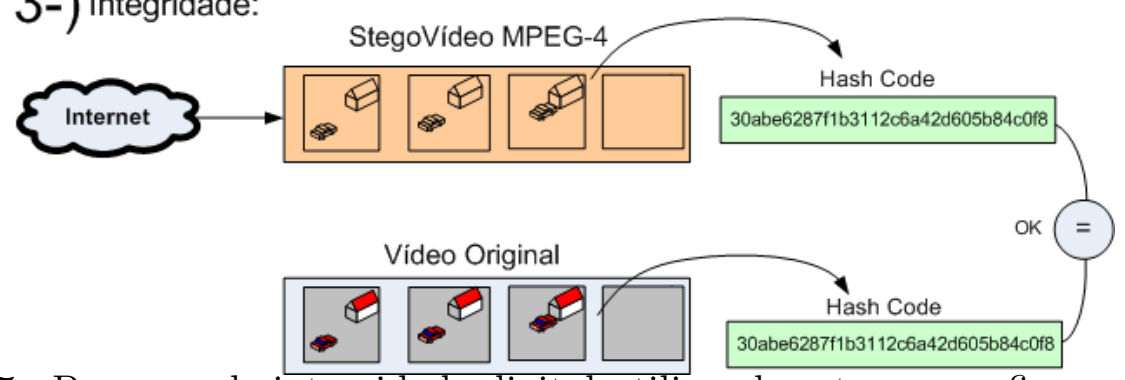

Figura 6.5: Processo de integridade digital utilizando esteganografia e criptografia.

A primeira etapa, é responsável por gerar um resumo hash do conteúdo do stream de vídeo MPEG-4 (fluxo elementar de vídeo dentro do arquivo .mp4). Já na segunda etapa, a técnica MP4Stego irá introduzir esse valor hash no interior do vídeo por meio de um stream MPEGLet gerando o Estego Vídeo. Esse Estego Vídeo é enviado por meio da Internet para o usuário final. Finalmente, na etapa 3, retira-se o hash do interior do vídeo MPEG-4. Para verificar a integridade do vídeo gera-se um hash do stream de vídeo original e compara-se com o hash obtido do Stego Vídeo.

Caso seja verificado que as duas cifras hashs são iguais, é possível garantir que o vídeo não foi corrompido/alterado no envio e que a cifra hash em seu interior realmente refere-se ao conteúdo do vídeo. Caso contrário, dois fatos podem ter ocorrido:

- Edição do vídeo por terceiros.

- Alteração do hash. 


\subsubsection{Modelo da Técnica}

MP4Stego para Integridade de Vídeos:Definida a quíntupla $\omega=<C, H, S, D, E>$, onde $C$ representa o objeto de cobertura, $H$ a cifra de via única do tipo hash, $S$ o objeto contendo a esteganografia, $E$ a função de esteganografia e $D$ a função de esteganografia reversa. A função que descreve os componentes do objeto de cobertura pode ser descrita por:

$C=\left\{C_{v}, C_{a}, \ldots, C_{m}\right\}$

Cada um dos diversos fluxos elementares MPEG-4 estão presentes em $C$ : $C_{v}$ corresponde ao fluxo elementar de vídeo, $C_{a}$ corresponde ao fluxo elementar de áudio e $C_{m}$ ao fluxo elementar de MPEGLets. Os demais fluxos elementares presentes, no objeto cobertura, tais como fluxo de descrição de cena estão representados por reticências (...).

A função de esteganografia, ou seja de ida $E$, corresponde:

$E: C_{m} \star H\left(C_{v}\right) \rightarrow S$

$E\left(C_{m}, H\left(C_{v}\right)\right)=S$

Já a função de volta (esteganografia reversa) $D$, corresponde:

$D: S \rightarrow H\left(C_{v}\right)$

$D\left(E\left(C_{m}, H\left(C_{v}\right)\right)\right)=H\left(C_{v}\right)$

As mesmas propriedades relativas a técnica MP4Stego estão presentes nessa aplicação para integridade de vídeos.

\subsubsection{Descrição da Aplicação}

Basicamente três entidades foram desenvolvidas para viabilizar tal aplicação. A primeira chama-se Video Server que tem o papel de criar os estegos vídeos contendo cifras hash de seu stream de vídeo. O Video Server corresponde a MP4Stego agregada a um repositório de dados conectado na Internet. A segunda entidade refere-se ao usuário cliente que receberá o Estego Vídeo. A terceira e última entidade denominada, Integrity Server, tem o papel de verificar se a cifra hash inserida no vídeo corresponde na cifra hash obtida do fluxo stream de vídeo.

Na Figura 6.6, ilustra-se o processo de integridade desenvolvido. Primeiramente, no Video Server, realiza-se a extração do fluxo stream de vídeo $(S V)$. Com posse do $S V$ cria-se a cifra hash de seu conteúdo obtendo $H(S V)$. O fluxo (stream) de vídeo $S V$ é passado para a MP4Stego para esteganografia da cifra hash no vídeo gerando $M P 4 S(H(S V))$. O $M P 4 S\left(H(S(V))\right.$ enviado pela rede para a entidade Cliente ${ }^{2}$ que poderá reproduzir o vídeo no player especializado. No momento da reprodução do vídeo é aberta uma aplicação Java possibilitando ao Cliente solicitar a verificação de integridade do vídeo. Nesse caso, será enviado para o Integrity Server o $H(S V)$ extraído pelo player especializado e o $S V$ extraído pela MP4Box ${ }^{3}$. O Integridade Server tem a capacidade de gerar uma nova cifra hash do $H(S V)$ gerando $H^{\prime}(S V)$. O $H^{\prime}(S V)$ é comparado com o $H(S V)$. Se os dois valores de cifras hash corresponderem ao mesmo valor temos a verificação de integridade do vídeo comprovada, caso os dois não tenham o mesmo valor podem significar dois eventos: alteração do fluxo de vídeo devido a uma edição ou alteração do $H(S V)$ do vídeo no

\footnotetext{
${ }^{2}$ Corresponde na transação 1 indicada pela seta azul na Figura 6.6

${ }^{3}$ Corresponde na transação 2 indicada pela seta preta na Figura 6.6
} 


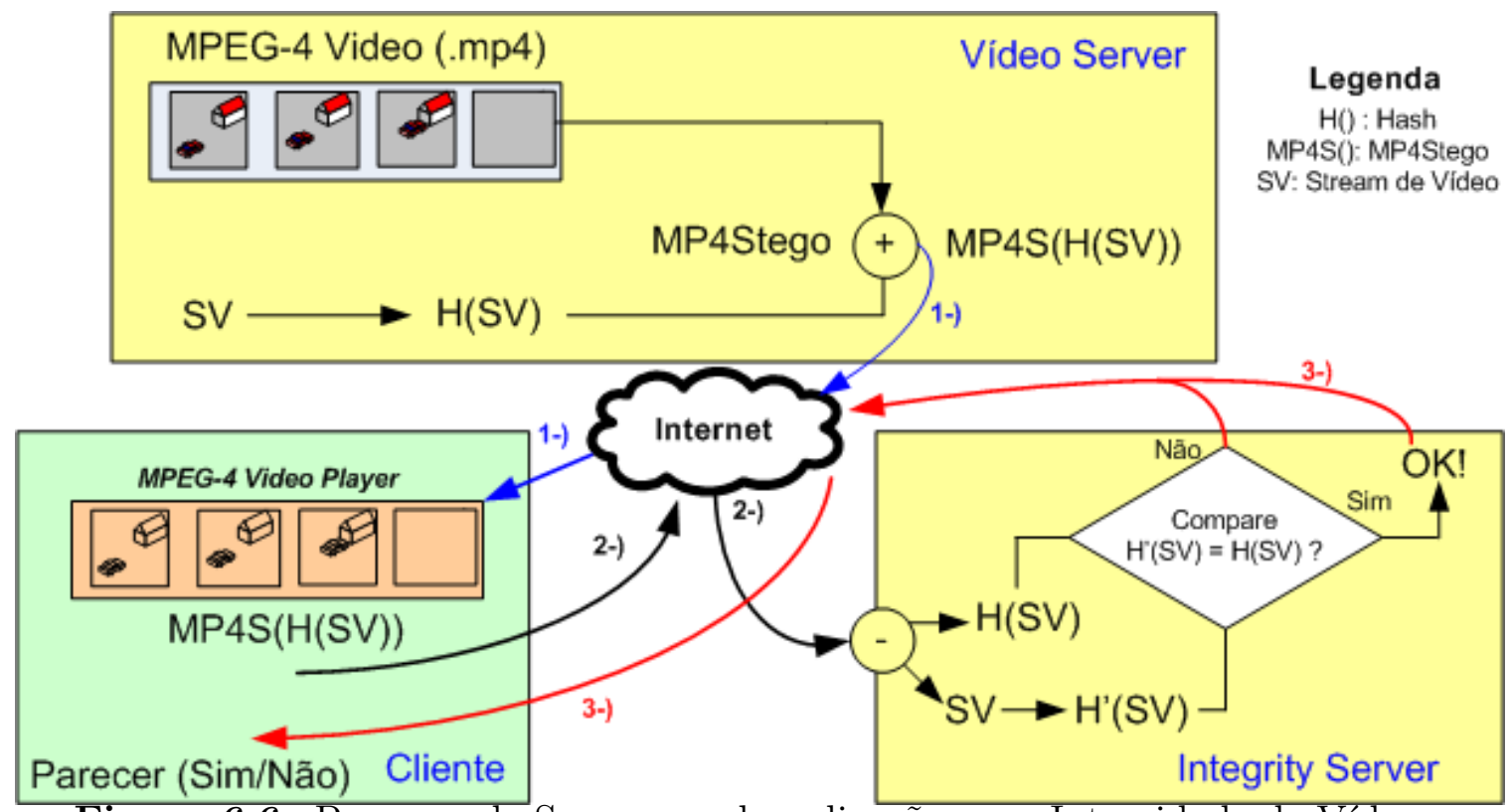

Figura 6.6: Processo de Segurança da aplicação para Integridade de Vídeos.

momento de envio pela rede. O resultado da verificação dos valores de $H(S V)$ e $H^{\prime}(S V)$ são enviados pela rede para a entidade Cliente ${ }^{4}$.

A entidade Integrity Server foi implementada a partir de modificações no MP4 Stego Server. Basicamente as informações são recebidas pela porta 1027 e enviadas pela porta 7000 para o player especializado. O Integrity Server chama um script que inicia a MP4Box que por sua vez extrai o fluxo de vídeo. Após essa etapa, o Integrity Server realiza o processo de construção do hash do fluxo de vídeo utilizando para tal tarefa o algoritmo SHA-256.

Um screenshot da aplicação pode ser verificado na Figura 6.7.

No screenshot da Figura 6.7 podemos verificar na parte superior esquerda o player Osmo modificado, reproduzindo um Estego Vídeo. Já na parte superior direita é possível visualizar um menu criado pela MPEGLet no interior do Estego Vídeo. Na parte inferior direita da Figura podemos verificar o Integrity Server comunicando-se com a MPEGLet e verificando a integridade do vídeo mediante análise da cifra hash recuperada.

\subsubsection{Testes e Análise}

Com o desenvolvimento da técnica MP4Stego, foi possível criar uma aplicação para integridade digital de vídeos MPEG-4 aliando a esteganografia à criptografia de única via.

O sistema de verificação de integridade digital para vídeos MPEG-4 criado apresenta maior nível de segurança quando comparado a utilização somente de técnicas de criptografia convencionais. Nos sistemas tradicionais de integridade para vídeos é utilizado o envio das cifras hash pela Internet para validação com o conteúdo original. Assim com posse do hash do vídeo original o usuário final compara com o hash gerado em sua máquina e verifica a integridade. Porém problemas de segurança podem ocorrer nessa etapa, uma vez que não se sabe exatamente se a cifra hash foi interceptada no envio e alterada antes

\footnotetext{
${ }^{4}$ Corresponde na transação 3 indicada pela seta vermelha na Figura 6.6
} 


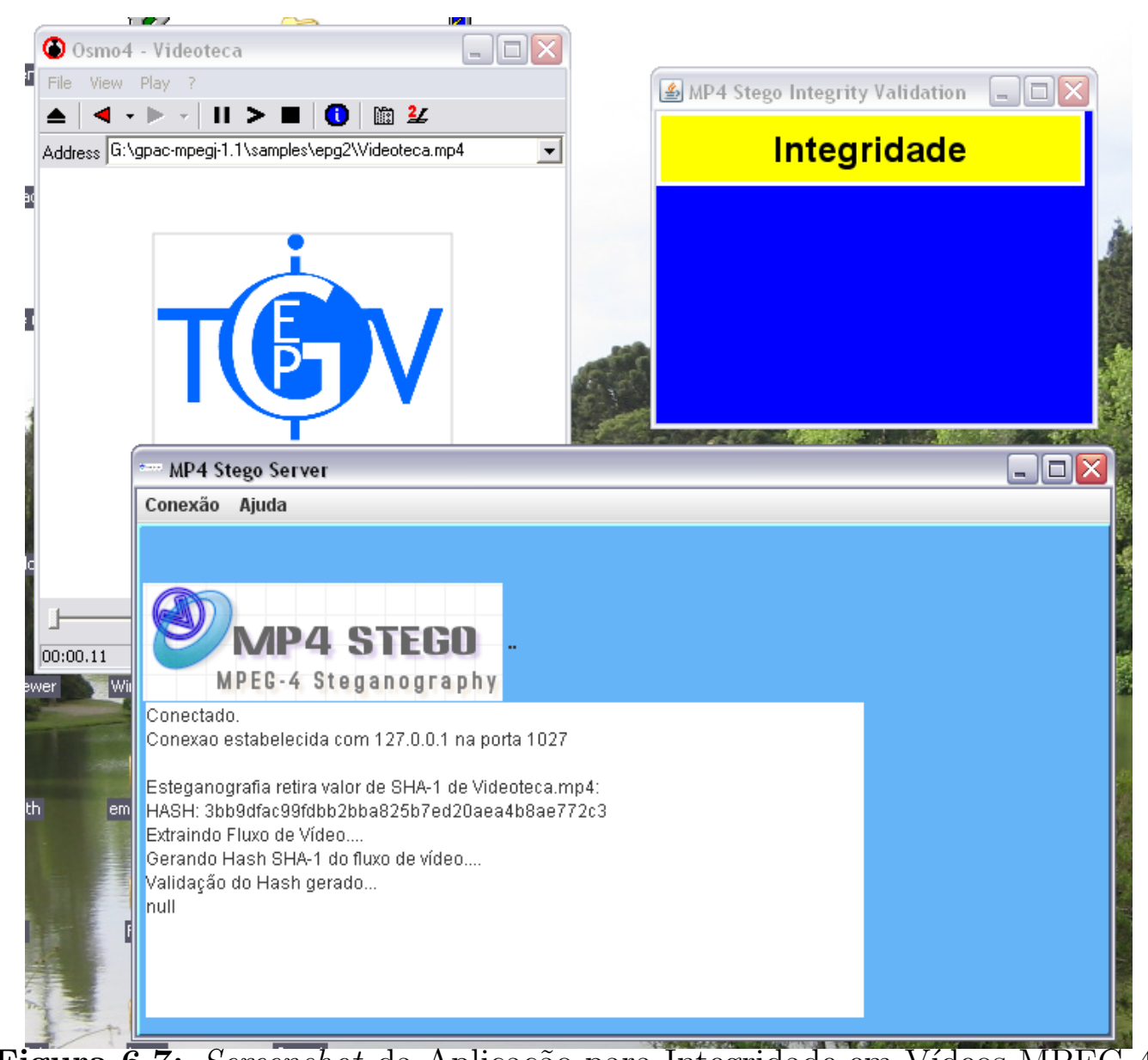

Figura 6.7: Screenshot da Aplicação para Integridade em Vídeos MPEG-4.

da chegada no usuário final. O mesmo pode ser dito a respeito do conteúdo do próprio vídeo.

Um intruso pode interceptar a cifra hash e o vídeo e alterá-los antes do envio para o usuário final. Este tipo de ataque chama-se man in the middle (MITM) e foi descrito inicialmente por [Landau, 1998]. Os ataques MITM tradicionalmente foram descritos para sistemas que utilizam chaves assimétricas (públicas e privadas) porém pode-se aplicar perfeitamente nesse cenário.

Temos um usuário 1 que irá enviar um vídeo $(V)$ e a cifra hash do vídeo $H(V)$ para o usuário 2. Um atacante $(X)$ coloca-se no meio da comunicao numa posição da rede que lhe permita interceptar os pacotes ${ }^{5}$. Quando o usuário 1 tenta estabelecer uma concexão com o usuário 2, o atacante $X$ intercepta os pacotes e liga-se ao usuário 2 fingindo ser o usuário 1. A partir desse momento ele pode receber o vídeo original do usuário 1 e editá-lo, gerando $V^{\prime}$, e criar uma cifra hash utilizando o mesmo algoritmo utilizado pelo usuário 1, obtendo $H\left(V^{\prime}\right)$. O atacante $X$ envia para o usuário 2 o $H\left(V^{\prime}\right)$ e $V^{\prime}$. O usuário 2 gera a partir de $V^{\prime}$ uma cifra hash $H^{\prime}\left(V^{\prime}\right)$ e compara com $H\left(V^{\prime}\right)$. Essa comparação dará positiva provando a integridade do vídeo enviado, quando na verdade tanto o vídeo quanto a cifra hash foram alteradas. A Figura 6.8 demonstra esse ataque.

\footnotetext{
${ }^{5} \mathrm{O}$ atacante pode utilizar para tal tarefa técnicas como tcp hijacking, fake dns, entre outras
} 


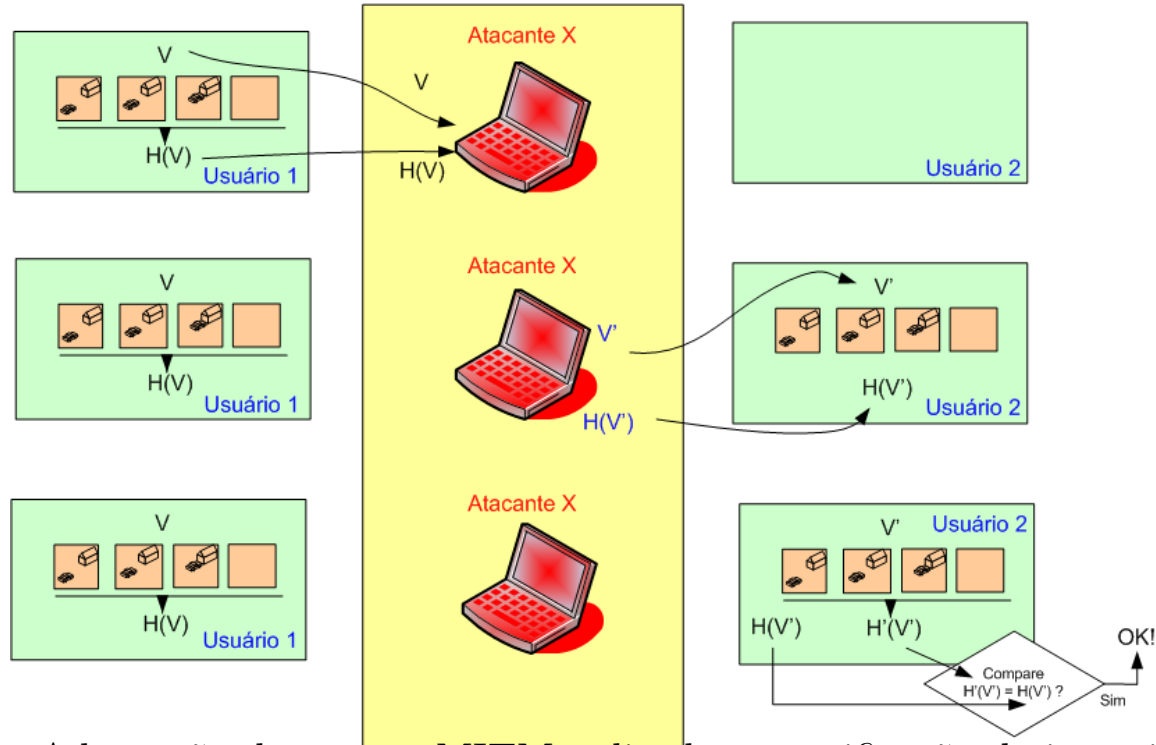

Figura 6.8: Adaptação do ataque MITM aplicado na verificação de integridade em vídeos.

Uma possível solução para esse problema corresponde na inserção de sigilo na cifra hash. Este sigilo pode ser alcançado com criptografia ou com esteganografia. A abordagem com esteganografia, utilizada neste trabalho, tem o papel de ocultar a cifra hash no interior do vídeo dificultando sua descoberta e possível obtenção. Já nas abordagens com criptografia, pode-se utilizar proteção com chaves simétricas em conjunto com infra-estrutura de assimétricas (chaves públicas e privadas (PKI) [Hellman, 1979]), a qual pode realizar uma verificação da validade da chave com uma entidade certificadora.

Vale lembrar também que a abordagem criada neste trabalho não realiza a criação de uma cifra hash a partir de todo o conteúdo do vídeo e apenas do fluxo stream de vídeo. Desse modo dificulta-se mais a criação de um hash editado ou criado a partir de um vídeo editado, pois o intruso não tem conhecimento dessa etapa ou terá dificuldade na retirada e alteração do fluxo correto (dentre os vários fluxos streams presentes no bitstream do vídeo MPEG-4 original).

\subsection{Considerações Finais}

Foi possivel verificar que tanto a técnica MP4Stego quanto as ferramentas de infra-estrutura (player especializado e MP4Stego Server) desenvolvidas apresentaram resultados interessantes em ambas as aplicações, entre elas:

- Tamanho do fluxo de vídeo não é alterado e assim não adiciona-se ruído nos demais fluxos streams MPEG-4.

- O player especializado tem a capacidade de reproduzir um vídeo normalmente caso o mesmo não contenha esteganografia.

- A compressão na inserção de dados em relação ao aumento do tamanho do vídeo original é de aproximadamente $1 / 3$. 
Dentre os problemas que poderiam ser solucionados podemos citar o desenvolvimento de uma ferramenta para inserir dados de forma mais organizada no interior do vídeo. Essa ferramenta pode ter a capacidade de inserir arquivos no interior do vídeo. Acredita-se que a limitação para inserção de dados no interior do vídeo corresponda a capacidade física da máquina uma vez que o comportamento da técnica para escrita secreta é linear.

Em relação aos ataques ao sistema de integridade digital, o fluxo adicional gerado é multiplexado em conjunto com os demais fluxos no bitstream final MPEG-4, dificultando a sua esteganálise uma vez que sua estrutura de dados está introduzida ao arquivo final de vídeo MP4. Desse modo, para um ataque, com intenção de quebra de integridade do vídeo, obter sucesso necessita satisfazer duas condições:

- Realização da engenharia reversa no padrão para descobrir como está disposto o bitstream final do vídeo e assim realizar uma análise na busca por informações ocultas.

- Alteração do conteúdo presente no resumo hash.

Além disso dentre os tipos de esteganálise conhecidos nenhum tem a capacidade no presente momento de encontrar informações do modo como elas foram inseridas com a MP4Stego. Os ataques aurais buscam por ruído adicional na mídia de cobertura, a técnica MP4Stego não adiciona ruído no stream de vídeo como foi comprovado na Tabela 6.2. Em relação aos ataques estruturais a técnica MP4Stego somente altera as estruturas conhecidas do padrão MPEG-4 não adicionando estruturas externas ao padrão. E por fim os ataques estatísticos, não existe técnica para análise de binários como é o caso do fluxo de MPEGLets.

A respeito de ataques contra políticas de segurança tais como Man in the Middle a técnica de integridade para vídeos utiliza a esteganografia para adicionar sigilo a cifra hash dificultando esse tipo de ataque. 


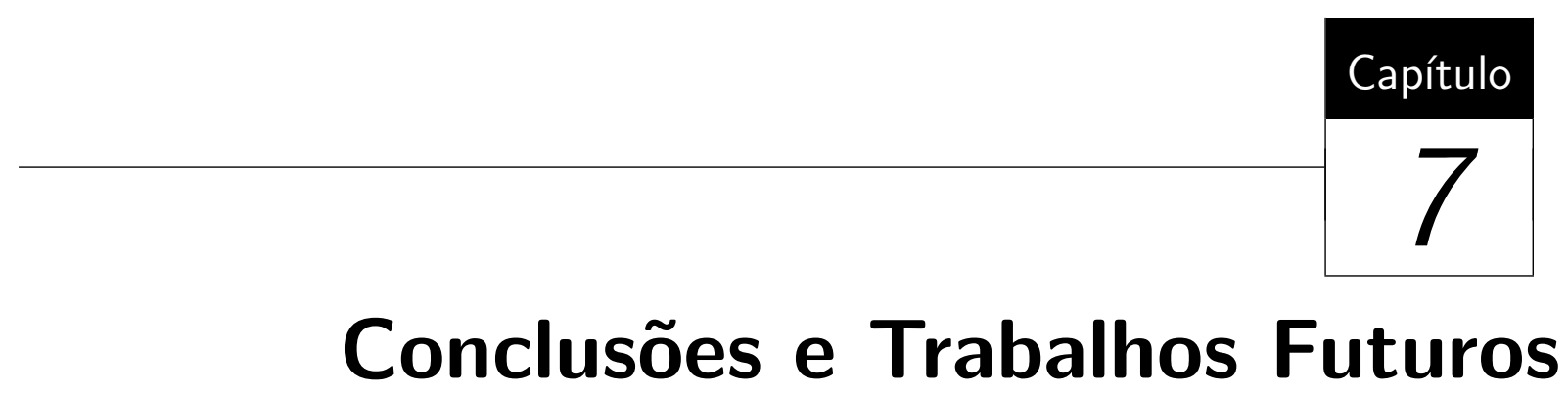

\subsection{Considerações Iniciais}

Neste trabalho foi desenvolvida uma técnica para esteganografia em vídeos digitais MPEG-4 no domínio de Escrita Secreta chamada MP4Stego. Para o desenvolvimento da técnica foi necessário criar um codificador de MPEGLets denominado MESE (seção 5.2.2) e estender ferramentas do projeto GPAC tais como a MP4Box e o player Osmo (seção 5.2.3).

Conforme descrito na seção 5.1, a MP4Stego foi implementada com requisitos de grande carga útil, segurança e fragilidade. Essas características diferenciaram a MP4Stego das demais técnicas encontradas na literatura (seção 4.2.3). Como conseqüência do processo de revisão sistemática da literatura, estruturou-se uma classificação das técnicas de esteganografia (seção 4.3.1).

A utilização de esteganografia em vídeos digitais traz algumas vantagens quando comparada a outras mídias tais como imagens. A maior vantagem relaciona-se na quantidade de informações inseridas no interior da mídia. Ao contrário das demais técnicas de esteganografia para vídeos, a MP4Stego não apresenta fator limitante para inserção de dados. Diferenciando-se, por sua vez, das demais técnicas encontradas na literatura, a MP4Stego não adiciona ruído no stream de vídeo, não está suscetível a técnicas de esteganálise até o presente momento e é passível de reprodução do estego vídeo em player comum. Essas afirmações foram comprovadas na seção 6.2.3. Na tabela 7.1, é exibido as técnicas encontradas na literatura com a última linha preenchida com a MP4Stego e suas características.

Tendo em vista a validação prática da MP4Stego, neste trabalho foram criadas duas aplicações em domínios distintos. A primeira aplicação (seção 6.2), demonstrou a capacidade de inserção de dados da técnica e a segunda aplicação (seção 6.3), demonstrou a sua utilização em uma aplicação de segurança digital. A utilização nesses domínios da MP4Stego demonstra sua versatilidade e abre possibilidades para aplicações em novos domínios em trabalhos futuros. 
A seção 7.2, descreve as contribuições apresentadas neste trabalho. A seção 7.3, relata as limitações da técnica MP4Stego. A seção 7.4, apresenta os trabalhos futuros decorrentes deste trabalho de mestrado. A seção 7.5, exibe as publicações do mestrado.

Tabela 7.1: Técnicas de Esteganografia para Vídeos.

\begin{tabular}{|c||l|l|l|l|l|}
\hline Técnica & Abord. & Complex. & MPEG & Carga & $\begin{array}{l}\text { Player } \\
\text { Comum }\end{array}$ \\
\hline \hline ALV & B1 & quadrático & 1,2 & médio & sim \\
\hline AC's GOP's & B1 & linear & 2 & baixo & sim \\
\hline DC's & B1 & linear & 1,2 & médio & sim \\
\hline DEW & B2 & quadrático & 2 & médio & sim \\
\hline LZ77 & B2 & logarítmico & 1,2 & baixo & sim \\
\hline Run Length & B2 & logarítmico & 1,2 & baixo & sim \\
\hline VLC - VFDW & B2 & quadrático & 1,2 & baixo & sim \\
\hline RVLC & B2 & quadrático & 1,2 & baixo & sim \\
\hline Girod & B2 & quadrático & 2 & baixo & sim \\
\hline XMT & C2 & logarítmico & 4 & alto & sim \\
\hline A/S Tree & C1 & logarítmico & 1,2 & alto & não \\
\hline MP4Stego & C2 & linear & $\mathbf{4}$ & alto & sim \\
\hline
\end{tabular}

\subsection{Contribuições}

Basicamente este trabalho de mestrado teve como contribuições principais:

- Classificação de técnicas de esteganografia em vídeos a partir de análise do levantamento bibliográfico realizado por meio de metodologia de revisão sistemática. Esse processo tem como objetivo o aumento da qualidade do processo e alcançar um panorama da área e técnicas de esteganografia em estruturas de compressão em imagens e vídeos.

- Desenvolvimento de codificador de fluxos elementares de MPEGLets (MESE) criado concomitantemente a este projeto e integrado a ferramenta livre MP4Stego do projeto GPAC.

- Desenvolvimento de uma técnica de esteganografia em vídeos comprimidos para o formato de arquivo MPEG-4. A qual apresenta as seguintes vantagens:

MP4Stego apresenta avanços na quantidade de dados inseridos em relação as demais encontradas na literatura até o momento. Mais especificamente, a técnica MP4Stego não tem limites para inserção de dados ocultos podendo ser até mesmo maior a quantidade de dados que o próprio objeto de cobertura.

Facilidade de reprodução e não inviabilização do conteúdo presente no fluxo de vídeo em um player comum, pois introduz a mensagem secreta em uma estrutura pertencente ao padrão MPEG-4 (MPEGLets). 
Em relação a técnicas de esteganálise até o presente momento não se tem notícia na literatura de técnica que tenha capacidade de verificar a existência de anomalias em todos os fluxos do padrão MPEG-4.

\subsection{Limitações}

Em relação as limitações relacionadas a área de multimídia podemos citar:

- A MP4Stego apenas é aplicável ao padrão de vídeo MPEG-4, por explorar recursos tais como MPEGLets não presentes nas versões anteriores da família MPEG.

- A MP4Stego apresenta complexidade linear para inserção de dados em seu interior $\mathrm{O}(\mathrm{n})$.

Em relação as limitações relacionadas a área de segurança computacional, podemos citar que a técnica MP4Stego puramente utilizada não respeita o princípio de Kerckchof [Kerckhoff, 1883] que diz: "Qualquer sistema criptográfico/esteganográfico deve ter sua segurança baseado na chave e não no método". Sendo assim, a MP4Stego, no presente momento não é uma técnica a ser utilizada em qualquer aplicação na área de segurança computacional e necessita ser aperfeiçoada com implementação baseada em chave.

\subsection{Trabalhos Futuros}

A realização deste trabalho criou diversas perspectivas para a realização de trablhos futuros como continuação desta pesquisa.

Novas estratégias de esteganografia em vídeos MPEG-4 deverão ser melhor investigadas e comparadas com os resultados apresentados. Pode-se desenvolver novas técnicas a partir da utilização de outros objetos presentes no padrão MPEG-4, tais como: XMT, GOPs, entre outros.

Outro ponto interessante consiste na realização de mais investigações sobre as técnicas encontradas na literatura visando atualização da revisão sistemática com finalidade de criação de um survey de técnicas de esteganografia em vídeos comprimidos.

Aprimoramento da técnica para aplicações de segurança computacional a fim de inserir uma chave para que a técnica esteja de acordo com os requisitos de Kerckchof [Kerckhoff, 1883]. Criação de aplicações em segurança computacional nos seguintes temas: Autenticação, Tempestividade, Sigilo.

Atualmente encontra-se em desenvolvimento um projeto de graduação com foco no desenvolvimento de uma técnica de esteganografia para mídias presentes na Internet visando facilitar a acessibilidade de conteúdo web.

\subsection{Produção Científica}

\section{Artigos completos em anais de eventos}

1. Carvalho D. F., Milanez M. G., Avelino M. J. B., Bruschi S. M., Goularte R. "SecBox: Uma abordagem para segurança de set-top boxes em TV Digital", 7th SBSEG Simpósio Brasileiro de Segurança - Rio de Janeiro, RJ, Agosto 2007. 
2. Carvalho D. F., Chies R., Freire A. P., Martimiano L. F., Goularte R. "Video Steganography in Confidential Documents: Integrity, Privacy and Version Control", 26th ACM International Conference on Design of Communication SIGDOC, Lisboa, Portugal, Setembro 2008.

3. Carvalho D. F., Chies R., Goularte R. "MP4Stego: Esteganografia para Vídeos MPEG4", 14th SBC Webmedia (Simpósio Brasileiro de Sistemas Multimídia e Web) - Vitória, ES, Outubro 2008.

\section{Artigos resumidos em anais de eventos}

1. Carvalho D. F., Chies R., Goularte, R. "Esteganografia em Vídeos MPEG-4", 13th SBC Webmedia (Simpósio Brasileiro de Sistemas Multimídia e Web) - Gramado, RS, Outubro 2007.

2. Carvalho D. F., Goularte, R. "Esteganografia em Vídeos Comprimidos: Uma abordagem para MPEG-4", WTDWEB - Workshop de Teses e Dissertações do 13th SBC Webmedia (Simpósio Brasileiro de Sistemas Multimídia e Web) - Gramado, RS, Outubro 2007.

\section{Relatório Técnico}

1. Carvalho D. F., Fortes R. P. M., Goularte, R. "Esteganografia em vídeos: Um estudo sobre o estado da arte", Relatório Técnico de número 292 do ICMC-USP, ISSN - 0103-2569, Janeiro 2007, disponível em http://www.icmc.usp.br/ biblio/BIBLIOTECA/rel_tec/RT_292.pdf. 
[Albuquerque, 2007] Albuquerque C. N., et. al. Esteganografia e suas aplicações. Procedings do Simpósio Brasileiro de Segurança da Informação - SBSEG (2007), págs. 199.

[Almeida, 2004] Almeida, J. F. (2004). Bíblia sagrada traduzida por joão ferreira de almeida. http://www.bibliasagrada.web.pt/ acessado em: 12/2007.

[Barbara, 2004] Barbara, K. (2004). Procedures for performing systematic reviews. Technical Report TR/SE-0401, Keele University.

[Bijan G., 2005] Bijan G., M. D. C. (2005). Lossless watermarking of compressed media using reversibly decodable packets. 2005, Signal Processing, Elsevier Inc. All Rights Reserved, vol. 07, no. 33, págs. 11.

[Buccigrossi, 2000] Buccigrossi, R. W.;Simoncelli, E. P. (2000). Image compression via joint statistical characterization in wavelet domain. IEEE Trans Image Proc, vol. 8, no. 12, págs. 18.

[Burr, 2006] Burr, E. W. (2006). Cryptographic hash standards: Where do we go from here? IEEE Security and Privacy, vol.4, no.2, págs. 4.

[Carvalho, 2005] Carvalho, D. F., Goularte R. (2005). Esteganografia digital: Uma abordagem baseada em vídeos. Procedings do XI Webmedia, Simpósio Brasileiro de Sistemas Multimídia e Web - SBC - Poços de Caldas - MG, págs. 230.

[Chang C. L., 2000] Chang C. L., Chan. T. (2000). A steganographic method based upon jpeg and quantization table modification. An International Journal - Information Science, vol.5, no. 20, págs. 14.

[Chiariglione, 2002] Chiariglione, L. (2002). Iso/iec. overview of the mpeg-4 standard (iso/iec jtc1/sc29/wg11 n4668). Disponível em: $<$ http://www.chiariglione.org/mpeg/standards/mpeg-4/mpeg-4.htm>, acessado em 06/2006.

[Cintia Borges Margi, 2003] Cintia Borges Margi, Grassa Bressan, W. V. R. (2003). Um mecanismo para distribuição segura de vídeo mpeg. POLI-USP, LARC Publicações Internas, disponível em <http://larc.usp.br/, acessado em 05/2006. 
[Duda R. O.; Hart, 2000] Duda R. O.; Hart, P. E.; Stork, D. G. (2000). Pattern classification. Wiley-Interscience. págs. 210.

[Dugelay, 2003] Dugelay J-L, et. al. (2003). A guide tour of video watermarking. 2003, Signal Processing, Image Comunication, Elsevier Inc. All Rights Reserved, págs. 20.

[Ebrahimi, 2002] Ebrahimi, F. P. T. (2002). The MPEG-4 book. IMSC Press Multimedia Series, ed. 3, págs. 740.

[Envivio, 2004] Envivio (2004). Envivio is a leading provider of complete mpeg-4 and h.264 solution. Disponível em http://www.envivio.com, acessado em 09/2007.

[Estadao, 2001] Estadao (2001). As epistolas de bin laden, disponível em http://www.estadao.com.br/magazine/materias/2001/out/01/314.htm, acessado em $12 / 05$.

[Chang., 2004] Chang Chin-Chen, et. al. (2004). New image steganographic methods using run-length approach. 2004, Information Science, Elsevier Inc. All Rights Reserved, vol. 02, no. 08, págs. 16 .

[Lou, 2002] Lou C., et. al. (2002). A copyright protect scheme for digital images using visual cryptography technique. ACM págs. 12.

[Carvalho, 2007] D. F. Carvalho, et. al. (2007). Esteganografia em vídeos: Um estudo sobre o estado da arte. Relatório técnico do ICMC-USP, no. 292.

[D. Robie, et. al. 2001] D. Robie, et. al. (2001). Video error correction using steganography. IEEE, vol. 2, no. 01, págs. 6.

[Fenlin Liu, 2006] Fenlin Liu, et. al. (2006). Real-time steganography in compressed video. 2006, MRCS, LNCS 4105, Springer, págs. 6.

[Ning Wu, 2002] Ning Wu, et. al. (2002). The use of steganography to enhance error detection and correction in mpeg-2 video. IEEE, págs. 6.

[D. Robie, 2001] D. Robie, et. al. (2001). Video error correction using data hiding techniques. IEEE, págs. 6.

[ISO, 2000] ISO, for Standardisation. (2000). Short MPEG-2 Description.

[Fridrich, 2002] Fridrich, J.;Goljan, M. (2002). Practical steganalysis of digital images state of art. Security Report Wisley, págs. 13.

[Girod, 1998] Girod, F. H. B. (1998). Watermarking of uncompressed and compressed video. 1998, Signal Processing, Elsevier Inc. All Rights Reserved, no.66, págs. 19.

[Goularte, 2003] Goularte, R. (2003). Personalização e adaptação de conteúdo baseadas em contexto para tv interativa. 262p. Tese (Doutorado). Instituto de Ciências Matemáticas e de Computação, Universidade de São Paulo, São Carlos.

[GPAC, 2002] GPAC (2002). Gpac project on advanced content. disponível em http://gpac.sourceforge.net, acessado em 12/2006. 
[ISO, 2001] ISO, for Standardisation. (2001). Iso/iec 14496-5:2001. Coding of Audio-Visual Objects Part 5: Reference.

[Hellman, 1979] Hellman, M. E. (1979). The mathematics of public-key cryptography. Scientific America vol.241, págs. 10.

[Horta, 2005] Horta, C., et. al. (2005). Processos de desenvolvimento para aplicações web: Uma revisão sistemática. Procedings do XI Webmedia, Simpósio Brasileiro de Sistemas Multimídia e Web - SBC - Poços de Caldas - MG, págs 230.

[Kerckhoff, 1883] Kerckhoff, A. (1883). La cryptographie militarie. Book Atlas, págs. 354.

[Koenen, 2002] Koenen, R. (2002). Overview of th mpeg4 standard, págs. 310.

[Landau, 1998] Landau, D. W. (1998). Privacy on the line. MIT PRess, págs. 8.

[Lonardi, 2003] Lonardi, M. J. A. S. (2003). Authentication of lz-77 compressed data. 2003, ACM, Procedings SAC (Symposium Aplied Computing), págs. 6.

[Lu, 2003] Lu, C.-S. (2003). Towards robust image watermarking: combining content-dependent key, moment normalization and side-informed embedding. IEEE págs. 12.

[Lu, 2005] Chun-Shien Lu, et. al. (2005). Real-time frame-dependent video watermarking in vlc domain. 2005, Signal Processing, Image Comunication, Elsevier Inc. All Rights Reserved, vol. 03, no.012, págs. 19.

[Mafra S., 2005] Mafra S., T. G. (2005). Técnicas de leitura de software uma revisão sistemática. Procedings do XIX Simpósio Brasileiro de Engenharia de Software (SBES), págs. 210.

[Motulsky, 2003] Motulsky, H.; Christopoulos, A. (2003). Fitting Models to Biological Data using Linear and Nonlinear Regression, GraphPad Prism. págs. 175.

[Pennebaker B. W., 1993] Pennebaker B. W., M. L. J. (1993). JPEG Still Image data compression standard. Thomson I. Publishing. págs. 230.

[Petitcolas, 1996] Pfitzman, P. A. B. (1996). Information hiding terminology. Information Hiding, Springer Lecture Notes in Computer Science, págs. 4.

[Provos, 2001] Provos, N. (2001). Defending against statistical steganalysis. 10th USENIX Security Symposium, págs. 12.

[Richardson, 2002] Richardson, I. E. G. (2002). Video Codec Design. John Wiley and Sons Ltda. págs. 234.

[Richardson, 2003] Richardson, I. E. G. (2003). H.264 and mpeg-4 video compression. págs. 315 .

[Rijmen, 2000] Rijmen, P. B. V. (2000). The whirlpool hashing function. First open NESSIE Workshop, págs. 8. 
[Rivest, 1992] Rivest, R. (1992). Rfc1321: The md5 message-digest algorithm. disponível em http://tools.ietf.org/html/rfc1321, acesso em 05/07.

[Rocha A., 2004] Rocha A., et. al. (2004). Segurança e privacidade na internet por esteganografia em imagens. Procedings do XI Webmedia, Simpósio Brasileiro de Sistemas Multimídia e Web - SBC-Poços de Caldas - MG, págs 230.

[Singh, 2001] Singh, S. (2001). O Livro dos Códigos, págs. 446. Editora Record.

[Tomás, 2004] Tomás, G. V. (2004). Sistemas operacionais: esteganografia. Information Science - An International Journal.

[Wayner, 2002] Wayner, P. (2002). Disappearing cryptography, págs. 432. Morgan Kauffman Publishers.

[Wolf, 1998] Wolf, A. W. G. (1998). Steganography un a video conferencing system. 1998, Information Hiding, LNCS 1525, Springer, págs. 16.

[Yin, 2006] Yin, H., et. al. (2006). A novel key-embedded scheme for secure video multicast systems. 2006, Computer and Electrical Engineering, Elsevier Inc. All Rights Reserved, vol. 12, no.01, págs. 18.

[Zhao, 1998] Zhao, J. (1998). In business today and tomorrow. ACM Communications of the $A C M$, págs. 7.

[Ziad Sakr, 2007] Ziad Sakr, D. N. G. (2007). Robust content-based mpeg-4 xmt scene structure authentication and multimedia content location. ACM Transactions on Multimedia Computing, Communications and Applications, vol. 3, no. 3, págs. 23. 


\section{Apêndice A}

Este apêndice apresenta as amostras utilizadas na aplicação para escrita secreta, conforme explicado na seção 6.2.2. O tamanho total do arquivo referente ao texto do antigo e novo testamento correspondem a 3.79 Mbytes. Optou-se por retirar trechos diferentes da Bíblia para que a compressão do tipo lossless com o algoritmo LZW não seja viciada podendo assim prejudicar o teste da técnica de esteganografia.

A seguir pode-se verificar a referência na Bíblia para cada uma das amostras utilizadas.

- Amostra 1:

Gênesis 1, 2-11.

- Amostra 2:

Gênesis 1, 12-28.

- Amostra 3:

Gênesis 9. Gn 9. e Gênesis 10. Gn 10. 1-11.

- Amostra 4:

Gênesis 5. Gn 5., 6 Gn 6., 7 Gn 7.

- Amostra 5:

Lamentações Lm 1., Lm 2., Lm3. Lm4.

- Amostra 6:

Eclesiastes: 12 capítulos, Cantares cap.1 e cap.2.

- Amostra 7:

Apocalipse 22 capítulos. E João: capítulos 1 a 3.

- Amostra 8:

Isaías: 66 capítulos.

- Amostra 9:

Salmos: 150 capítulos; Provérbios de 1 a 14. 
- Amostra 10:

Gênesis 50 capítulos, Êxodo 40 capítulos, Levítico: 27 capítulos, Números capítulos de 1 a 11 .

- Amostra 11:

Deuteronômio: 34 caps., Josué: 24 caps., Juízes: 21 caps., Rute: 4 caps., Samuel: 55 caps., Reis: 22 caps., Crônicas: 29 caps., Esdras: 10 caps.

- Amostra 12:

Salmos: 150 caps., Provérbios 31 caps., Eclesiastes 12 caps.,Cantares 8 caps.,Isaías 66 caps.,Jeremias 52 caps., Lamentações 5 caps., Ezequiel 48 caps, Daniel 12 caps., Oseias 14 caps., Joel 3 caps., Amós 9 caps., Obadias 1 cap., Jonas 4 caps., Miqueias 7 caps., Naum 3 caps., Abacuque 3 caps., Sofonias 3 caps., Ageu 2 caps., Coríntions *2- 13 caps., Gálatas 6 caps., Efésios 6 caps., Filipenses 4 caps., Colossenses 4 caps., Tessalonicenses $*^{*} 1-5$ caps., Tessalonicenses $* 2$ - 3 caps., Timóteo 6 caps., Tito 3 caps., Filemon 1 cap., Hebreus 13 caps., Tiago 5 caps., Pedro *1 - 5 caps., Pedro *2 - 3 caps., João *1-5 caps.,João *2-2 caps., Judas 1 cap. Apocalipse 22 caps.. 


\section{Glossário}

Amostragem - Em telecomunicações e processamento de sinais, amostragem é o processo de discretização temporal de um sinal contínuo.

Bloco - Estrutura utilizada em compressão de imagens e vídeo. É formada por um conjunto de oito linhas, onde cada linha contém oito pixels, totalizando 64 pixels.

Codificação - Em processamento digital de sinais, codificação significa a modificação de características de um sinal para torná-lo mais apropriado para uma aplicação específica, como por exemplo, transmissão ou armazenamento de dados.

Codificador - Dispositivo que realiza o processo de codificação.

Decodificação - Decodificação é o processo contrário da codificação, ou seja, as características modificadas de um sinal são transformadas em seu formato original.

Decodificador - Dispositivo que realiza o processo de decodificação.

Estimativa e Compensação de Movimento - Técnica utilizada para eliminar a redundância temporal de um sinal de vídeo. O algoritmo compara quadros próximos uns dos outros e verifica quais áreas da imagem são equivalentes ou mesmo qual foi o movimento realizado pela área de um quadro para outro. Essas áreas equivalentes são eliminadas, e no lugar, são armazenadas no arquivo codificado apenas essas informações de controle, que serão mais tarde processadas pelo decodificador, para recostrução da imagem original.

Ethernet - É uma tecnologia de interconexão para redes locais baseada no envio de pacotes.

Framework - Um framework provê uma solução para uma família de problemas semelhantes, usando um conjunto de classes e interfaces que mostra como decompor essa família de problemas, e como objetos dessas classes colaboram para cumprir suas responsabilidades. O conjunto de classes deve ser flexível e extensível para permitir a construção 
de várias aplicações com pouco esforço, especificando apenas as particularidades de cada aplicação.

GOV - Group of VOPS, Conjunto de VOPS. OS GOVS contém um cabeçalho de informações e formas de acesso aos $V O P S$, além de realização de resincronização no caso de erros de codificação.

Hipertexto - É uma maneira de representar informações textuais de forma não-linear, permitindo que, a partir de um documento, usuários acessem outros documentos.

HTML - HyperText Markup Language (Linguagem de Marcação de Hipertexto). Linguagem de marcação de texto utilizada para a apresentação de hiperdocumentos na Internet.

HTTP - Hypertext Transfer Protocol (Protocolo de Trasferência de Hipertexto). É um protocolo utilizado para transferência de dados hipermídia (imagens, sons, texto, etc.) e pela comunicação entre cliente e servidor na Internet.

IP - Internet Protocol (Protocolo de Internet). É um protocolo usado entre duas máquinas em rede para encaminhamento dos dados.

Macrobloco - Estrutura utilizada em compressão de imagens e vídeo. É formada por um conjunto de quatro blocos de luminância, mais um determinado número de blocos de crominância.

Multimídia - É a utilização simultânea de vários tipos de mídia (texto, sons, imagens, gráficos, vídeos e animações).

Quadro de Vídeo - É uma das inúmeras imagens que compõem um vídeo; ao tocar um vídeo, cada quadro é mostrado na tela por um tempo especificado pela taxa de quadros: se o vídeo está configurado a 25 quadros/s, então cada quadro será apresentado por um período de 0,040 segundos.

Quadro B - Na eliminação da redundância temporal, a estimativa de movimento utiliza quadros do tipo I ou $\mathrm{P}$ antecedentes ou posteriores a ele como referência para a codificação de seus dados.

Quadro I - É codificado eliminando apenas a redundância espacial. É o tipo de quadro que requer a maior quantidade de bits para representá-lo, pois uma vez que não é eliminada a redundância temporal, seu nível de codificação é baixo.

Quadro P - Na eliminação da redundância temporal, a estimativa de movimento utiliza quadros do tipo I ou P antecedentes a ele como referência para a codificação de seus dados.

Quantização - Consiste em converter um sinal de amplitudes contínuas em um número finito de amplitudes discretas. Todo sinal deve ser quantizado para ser armazenado ou transmitido na forma digital. Nesta técnica, a quantidade de bits que representa os dados é diminuída, provocando uma degradação na imagem. No entanto, se a quantidade de níveis de quantização, ou a taxa de bits for alta, a perda de qualidade pode ser imperceptível. 
Como exemplo clássico de quantização, pode-se citar o arredondamento de números no formato ponto-flutuante para números em formato inteiro.

Redundância Espacial - Algumas informações de cores presentes em uma imagem não são perceptíveis pelo olho humano, e podem ser eliminadas sem que a qualidade da imagem seja prejudicada. Essa eliminação é realizada pela aplicação da transformada discreta do cosseno, e em seguida, a quantização.

Redundância Temporal - São repetições de certas informações presentes em sinais de vídeo que podem ser eliminadas por codificadores sem a percepção do telespectador. Comparando-se quadros próximos uns dos outros, algumas áreas da imagem, tais como plano de fundo, objetos sem movimento, etc., são iguais, e podem, na codificação, ser eliminadas para diminuir o tamanho do arquivo. Assim, durante a decodificação, o decodificador, ao verificar que essas áreas foram eliminadas em um determinado quadro, irá "emprestar" essas informações de quadros próximos, a fim de recostruir a imagem original.

Resolução Espacial - Define o tamanho de um quadro de um vídeo, normalmente expressa em pixels.

Resolução Temporal - Define a taxa de quadros de um vídeo, normalmente expressa em quadros/s.

TCP - Transmission Control Protocol (Protocolo de Controle de Transmissão). É um protocolo amplamente utilizado na Internet atualmente, devido à sua versatilidade e robustez, permitindo, entre outras funcionalidades, saber se os dados estão sendo enviados de maneira correta, na seqüência apropriada e sem erros.

Transformada Discreta do Cosseno - Técnica utilizada na eliminação da redundância espacial de uma imagem. Ela transforma os dados do domínio espacial para o domínio de freqüências, onde quanto mais alta é uma freqüência, menos perceptível ela é para o olho humano. Após a transformação, os dados são submetidos à quantização, que é onde a eliminação da redundância é realizada.

Transformada Discreta do Cosseno Inversa - É a inversa da transformada discreta do cosseno. Ela transforma os dados do domínio de freqüências para o domínio espacial.

Vetor de Movimento - Termo utilizado em compressão de vídeo. Indica a translação espacial de um bloco para outro em quadros distintos, onde essa translação é especificada pela aplicação da técnica estimativa de movimento.

Vídeo Digital - Esse tipo de formato, ao contrário dos vídeos analógicos, digitalizam as imagens por meio de circuitos denominados CCDs, que convertem a luz em dados compreensíveis ao computador, digitalizando as imagens. A principal vantagem de se utilizar vídeo digital ao invés de vídeo analógico é que o primeiro contém melhor resolução do que 
o segundo e, além disso, o vídeo digital é reproduzido utilizando-se o sinal componente, ao contrário dos vídeos analógicos, que utilizam o sinal S-vídeo e o sinal composto.

VLC - Variable Length Coding, Tipo de codificação de seqüências de bits tais como Run length, Huffman, LZW.

VOP - Tipicamente, um Video Object é uma área no interior de um vídeo que ocupa um certo espaço em um certo tempo de aparição. Uma instância de um video object $V O$ denomina-se $\operatorname{VOP}$ (video object plane).

VOP-I ou VOP-P - A representação dos VOPS de tipos $I$ ou $P$ consiste de um cabeçaho $V O P$, um cabeçalho opcional de pacote de vídeo e de macroblocos codificados. A codificação dessas estruturas de objetos visuais é extremamente importante para a correta codificação de uma cena do vídeo MPEG-4.

XML - Extensible Markup Language (Linguagem de Marcação Extensiva). É uma especificação desenvolvida pela W3C utilizada em documentos da web. Permite que projetistas criem suas próprias tags, disponibilizando a definição, transmissão, validação e interpretação de dados entre aplicações e organizações. 